\title{
Comparative Statistical Analysis of Test Parts Manufactured in Production Environments
}

\section{David E. Gilsinn}

U.S. DEPARTMENT OF COMMERCE Technology Administration Mathematical and Computational Sciences Division National Institute of Standards and Technology

Gaithersburg, MD 20899-8910

\section{Alice V. Ling}

AFRL/DEX

3550 Aberdeen Ave SE

Kirtland AFB, NM 87117-5776

\section{QC}





\section{NISTIR 6868}

\section{Comparative Statistical Analysis of Test Parts Manufactured in Production Environments}

\section{David E. Gilsinn}

U.S. DEPARTMENT OF COMMERCE Technology Administration

Mathematical and Computational Sciences Division

National Institute of Standards and Technology

Gaithersburg, MD 20899-8910

\section{Alice V. Ling}

AFRL/DEX

3550 Aberdeen Ave SE

Kirtland AFB, NM 87117-5776

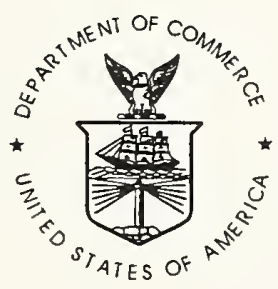

U.S. DEPARTMENT OF COMMERCE Donald L. Evans, Secretary

TECHNOLOGY ADMINISTRATION

Phillip J. Bond, Under Secretary for Technolog

NATIONAL INSTITUTE OF STANDARDS

AND TECHNOLOGY

Arden L. Bement, Jr., Director 
Certain commercial software products are identified in this paper in order to adequately specify the computational procedures. Such identification does not imply recommendation or endorsement by the National Institute of Standards and Technology, nor does it imply that the software products identified are necessarily the best available for the purpose. 


\begin{abstract}
Estimating error uncertainties arising in parts produced on machine tools in production machine shops is not a well understood process. The current study details a process of estimating these error uncertainties. A part with significant features was defined and a vertical turning center was selected in a production shop to make multiple copies of the part. Machine tool error components were measured using a laser ball bar instrument. Twenty-one copies of the part were produced and measured on a coordinate measuring machine. A machine tool error model based on the measurements of the vertical turning center machine tool errors was developed. Uncertainty estimates of the errors in the working volume were calculated. From coordinate measuring machine data error uncertainties at points on the part were developed. Distances between hole centers were computed and uncertainty estimates of these lengths generated. Many of the hole centers were designed to fall along orthogonal lines. Uncertainty estimates were computed of the orthogonality of these lines. All of these estimated uncertainties were compared against uncertainties computed from the measured parts. The main conclusion of the work is that the Law of Propagation of Uncertainties can be used to estimate machining uncertainties and that predicted uncertainties can be related to actual part error uncertainties.
\end{abstract}

Keywords: coordinate measuring machine, drilling, error uncertainties, laser ball bar, machine tools, machine tool errors, milling, Monte Carlo, propagation of uncertainty, vertical turning center. 


\section{Glossary}

ASME

CMM

ISO

LBB

NC
American Society of Mechanical Engineers

Coordinate Measuring Machine

International Organization for Standardization

Laser Ball Bar

Numerical Controlled 


\section{Table of Contents}

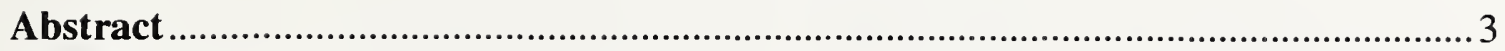

Glossary

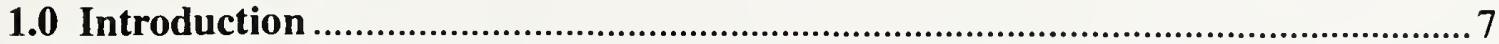

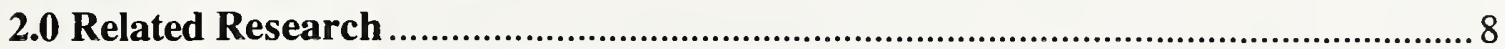

3.0 Parts Manufacturing and Machine Metrology .................................................. 10

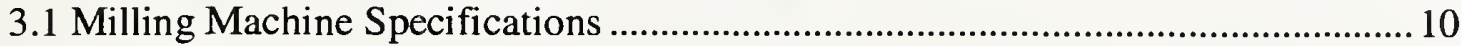

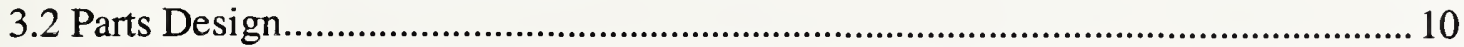

3.3 Measuring the Vertical Machining Center ........................................................... 11

4.0 Part Uncertainty through Model Prediction ...................................................... 14

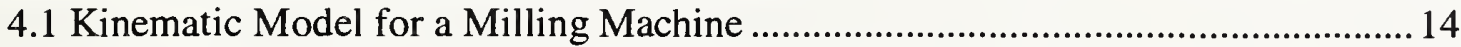

4.2 Regression Models for the Component Errors ................................................ 18

4.3 General Propagation of Uncertainties Using the Kinematic Model..........................23

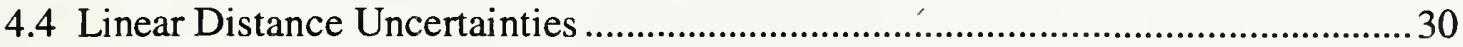

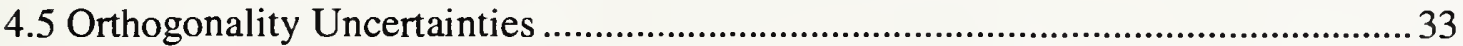

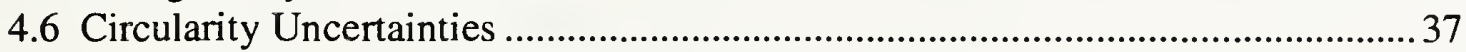

5.0 Part Uncertainties by Coordinate Measuring Machine Measurements ............... 40

5.1 Hole Center Location Uncertainties for Manufactured Part ..................................40

5.2 Estimating the Uncertainty of a Machined Length Feature from CMM

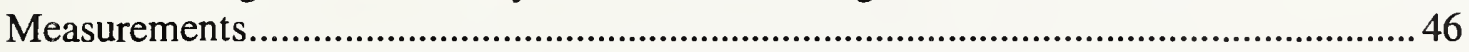

5.3 Estimating the Uncertainty of Machined Part Orthogonality from CMM

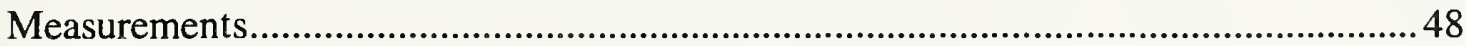

5.4 Estimating the Uncertainty of a Machined Part Circularity from CMM

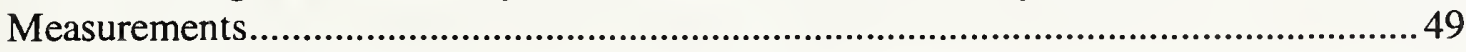

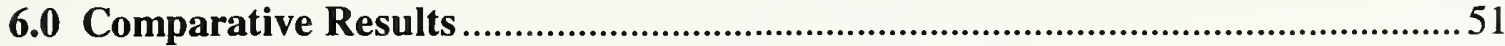

6.1 Comparison of Hole Location Errors and Uncertainties ..........................................51

6.2 Comparison of Length Uncertainties ............................................................52

6.3 Comparison of Orthogonality Uncertainties. ...........................................................53

6.4 Comparison of Circularity Uncertainties .............................................................53

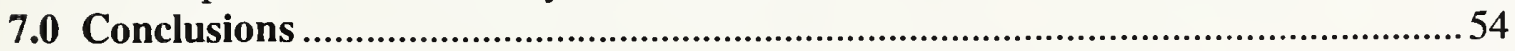

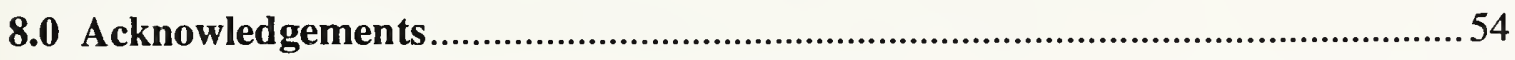

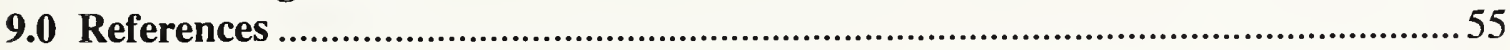

APPENDIX A: Model Based Estimates of Point Error Variances and Confidence

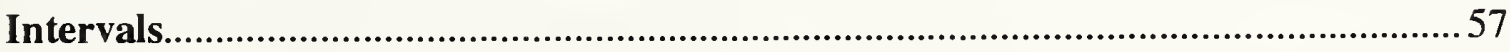

APPENDIX B: Uncertainty Estimates for Hole Centers Based on CMM

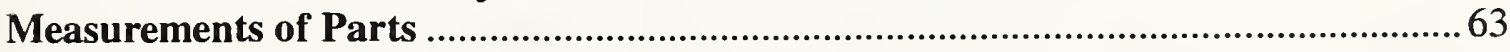

APPENDIX C: Analysis of Variance for Selected Hole Centers ................................71

APPENDIX D: Derivation of the Variance of Length Equation ................................8 83

APPENDIX E: MACSYMA Program to Generate the Kinematic Model Error

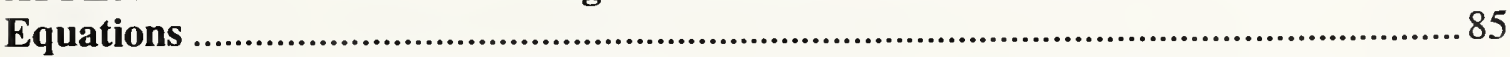

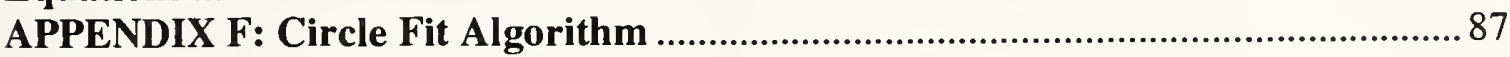

APPENDIX G: Analysis of Variance for Computed Orthogonalities from CMM Measurements.......................................................................................................... 93

APPENDIX H: Analysis of Variance Tables for Circularities Computed from CMM Measurements 


\subsection{Introduction ${ }^{1}$}

In the production of machined parts a major problem can face a parts designer. Given a particular machine tool, how does one estimate beforehand the errors in features for the parts produced by that machine? Although there are general guides for reporting uncertainties in experiments (see ISO [1], Taylor and Kuyatt [2], American National Standards Institute [3]) there have been no published practical case studies on how to estimate uncertainties of errors of machined part features. Producing such a guide on the basis of case studies for a wide range of machine tools would be a large undertaking. This report can be regarded as an attempt at one chapter of such a guide.

A project was defined in which a part was specified and given to a production machine shop with an order to make twenty one copies of the part on the same machine. A threeaxis machining center on the shop floor was selected (See Figure 1). The part designed had drilled and milled holes and a circular slot (See Figure 2). The error components of the machine tool were measured multiple times by a laser ball bar (LBB). An error model of the machining center was developed and axis error uncertainties estimated by using the propagation of error formula from the ISO Guide [1]. An analytic formula was developed that could be used to estimate the variation in distance between features, such as hole centers. For orthogonal and circular features, Monte Carlo techniques had to be developed in order to estimate uncertainties. The parts themselves were measured on a coordinate measuring machine (CMM) and an analysis of variance technique was used to separate the measurement and manufacturing uncertainties of the measured hole centers and inner and outer radii of the circular slot. The various techniques employed are documented in this report in order to form a basis for estimating the uncertainties involved in producing parts on machine tools.

The measurement of the machine tool (described in Section 3) was done by an instrument that measured machine tool errors at points on a plane above the parts production surface. Estimates of this height were not obtained at the time the machine tool error measurements were made. Therefore, the model as finally used in this report does not contain terms that include the errors due to this height difference. In future error measurements of similar machine tools these terms should be included. Since the object of this report was to develop a methodology, the authors feel that this oversight does not invalidate the overall procedures developed.

A review of the related research literature is given in Section 2. Section 3 briefly describes the machine tool measurement procedure and the part design. Section 4 describes the kinematic model of a three axis machine tool along with the methods of estimating errors for point location, linear distances, orthogonalities and circularities. The uncertainty estimates for CMM measurements of the parts are given in Section 5. The comparative results are given in Section 6 with some final conclusions given in section 7 .

\footnotetext{
${ }^{1}$ The term "error" used in this report is used in the machining sense to refer to axis errors, e.g. linear axis errors, straightness errors, or orthogonality errors, rather than in the statistical sense.
} 


\subsection{Related Research}

Various authors discuss different aspects of the problem of machining uncertainties. Under a controlled set of experiments Wilhelm, Srinivasan and Farabaugh [4] have demonstrated that the measured behavior of the machine tool could be related to variations found in prismatic part features cut on that machine tool. The machining and metrology conditions were tightly controlled. A horizontal machining center was used. Parts, with features similar to those in the current study were cut. The results indicated that most part errors fell within two standard deviations of the machine errors. However, under uncontrolled conditions, a recent study by Chatterjee [5] has shown that there is a significant deviation in machine tool performance between static and operating conditions, where machine parameters are likely to vary due to cutting and thermal loads.

Shin and Wei [6] developed a kinematic model for a multi-axis machine tool in order to predict deterministic errors. They added stochastic terms to the predicted errors and theoretically estimated the means and variances of the kinematic errors, but provide no experimental data comparison

The inaccuracies that relate to drilling operations have been studied by a number of authors. These results, however, are in general experimental or analytic in nature and are not formulated in terms of uncertainties. Kaminski and Crafoord [7] state that drilling operations give rise to forces in the $\mathrm{X}, \mathrm{Y}$ and $\mathrm{Z}$ directions as well as torque. They found that the tool deflects more under dynamic cutting conditions than under static simulated force loads. Lehtihet and Gunasena [8] use a simulation to show the influence of tolerance specification, size of the tolerance zone, hole size density, and production errors on the probability of producing an acceptable hole. Lee, Eman and Wu [9] discuss a mathematical model for drill wandering motion to explain the formation of odd-sided polygonal holes during initial penetration. Fujii, Marui and Ema [10, 11, 12] find that the drill point deflects along an elliptical orbit during whirling vibration. Magrab and Gilsinn [13] model a drill bit as a twisted Euler beam under axial loading that is clamped at both ends. The representative set of modes obtained exhibit a complex out-of-plane twistingtype motion that suggests a possible explanation for the out-of-roundness of certain drilled holes.

In a work that relates to the current report Shen and Duffie $[14,15]$ develop an uncertainty analysis method that allows the modeling and computation of component error uncertainty sources that lead to coordinate transformation uncertainties. They show how uncertainties propagate in the homogeneous transformations of points, products of transformations and inverse transformations. They characterize the uncertainties associated with workpiece positions and orientations in terms of two components, a bias and a precision uncertainty component. They demonstrate that the bias and precision components can be propagated independently and combined to represent the uncertainties of the coordinate transformation relations. They validate the method by using Monte Carlo simulation (Bauer [16]). 
Several recent papers relate measurement uncertainties in CMM measurements to the sampling strategy. Yau [17] proposes a general mathematical basis for representing vectorial tolerances. He develops a nonlinear, best-fit algorithm to evaluate vector tolerances for both analytic geometric elements and free-form surfaces. He then studies the uncertainty of the best-fit result caused by the sampling strategy and dimensional errors. Phillips et al. [18] examine the uncertainty of small circular features as a function of sampling strategy, i.e. the number and distribution of measurement points. They study the effect of measuring a circular feature using a three-point sampling strategy and show that the measurement uncertainty varies by four orders of magnitude as a function of the angular distribution of the measurement points. 


\subsection{Parts Manufacturing and Machine Metrology}

\subsection{Milling Machine Specifications}

The milling machine used to manufacture the test parts (Figure 1) is a three-axis vertical machining center with an X-axis (Longitudinal table) travel of $1020 \mathrm{~mm}$ (40 in), a Y-axis (Cross table) travel of $762 \mathrm{~mm}$ (30 in), and a Z-axis (Vertical head) travel of $560 \mathrm{~mm}$ (22 in). The programming resolution for all three axes is $0.001 \mathrm{~mm}(0.0001 \mathrm{in})$. The repeatability is reported by the machine manufacturer as $0.005 \mathrm{~mm}(0.0002$ in) by the VDI 3441 method and $+/-0.0025 \mathrm{~mm}(+/-0.0001$ in) by the JIS 6330 method.

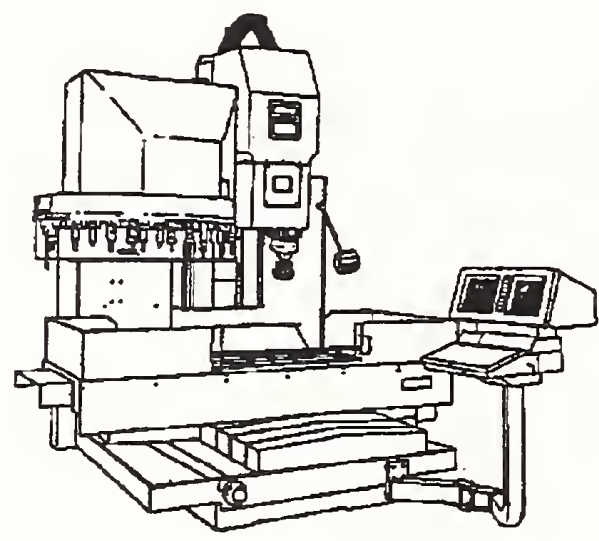

Figure 1: Three-Axis Machining Center

\subsection{Parts Design}

The part, shown in Figure 2, was designed to illustrate several characteristics of the machining center. The holes around the outer edge have several purposes. First, drilled holes in the center were used to compute uncertainties in drilled hole center positioning. The "squared" outer holes allowed comparison of milled hole centers to the drilled hole centers. The large square with $150 \mathrm{~mm}$ sides was machined to check the orthogonality or perpendicularity of the machine's $\mathrm{X}$ and $\mathrm{Y}$ axes. This property is sometimes called squareness. The large internal circular features were cut in order to test the contouring performance of the machine. 


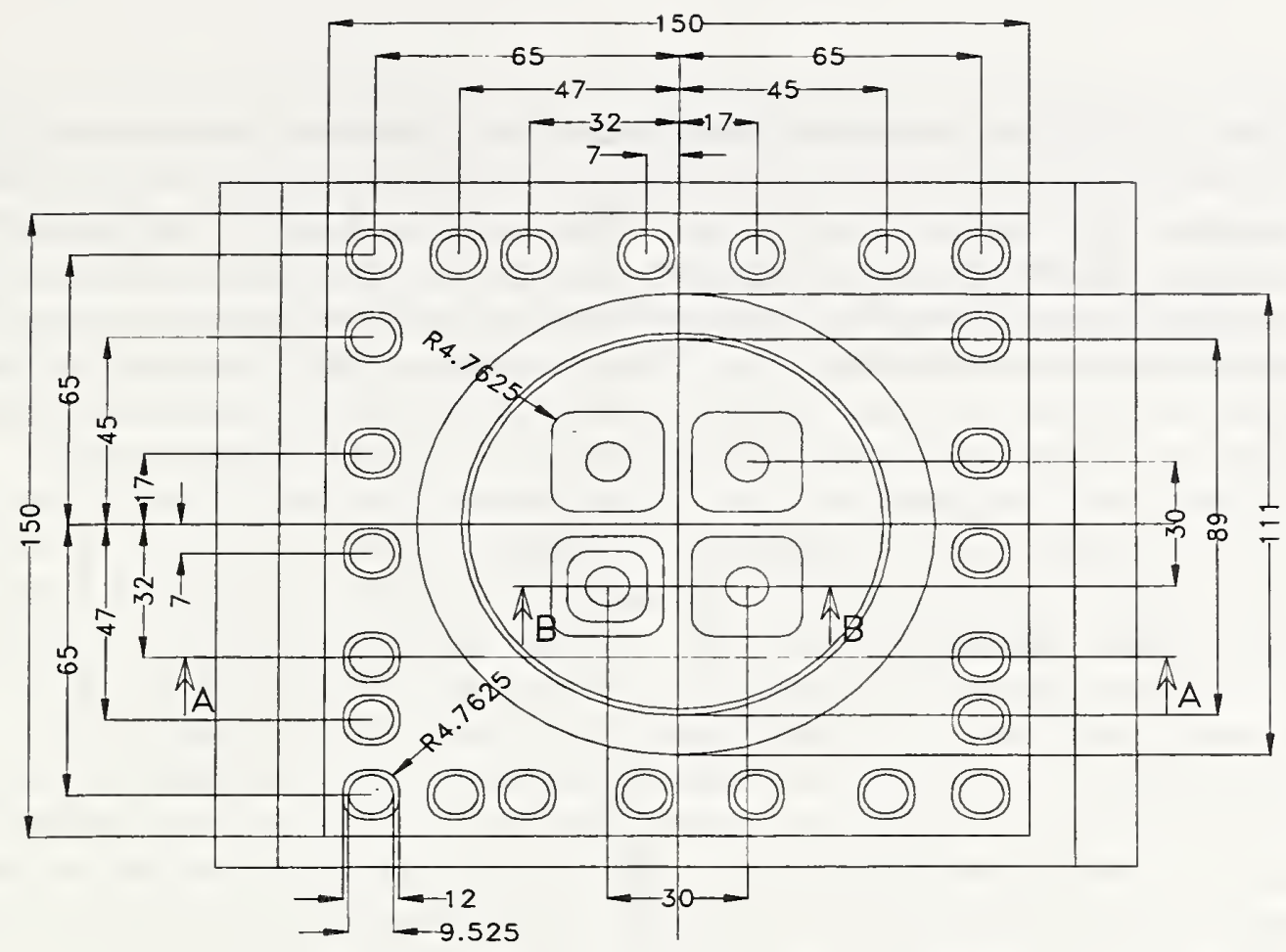

CROSS SECTION AA

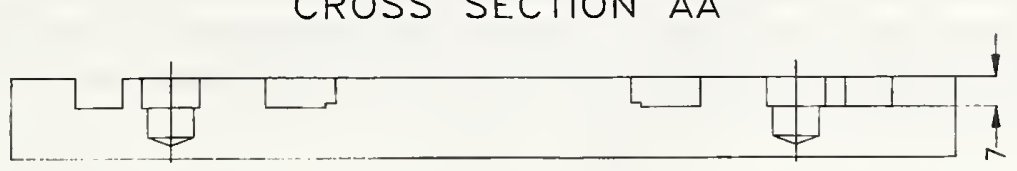

CROSS SECTION BB

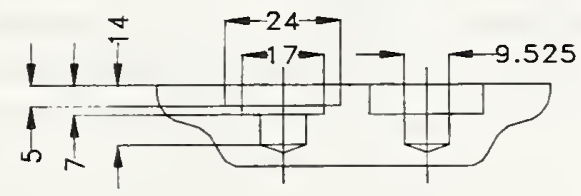

Figure 2: Test Part Specifications. Dimensions are in millimeters

\subsection{Measuring the Vertical Machining Center}

The dimensional accuracy of the work piece is affected by the errors of the various positioning elements of the machine tool which contribute to the positioning accuracy of the cutting tool. Each machine element normally has one degree of freedom of nominal motion. But, there are six error components associated with each axis of motion. These six error components consist of three translations along, and three rotations about the three coordinate axes(roll, pitch and yaw). They are referred to as parametric errors, and in general are functions of axis position. For a three-axis machine tool there are twentyone error components (six for each axis and three axis orthogonality errors). 
ASME B5.54 [19] outlines techniques for performing parametric error measurements of machine tools using instruments such as laser interferometers, precision straight edges, capacitance gauges, and electronic levels. The use of these devices to perform error component measurements requires care and considerable time. Kakino, Ihara and Nakatsu [20] report the results of using a telescoping magnetic ball bar to measure circular motion errors of $\mathrm{NC}$ machines. They develop a formula that relates the radial displacement errors of the telescoping magnetic ball bar to the machine position error vector at a nominal point in the NC machine tool work volume. However, direct measurements of the spatial position of the tool are made feasible by using a metrology device that measures spatial positions by trilateration, called a laser ball bar (LBB) (see Figure 3). Trilateration is a technique in which a tetrahedron is formed with three base points (vertices) attached to the machine table, and the fourth attached to the tool holder. The three base points define a coordinate system. Simple geometric relationships allow the spatial coordinates of the fourth point or tool to be determined relative to this coordinate system. As the tool moves through space relative to the table, the lengths of the edges change causing the tetrahedron to deform. The LBB uses interferometry to measure the lengths of the tetrahedron edges and thus the tool position. The resulting measurement includes all effects which can cause positioning error: geometric, thermal and elastic. For a detailed discussion of the LBB and a comparison of the results of LBB measurements with ASME B5.54 measurements see Ziegert and Mize [21]. For a discussion of the use of a LBB in dynamic path measurements see Schmitz and Ziegert [22] and in modeling and predicting thermally induced errors see Srinivasa and Ziegert [23].

Various error components of the machine tool are measurable by the LBB. For example, when a single axis of a machine is actuated, the tool point is intended to move from the starting point to the ending point in a straight line. The distance between the starting and ending points should be exactly the displacement commanded. If it is not, then the machine is said to exhibit a linear displacement error. In general, the amount of the linear displacement error is a function of the axis position and direction of motion. Due to imperfections in the guideway system, the actual motion deviates from a perfect straight line. These deviations are termed straightness errors. The individual axes of a machine tool are constructed to provide axis motions which are perpendicular to each other. Due to imperfections in the machine construction, the actual motions of the axes are not exactly perpendicular. These errors are called axis alignment errors or squareness errors. Besides measuring displacement, straightness and squareness errors the LBB can measure the angular errors exhibited by the axes during motions. These are called roll, pitch and yaw. The measurement of these angular errors is accomplished by replacing the single tool socket with a fixture which holds three sockets, one of which is on the spindle centerline. The center socket is used to determine the linear displacement and straightness errors. Due to orientation changes, the displacement of the other two sockets will not be the same as the first. The LBB uses the difference in displacements of the three sockets to determine roll, pitch and yaw errors of the machine axis at each point along its travel. 
The machine measurements were made by the following procedure. Five passes in both a forward and reverse direction were made in a large work volume that contained the smaller work volume enclosing the machined parts. This provided ten sets of data as a basis to model each of the error components of the milling machine. The LBB measured all twenty-one error components that define the errors for a three-axis mill. The data was used to develop regression models of the error components as functions of the positions along each machine axis. All five passes by the LBB were performed consecutively over a period of eight hours.

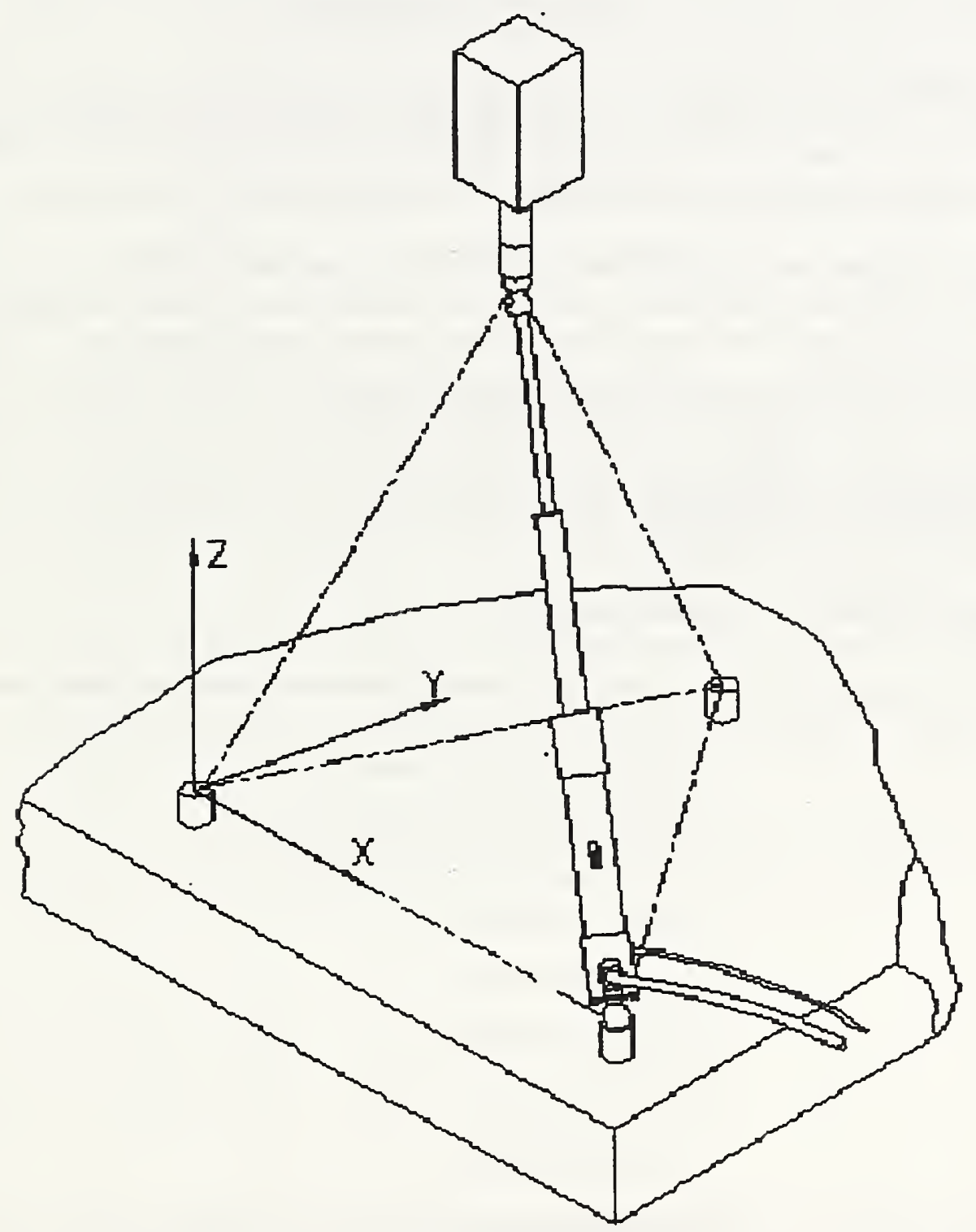

Figure 3: Laser Ball Bar Configuration 


\subsection{Part Uncertainty through Model Prediction}

Predicting part uncertainty by using a kinematic machine tool model requires a number of approximations. The first approximation assumes that the various error components combining to form a kinematic model of the machine tool errors enter in a linear fashion only. This is reasonable when the order of magnitude of the error components is examined. Any higher powers of the components become negligible. Second, the measurement of the machine error components indicate thermal drift of the errors between measurement repetitions as will be shown below. The authors recognize that the drift existed but could not control it during the measurement process. Thus for the purpose of this study the drift curves are treated as bona fide repeat curves and the resulting analysis will be assumed to be overly conservative. Finally, in order to estimate such quantities as circularity that are not defined in an analytical form, Monte Carlo simulation must be used in which an approximation to the distribution of the coverage factor for point uncertainties must be made. This will be discussed further below.

In this section, a kinematic model of the machine tool, described in Section 3.1, will first be constructed. The error components entering into this kinematic model will then be shown to exhibit a linear trend over the workspace of the manufactured parts. A general analysis of point location uncertainties, based on this model, will then be given. Using the point uncertainty estimates an analytic method will be developed to estimate length uncertainties between feature points. Both analytic and Monte Carlo methods will then be used to estimate orthogonality uncertainties. Finally a Monte Carlo procedure will be used to estimate circularity uncertainty.

\subsection{Kinematic Model for a Milling Machine}

The following notation will be used to describe the kinematic model for the three axis mill.

$\begin{array}{lll}\text { 1. } \alpha_{x}(y) & - & \text { Angle between the } \mathrm{X} \text { and } \mathrm{Y} \text { axes } \\ \text { 2. } \alpha_{x}(z) & - & \text { Angle between the } \mathrm{X} \text { and } \mathrm{Z} \text { axes } \\ \text { 3. } \alpha_{y}(z) & - & \text { Angle between } \mathrm{Y} \text { and } \mathrm{Z} \text { axes } \\ \text { 4. } \delta_{x}(x) & - & \mathrm{X} \text {-Axis Scale Error } \\ \text { 5. } \delta_{y}(y) & - & \text { Y-Axis Scale Error } \\ \text { 6. } \delta_{z}(z) & - & \text { Z-Axis Scale Error } \\ \text { 7. } \delta_{y}(x) & - & \mathrm{Y} \text { Straightness of } \mathrm{X} \\ \text { 8. } \delta_{z}(x) & - & \mathrm{Z} \text { Straightness of } \mathrm{X} \\ \text { 9. } \delta_{x}(y) & - & \mathrm{X} \text { Straightness of } \mathrm{Y} \\ \text { 10. } \delta_{z}(y) & - & \mathrm{Z} \text { Straightness of } \mathrm{Y} \\ \text { 11. } \delta_{x}(z) & - & \mathrm{X} \text { Straightness of } \mathrm{Z} \\ \text { 12. } \delta_{y}(z) & - & \mathrm{Y} \text { Straightness of } \mathrm{Z} \\ \text { 13. } \varepsilon_{x}(x) & - & \mathrm{X} \text { Rotation of } \mathrm{X} \text { (roll of } \mathrm{X} \text { ) }\end{array}$



14. $\varepsilon_{y}(x)$
Y Rotation of X (pitch of X)
15. $\varepsilon_{z}(x)$
$Z$ Rotation of $X$ (yaw of $X$ )
16. $\varepsilon_{x}(y)$
$X$ Rotation of $Y$ (pitch of $Y$ )
17. $\varepsilon_{y}(y)$
Y Rotation of Y (roll of Y)
18. $\varepsilon_{z}(y)$
Z Rotation of $Y$ (yaw of $Y$ )
19. $\varepsilon_{x}(z)$
$X$ Rotation of $Z$ (pitch of $Z$ )
20. $\varepsilon_{y}(z)$
Y Rotation of $Z$ (yaw of Z)
21. $\varepsilon_{z}(z)$
Z Rotation of Z (roll of Z)

Three of the straightness errors must be modified to form generalized straightness errors due to the angular errors between axes. In particular

1. A generalized X-straightness error of $Y$ motion is given by $\delta_{x}(y)+\alpha_{x}(y) \Delta y$.

2. A generalized $X$-straightness error of $Z$ motion is given by $\delta_{x}(z)+\alpha_{x}(z) \Delta z$.

3. A generalized $\mathrm{Y}$-straightness error of $\mathrm{Z}$ motion is given by $\delta_{y}(z)+\alpha_{y}(z) \Delta z$.

In these formulas $\Delta y$ and $\Delta z$ represent incremental steps along the $\mathrm{Y}$ and $\mathrm{Z}$ axes.

The construction of the kinematic model along the lines of Donmez [24] begins by assuming that a reference axis system is established by setting the part zero at the lower left corner of the part. The vertical, or $Z$, axis system is initialized vertically over the part zero but offset from it by a tool offset, $z_{0}$. To model a drilling operation three steps are performed. First, the $\mathrm{Y}$ slide is moved forward, or in the negative $\mathrm{Y}$ direction. This slide carries the $X$ slide along and holds the $Z$ slide fixed. The second step is to move the $X$ slide to the left and hold both the $\mathrm{Y}$ and $\mathrm{Z}$ slide fixed. Finally the $\mathrm{Z}$ slide is moved in a downward or negative $Z$ direction to produce the drilled hole (See Figure 4 below).

The motion of the $\mathrm{Y}$ slide with respect to the reference axis system is modeled by the product of an ideal motion matrix and the motion error matrix. This is given by

$$
{ }^{R} T_{y}=\left(\begin{array}{llll}
1 & 0 & 0 & 0 \\
0 & 1 & 0 & y \\
0 & 0 & 1 & 0 \\
0 & 0 & 0 & 1
\end{array}\right)\left(\begin{array}{cccc}
1 & -\varepsilon_{z}(y) & \varepsilon_{y}(y) & \delta_{x}(y)-\alpha_{x}(y) d y \\
\varepsilon_{z}(y) & 1 & -\varepsilon_{x}(y) & \delta_{y}(y) \\
-\varepsilon_{y}(y) & \varepsilon_{x}(y) & 1 & \delta_{z}(y) \\
0 & 0 & 0 & 1
\end{array}\right)
$$

The motion of the $\mathrm{X}$ slide with respect to the $\mathrm{Y}$ slide is modeled by the product of an ideal motion matrix and the motion error matrix. This is given by 


$$
{ }^{y} T_{x}=\left(\begin{array}{cccc}
1 & 0 & 0 & x \\
0 & 1 & 0 & 0 \\
0 & 0 & 1 & 0 \\
0 & 0 & 0 & 1
\end{array}\right)\left(\begin{array}{cccc}
1 & -\varepsilon_{z}(x) & \varepsilon_{y}(x) & \delta_{x}(x) \\
\varepsilon_{z}(x) & 1 & -\varepsilon_{x}(x) & \delta_{y}(x) \\
-\varepsilon_{y}(x) & \varepsilon_{x}(x) & 1 & \delta_{x}(x) \\
0 & 0 & 0 & 1
\end{array}\right)
$$

The work piece point with respect to the $\mathrm{X}$ slide involves only a translation matrix so that

$$
{ }^{x} T_{w}=\left(\begin{array}{cccc}
1 & 0 & 0 & -x \\
0 & 1 & 0 & -y \\
0 & 0 & 1 & y \\
0 & 0 & 0 & 1
\end{array}\right)
$$

The motion of the $\mathrm{Z}$ slide with respect to the reference axis system is given by the product of the ideal motion matrix and the motion error matrix as

$$
{ }^{R} T_{z}=\left(\begin{array}{cccc}
1 & 0 & 0 & 0 \\
0 & 1 & 0 & 0 \\
0 & 0 & 1 & z \\
0 & 0 & 0 & 1
\end{array}\right)\left(\begin{array}{cccc}
1 & -\varepsilon_{z}(z) & \varepsilon_{y}(z) & \delta_{x}(z)-\alpha_{x}(z) d z \\
\varepsilon_{z}(z) & 1 & -\varepsilon_{x}(z) & \delta_{y}(z)-\alpha_{y}(z) d z \\
-\varepsilon_{y}(z) & \varepsilon_{x}(z) & 1 & \delta_{z}(z) \\
0 & 0 & 0 & 1
\end{array}\right) .
$$

Finally the tool point with respect to the $\mathrm{Z}$ slide involves only an identity matrix as

$$
{ }^{2} T_{t}=\left(\begin{array}{llll}
1 & 0 & 0 & 0 \\
0 & 1 & 0 & 0 \\
0 & 0 & 1 & 0 \\
0 & 0 & 0 & 1
\end{array}\right)
$$

The matrix relating the work piece point relative to the reference axis, ${ }^{R} T_{w}$, is given by the matrix product

$$
{ }^{R} T_{w}={ }^{R} T_{y}{ }^{y} T_{x}{ }^{x} T_{w}
$$


and the matrix relating the tool tip to the reference axis, ${ }^{R} T_{t}$, is given by the matrix product

$$
{ }^{R} T_{t}={ }^{R} T_{z}{ }^{z} T_{t}
$$

The error matrix relating the tool point to the workpiece, $\mathrm{E}$, is then given by

$$
E={ }^{R} T_{t}^{-1 R} T_{w}
$$

Using a symbol manipulator, such as MACSYMA, it is possible to compute the displacement errors of the work point with respect to the zero reference point (see Appendix E). These errors, ignoring cross-products and higher-order terms, are given by

$$
\begin{aligned}
& E_{x}=y \varepsilon_{z}(y)+z \varepsilon_{y}(y)+\delta_{x}(y)+y \varepsilon_{z}(x)+\delta_{x}(x)-\delta_{x}(z)-y \alpha_{x}(y)+z \alpha_{x}(z)+z \varepsilon_{y}(x) \\
& E_{y}=\delta_{y}(y)-x \varepsilon_{z}(x)+\delta_{y}(x)-z \varepsilon_{x}(y)-\delta_{y}(z)+z \alpha_{y}(z)-z \varepsilon_{x}(x) \\
& E_{z}=-y \varepsilon_{x}(y)+\delta_{z}(y)+x \varepsilon_{y}(x)-y \varepsilon_{x}(x)+\delta_{z}(x)-\delta_{z}(z)
\end{aligned}
$$

Equation (9) provides a formula for combining individual machine error components to estimate the resultant positioning error between the tool and the work piece. Individual error components can be obtained using machine tool metrology characterization procedures outlined in the literature ASME B5.54 [19]. However, in this study the LBB methods described in Section 3.3 were used. Although most of these errors are repeatable, there is always a measurable amount of variation in the machine behavior due to various factors influencing the machine performance. These variations result in the variation of the estimates obtained by the kinematic equations given in equation (9) as well as the variation in the machined part dimensions and form.

Since only planar errors are to be studied in this report any terms in equations (9) that involve a $z$ coordinate value are dropped so that the final equations used to analyze the data are given by the following equations.

$$
\begin{aligned}
& E_{x}=y \varepsilon_{z}(y)+\delta_{x}(y)+y \varepsilon_{z}(x)+\delta_{x}(x)-y \alpha_{x}(y) \\
& E_{y}=\delta_{y}(y)-x \varepsilon_{z}(x)+\delta_{y}(x)
\end{aligned}
$$

In order to evaluate these formulas the first task was to develop equations for each of the components that relate the component errors to the coordinates $x$ and $y$. 
Axis System for the Three Axis Machining Center

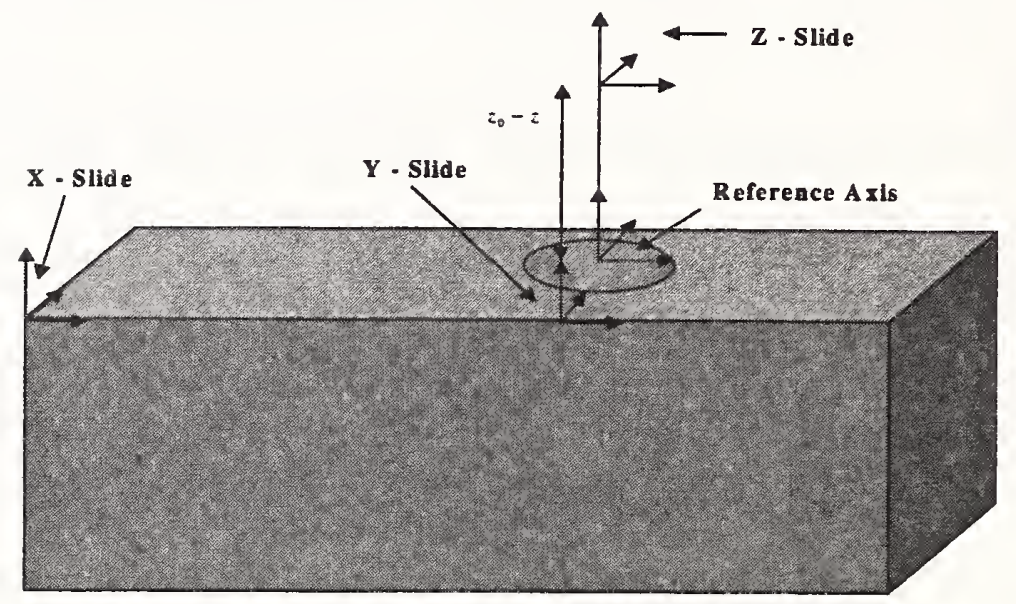

Figure 4: Kinematic Model Axes Systems

\subsection{Regression Models for the Component Errors}

In order to compare the results obtained from modeling machine tool errors with those measured on parts produced on the machine the strategy was to align the coordinate systems so that the origins and axes overlap. The data taken by the LBB was measured relative to the machine's coordinate axis. The first step in modeling the data was to locate the part origin for measurements within the machine coordinate system. This was the point used as the part origin when the parts were measured on a CMM. Although the part origin for machining was taken as the center of the part shown in Figure 2, the part origin for measurements was taken as the lower left corner of the inner 150 by $150 \mathrm{~mm}$ square. The component error data on the machine tool was taken by the LBB relative to the machine coordinate system in steps of $25.4 \mathrm{~mm}$ in both the $x$ and the $y$ direction, with twenty-five steps in the $x$ direction and twenty-six steps in the $y$ direction. For each of these points there were ten data values. The part origin for measurement in the machine coordinate system was located within one of these intervals for $x$ and one for $y$. The mean values of the ten data values for each of the error components were computed and their values were interpolated to find the values of the components at the part origin for measurement. The data and the $x$ and $y$ scales were then shifted so that the part origin for measurement became the zero in the $\mathrm{x}$ and $\mathrm{y}$ coordinate system and the mean component errors at the part origin for measurement also became zero. This process aligned the onmachine measurements by the LBB with the part measurements made on the CMM. 
Figures 5 through 10 below show the shifted data values recorded by the LBB for six of the seven critical error components. The figures show linear trends in the error components over the work volume of the test parts. Simple linear regression models were fit to each of the six data sets. Since eight of the measurement steps fell within the work volume of the part being milled, only the data from those eight entered the regression analysis. In that case $n=80$ observations were made for each of the six error components

$$
\delta_{x}(x), \delta_{y}(x), \delta_{y}(y), \delta_{x}(y), \varepsilon_{z}(x), \varepsilon_{z}(y)
$$

These observations were comprised of ten observations at each of eight locations in each of the $x$ and $y$ coordinates. The measurements have been normalized to part zero so that the zero point on the horizontal axis represents the part zero. Both forward measurement beginning from the left in the figures below and reverse measurement show backlash error.

The figures show a definite effect of thermal conditions. There is a general tendency of the graphs for the displacement and straightness errors to rise as the number of runs increases. The angular error components rise through the third pass, with retreat indicating a reversal of rotation after about five hours of continual running. This thermal effect introduces a nonstationarity in the data so that traditional assumptions of the distribution of sample repetitions can not be applied, but for the purpose of this study they can be considered as legitimate repeats and the resulting analysis accepted as overly conservative.

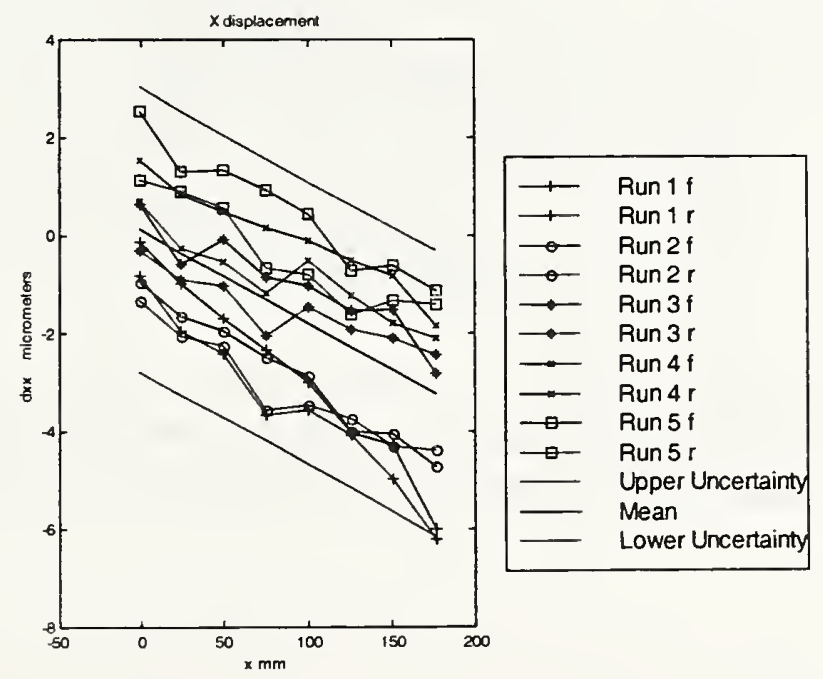

Figure 5: LBB Measurements of X Displacement Errors

Showing the Mean Least Squares Trend Line with Uncertainty Band Using a Coverage Factor of 2 


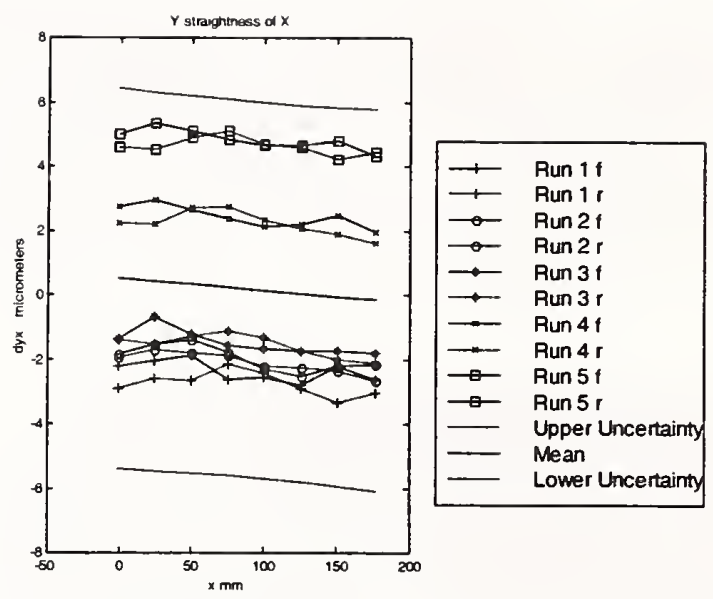

Figure 6: LBB Measurements of Y Straightness of X Errors Showing the Mean Least Squares Trend Line with Uncertainty Band Using a Coverage Factor of 2

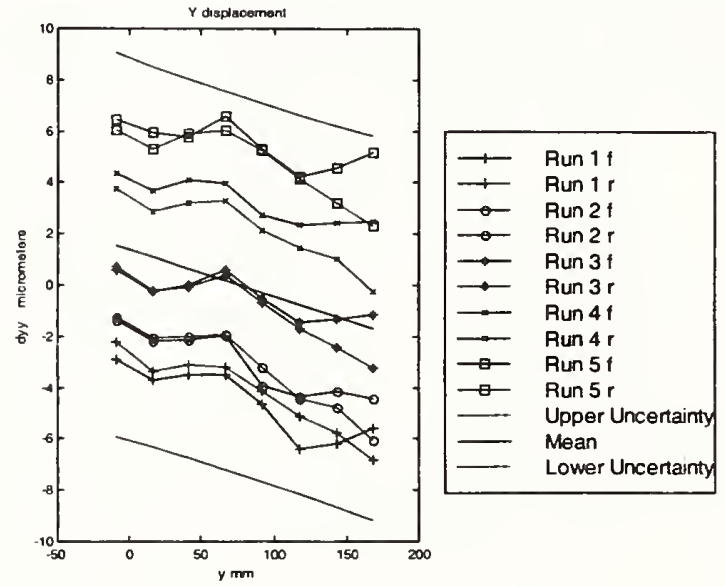

Figure 7: LBB Measurements of Y Displacement Errors Showing the Mean Least Squares Trend Line with Uncertainty Band Using a Coverage Factor of 2 


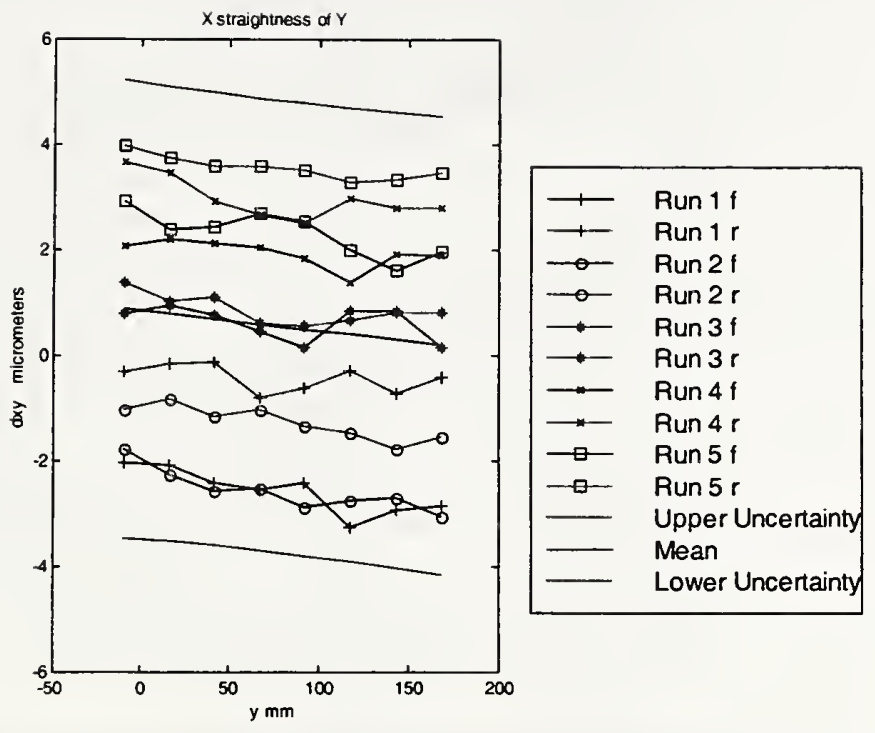

Figure 8: LBB Measurements of Y Straightness of X Errors Showing the Mean Least Squares Trend Line with Uncertainty Band Using a Coverage Factor of 2

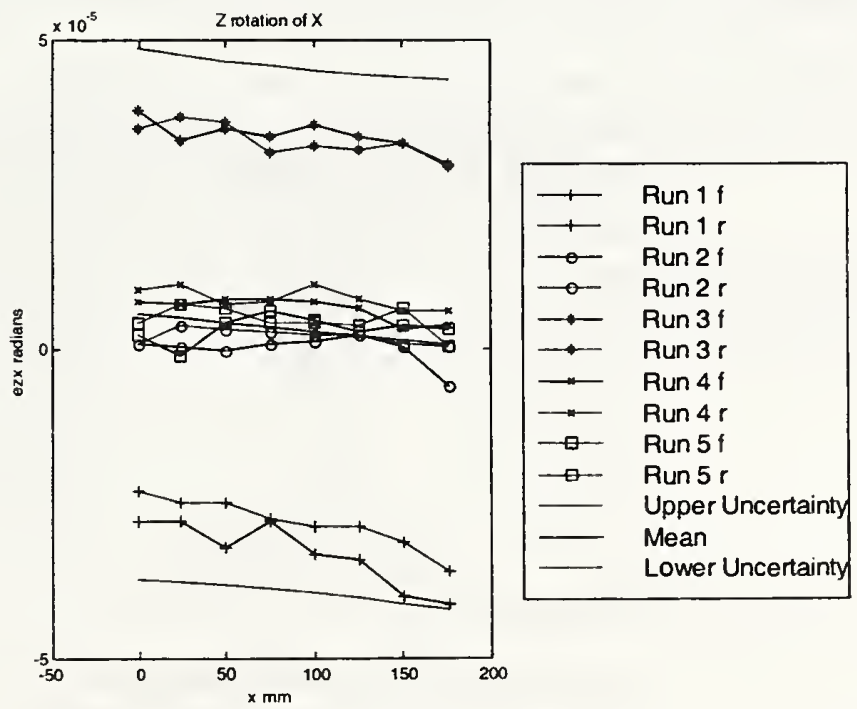

Figure 9: LBB Measurements of Rotation About $Z$ with $X$ Motion Errors Showing the Mean Least Squares Trend Line with Uncertainty Band Using a Coverage Factor of 2 


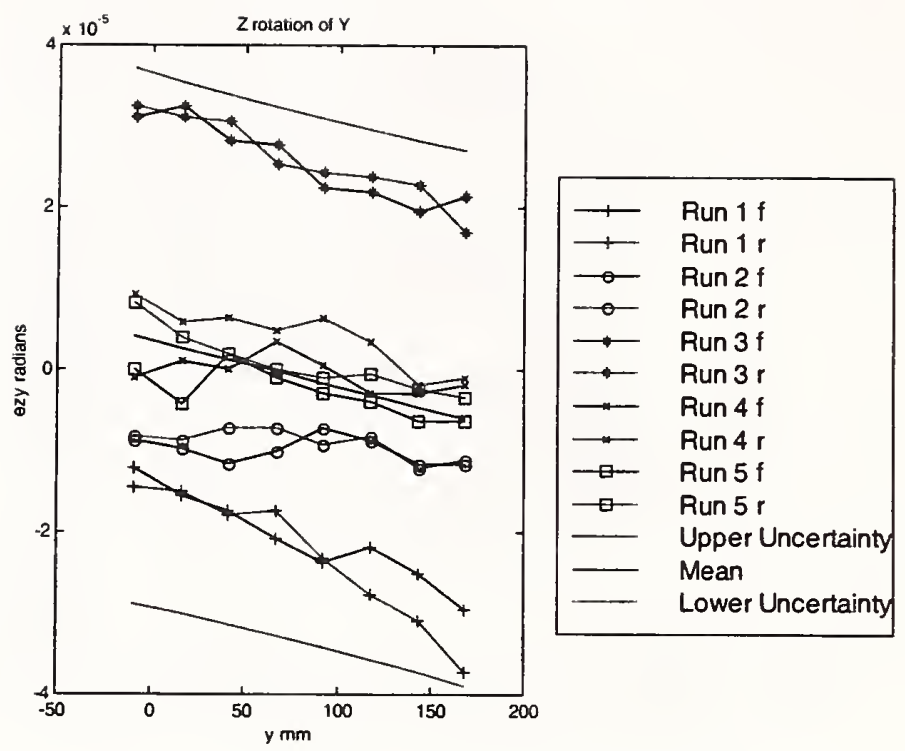

\section{Figure 10: LBB Measurements of Rotation About $Z$ with $Y$ Motion Errors Showing the Mean Least Squares Trend Line with Uncertainty Band Using a Coverage Factor of 2}

The LBB measurement of the angular error between the $x$ and $y$ axes is independent of coordinate position. Table 1 gives the errors measured by the LBB in arc seconds and radians. The mean error in radians, estimated standard deviation and degrees of freedom are also given. These are used to estimate the confidence interval of a future observation of the angular error.

\begin{tabular}{|c|c|c|}
\hline \multicolumn{3}{|c|}{ Angular Error Between $\mathrm{X}$ and $\mathrm{Y}$ Axes } \\
\hline Pass \# & Error (arcsec) & Error(radians) \\
\hline \hline 1 & -6.99 & $-3.39-05$ \\
\hline 2 & -6.43 & $-3.12 \mathrm{E}-05$ \\
\hline 3 & -7.39 & $-3.58 \mathrm{E}-05$ \\
\hline 4 & -6.76 & $-3.27 \mathrm{E}-05$ \\
\hline 5 & -6.79 & $-3.29 \mathrm{E}-05$ \\
\hline & Mean & $-3.33 \mathrm{E}-05$ \\
\hline \multicolumn{3}{|c|}{} \\
\cline { 2 - 3 } & Est. Std. Dev. & $1.67 \mathrm{E}-06$ \\
\cline { 2 - 3 } & Deg. Of Freedom & 4 \\
\hline
\end{tabular}

Table 1: LBB Measurements of the Angular Errors Between the $\mathrm{X}$ and $\mathrm{Y}$ axes

Table 2 gives the slope and intercept values for the linear trend equations describing the error components shown in Figures 5 through 10. 


\begin{tabular}{|c|c|c|}
\hline \multicolumn{3}{|c|}{ Kinematic Error component Coefficients } \\
\hline \multirow{2}{*}{} & Displacement & Errors \\
\cline { 2 - 3 } & Slope & Intercept \\
\cline { 2 - 3 }$\delta_{x}(x)$ & Nondim. & mm \\
\hline$\delta_{y}(x)$ & $-1.89 \mathrm{E}-05$ & $1.04 \mathrm{E}-04$ \\
\hline$\delta_{y}(y)$ & $-3.78 \mathrm{E}-06$ & $5.16 \mathrm{E}-04$ \\
\hline$\delta_{x}(y)$ & $-1.823 \mathrm{E}-05$ & $1.38 \mathrm{E}-03$ \\
\hline \hline \multirow{3}{*}{} & $-3.88 \mathrm{E}-06$ & $8.55 \mathrm{E}-04$ \\
\cline { 2 - 3 } & Rotational & Errors \\
\cline { 2 - 3 } & Slope & Intercept \\
\hline \hline \multirow{2}{*}{$\varepsilon_{z}(x)$} & Nondim. & radians \\
\hline \multirow{2}{*}{$\varepsilon_{z}(y)$} & $-2.87 \mathrm{E}-08$ & $5.73 \mathrm{E}-06$ \\
\hline \hline & $-5.62 \mathrm{E}-08$ & $3.52 \mathrm{E}-06$ \\
\hline & X-Y Axes Angle & Error \\
\cline { 2 - 3 } & Slope & Intercept \\
\cline { 2 - 3 } & Nondim. & radians \\
\hline \hline$\alpha_{x y}$ & $0.0000 \mathrm{E}+00$ & $-3.33 \mathrm{E}-05$ \\
\hline
\end{tabular}

\section{Table 2: Error Component Coefficients}

\subsection{General Propagation of Uncertainties Using the Kinematic Model}

In order to estimate the uncertainties associated with the resultant errors a preliminary assumption is made that the individual error terms are uncorrelated since it is difficult to estimate the cross correlation of the different dimensional errors.

According to the Law of Propagation of Uncertainty, outlined in the ISO Guide [1], Taylor and Kuyatt [2], Coleman and Steele [25] and Wheeler and Ganji [26], if a variable $\mathrm{E}$, such as those in equation (9), is a function of $\mathrm{N}$ stochastic components that are uncorrelated

$$
E=f\left(\gamma_{1}, \cdots, \gamma_{N}\right)
$$

then the combined uncertainty of $\mathrm{E}, u_{c}(E)$, can be estimated in terms of the uncertainties of the components, ignoring second order terms, by

$$
u_{c}^{2}(E) \approx \sum_{i=1}^{N}\left(\frac{\partial f}{\partial \gamma_{i}}\right)^{2} u^{2}\left(\gamma_{i}\right)
$$


The variances of the positioning errors in equation (9) can be computed from the propagation of uncertainties law by taking the appropriate partial derivatives as

$$
\begin{aligned}
u_{c}^{2}\left(E_{x}\right)= & y^{2} u^{2}\left(\varepsilon_{z}(y)\right)+z^{2} u^{2}\left(\varepsilon_{y}(y)\right)+u^{2}\left(\delta_{x}(y)\right)+y^{2} u^{2}\left(\varepsilon_{z}(x)\right) \\
& +u^{2}\left(\delta_{x}(x)\right)+u^{2}\left(\delta_{x}(z)\right)+y^{2} u^{2}\left(\alpha_{x y}\right)+z^{2} u^{2}\left(\alpha_{x z}\right)+z^{2} u^{2}\left(\varepsilon_{y}(x)\right) \\
u_{c}^{2}\left(E_{y}\right)= & u^{2}\left(\delta_{y}(y)\right)+x^{2} u^{2}\left(\varepsilon_{z}(x)\right)+u^{2}\left(\delta_{y}(x)\right)+z^{2} u^{2}\left(\varepsilon_{x}(y)\right)+u^{2}\left(\delta_{y}(z)\right) \\
& +z^{2} u^{2}\left(\alpha_{y z}\right)+z^{2} u^{2}\left(\varepsilon_{x}(x)\right) \\
u_{c}^{2}\left(E_{z}\right)= & y^{2} u^{2}\left(\varepsilon_{x}(y)\right)+u^{2}\left(\delta_{z}(y)\right)+x^{2} u^{2}\left(\varepsilon_{y}(x)\right)+y^{2} u^{2}\left(\varepsilon_{x}(x)\right)+u^{2}\left(\delta_{z}(x)\right) \\
& +u^{2}\left(\delta_{z}(z)\right)
\end{aligned}
$$

To evaluate the uncertainties $u_{c}\left(E_{x}\right), u_{c}\left(E_{y}\right), u_{c}\left(E_{z}\right)$ one has to determine the uncertainties of individual error components using machine characterization data. For completeness, equation (13) gives the error vector at any given point $(x, y, z)$ in the workspace, but since only uncertainties associated with planar features are of interest here the uncertainty equations reduce to

$$
\begin{aligned}
& u_{c}^{2}\left(E_{x}(x, y)\right)=y^{2} u^{2}\left(\varepsilon_{z}(y)\right)+u^{2}\left(\delta_{x}(y)\right)+y^{2} u^{2}\left(\varepsilon_{z}(x)\right)+u^{2}\left(\delta_{x}(x)\right)+y^{2} u^{2}\left(\alpha_{x}(y)\right) \\
& u_{r}^{2}\left(E_{y}(x, y)\right)=u^{2}\left(\delta_{y}(y)\right)+x^{2} u^{2}\left(\varepsilon_{z}(x)\right)+u^{2}\left(\delta_{y}(x)\right)
\end{aligned}
$$

The approximation here is that the components are taken to be uncorrelated. Since the measurement instrumentation used did not allow simultaneous measurements of all component errors the assumption is necessary but simultaneous measurement is considered a standard in scientific work.

The uncertainties of the components can be estimated from their equations. The methods are described in Montgomery and Peck [27]. Since the component errors are modeled as linear equations their regression equations take the form

$$
y=X \beta+\varepsilon
$$

where $\varepsilon$ refers to the regression error, not to be mistaken for the rotational errors above, and 


$$
\begin{aligned}
& y=\left[\begin{array}{c}
y_{1} \\
y_{2} \\
\vdots \\
y_{n}
\end{array}\right], \quad X=\left[\begin{array}{cc}
1 & x_{1} \\
1 & x_{2} \\
\vdots & \vdots \\
1 & x_{n}
\end{array}\right] \\
& \beta=\left[\begin{array}{c}
\beta_{1} \\
\beta_{2}
\end{array}\right], \quad \varepsilon=\left[\begin{array}{c}
\varepsilon_{1} \\
\varepsilon_{2} \\
\vdots \\
\varepsilon_{n}
\end{array}\right]
\end{aligned}
$$

In general, $y$ is an $n \times 1$ vector of observations. $X$ is an $n \times 2$ matrix of the regressor variables. $\beta$ is a $2 \times 1$ vector whose components are: $\beta_{1}$ the line intercept and $\beta_{2}$ the line slope. $\varepsilon$ is an $n \times 1$ vector of random errors.

The least squares estimator of $\beta$ is given by the well known formula

$$
\hat{\beta}=\left(X^{T} X\right)^{-1} X^{T} y
$$

Given a coordinate $x_{1}$, which could be along the $x$ or $y$ coordinate axis depending on the approximate error component equation that is being evaluated, the predicted value is computed as

$$
\hat{y}=x^{T} \hat{\beta}
$$

where $x^{T}=\left[\begin{array}{ll}1 & x_{1}\end{array}\right]$ is the regressor variable.

The regression model (15) can be used to predict a particular value of $y_{0}$ corresponding to a specified level of regressor variable of $x_{0}$. In particular, let $x_{0}^{T}=\left[\begin{array}{ll}1 & x_{01}\end{array}\right]$, then a point estimate of the future observation $y_{0}$ is given by (18) as

$$
\hat{y}_{0}=x_{0}^{T} \hat{\beta}
$$

Under the conditions that the repetition samples and their standard errors satisfy certain strict probability distribution requirements a confidence interval for this predicted observation is

$$
\begin{aligned}
& \hat{y}_{0}-k_{p} \sqrt{\hat{\sigma}^{2}\left(1+x_{0}^{T}\left(X^{T} X\right)^{-1} x_{0}\right)} \\
& \leq y_{0} \leq \hat{y}_{0}+k_{p} \sqrt{\hat{\sigma}^{2}\left(1+x_{0}^{T}\left(X^{T} X\right)^{-1} x_{0}\right)}
\end{aligned}
$$


where $k_{p}$ is the coverage factor, taken here as $k_{p}=2$ [2]. This interval is referred to as a prediction interval for a future observation of $y_{0}$ [27]. It is more conservative than the confidence interval for the mean, but it is more meaningful for of parts production. For the rest of this report the use of the term confidence interval will mean the prediction interval. Also for the rest of this report the term $\sqrt{\hat{\sigma}^{2}\left(1+x_{0}^{T}\left(X^{T} X\right)^{-1} x_{0}\right.}$ will be referred to as the standard uncertainty with the understanding that it is the standard error of a new observation given a value of the regressor variable. The expanded standard uncertainty is then

$$
u\left(x_{0}\right)=2 \sqrt{\hat{\sigma}^{2}\left(1+x_{0}^{T}\left(X^{T} X\right)^{-1} x_{0}\right)}
$$

where

$$
\hat{\sigma}^{2}=\frac{y^{T} y-\hat{\beta}^{T} X^{T} y}{n-2}
$$

with $y$ being the data used in (16).

Figures 5 through 10 show the linear equation fit to the data as well as the upper and lower uncertainty bands based on the interval (20) with a coverage factor of 2 . The coefficients of the fitted linear equations are given in Table 2.

At this point we will show how the formulas above, used to estimate an uncertainty interval for the next observation for a linear regression problem, can also be used to estimate an uncertainty interval for the next sample of the angular error given in Table 1. Although the angular error model is considered be a constant, the representation we select is given by equation (15) with the y vector given by the five angular errors in Table 1 and the $\mathrm{X}$ matrix given by $\left[\begin{array}{lllll}1 & 1 & 1 & 1 & 1\end{array}\right]^{T}$. The parameter estimates are then given by equation (17). In this case $\hat{\beta}=\left(X^{T} X\right)^{-1} X^{T} Y=\frac{1}{5} \sum_{i=1}^{5} \alpha_{x y, i}=\bar{\alpha}_{x y}$. Thus the least squares model in this case is the mean of the samples. Furthermore $x_{0}=[1]$, so that $x_{0}^{T}\left(X^{T} X\right)^{-1} x_{0}=\frac{1}{5}$. The coverage factor will again be selected as 2 . In this case, the confidence interval for a future sample of the angular error between the $\mathrm{x}$ and $\mathrm{y}$ axes is given by

$$
\bar{\alpha}_{x y}-2 \sqrt{\frac{6}{5} \hat{\sigma}^{2}} \leq \alpha_{x y} \leq \bar{\alpha}_{x y}+2 \sqrt{\frac{6}{5} \hat{\sigma}^{2}}
$$

where 


$$
\hat{\sigma}^{2}=\frac{1}{4}\left(\sum_{i=1}^{5} \alpha_{x y, i}^{2}-\hat{\beta} \sum_{i=1}^{5} \alpha_{x y, i}\right)
$$

which for the data in Table 1 is $2.88849 \mathrm{e}-12$ radian squared. Therefore the uncertainty interval for a future angular error observation in radians is

$$
-3.70355 e-5 \leq \alpha_{x y} \leq-2.95885 e-5
$$

where the estimated standard deviation for a future sample is $1.86177 \mathrm{e}-6$ radians.

From the entries in Table 2 above one can substitute estimates into the component error equations of the form

$$
\begin{aligned}
& \hat{\delta}_{x}(x)=\beta_{11} x+\beta_{12} \\
& \hat{\delta}_{y}(x)=\beta_{21} x+\beta_{22} \\
& \hat{\delta}_{y}(y)=\beta_{31} y+\beta_{32} \\
& \hat{\delta}_{x}(y)=\beta_{41} y+\beta_{42} \\
& \hat{\varepsilon}_{z}(x)=\beta_{51} x+\beta_{52} \\
& \hat{\varepsilon}_{z}(y)=\beta_{61} y+\beta_{62} \\
& \hat{\alpha}_{x y}=\beta_{72}
\end{aligned}
$$

Where the hat notation indicates that these equations are taken as estimates for the variables on the left. The degree of freedom of each of the first six estimates is seventy eight, since there are eighty samples used to estimate the linear error component functions, and the degree of freedom of the last is four. The estimates of $\sigma^{2}$ for each of the equations in (26) are given by 


$$
\begin{aligned}
& \sigma_{\delta_{x}(x)}^{2}=\frac{1}{78}\left\{\sum_{i=1}^{80}\left(\delta_{x}(x)_{i}-\beta_{11} x_{i}-\beta_{12}\right)^{2}\right\} \\
& \sigma_{\delta_{y}(x)}^{2}=\frac{1}{78}\left\{\sum_{i=1}^{80}\left(\delta_{y}(x)_{i}-\beta_{21} x_{i}-\beta_{22}\right)^{2}\right\} \\
& \sigma_{\delta_{y}(y)}^{2}=\frac{1}{78}\left\{\sum_{i=1}^{80}\left(\delta_{y}(y)_{i}-\beta_{31} y_{i}-\beta_{32}\right)^{2}\right\} \\
& \sigma_{\delta_{x}(y)}^{2}=\frac{1}{78}\left\{\sum_{i=1}^{80}\left(\delta_{x}(y)_{i}-\beta_{41} y_{i}-\beta_{42}\right)^{2}\right\} \\
& \sigma_{\varepsilon_{z}(x)}^{2}=\frac{1}{78}\left\{\sum_{i=1}^{80}\left(\varepsilon_{z}(x)_{i}-\beta_{51} x_{i}-\beta_{52}\right)^{2}\right\} \\
& \sigma_{\varepsilon_{z}(y)}^{2}=\frac{1}{78}\left\{\sum_{i=1}^{80}\left(\varepsilon_{z}(y)_{i}-\beta_{61} y_{i}-\beta_{62}\right)^{2}\right\} \\
& \sigma_{\alpha_{y y}}^{2}=\frac{1}{4}\left\{\sum_{i=1}^{5}\left(\alpha_{x y, i}-\beta_{72}\right)^{2}\right\}
\end{aligned}
$$

With these one can now estimate the variance of the variables on the left of (26) at a specific point $\left(x_{0}, y_{0}\right)$ in the workspace. These are given by

$$
\begin{aligned}
& u^{2}\left(\hat{\delta}_{x}\left(x_{0}\right)\right)=\sigma_{\delta_{x}(x)}^{2}\left\{\frac{1}{80}+\frac{\left(x_{0}-\bar{x}\right)}{\sum_{i=1}^{80}\left(x_{i}-\bar{x}\right)^{2}}\right\} \\
& u^{2}\left(\hat{\delta}_{y}\left(x_{0}\right)\right)=\sigma_{\delta_{y}(x)}^{2}\left\{\frac{1}{80}+\frac{\left(x_{0}-\bar{x}\right)}{\sum_{i=1}^{80}\left(x_{i}-\bar{x}\right)^{2}}\right\} \\
& u^{2}\left(\hat{\delta}_{y}\left(y_{0}\right)\right)=\sigma_{\delta_{y}(y)}^{2}\left\{\frac{1}{80}+\frac{\left(y_{0}-\bar{y}\right)}{\sum_{i=1}^{80}\left(y_{i}-\bar{y}\right)^{2}}\right\} \\
& u^{2}\left(\hat{\delta}_{x}\left(y_{0}\right)\right)=\sigma_{\delta_{x}(y)}^{2}\left\{\frac{1}{80}+\frac{\left(y_{0}-\bar{y}\right)}{\sum_{i=1}^{80}\left(y_{i}-\bar{y}\right)^{2}}\right\}
\end{aligned}
$$




$$
\begin{aligned}
& u^{2}\left(\hat{\varepsilon}_{z}\left(x_{0}\right)\right)=\sigma_{\varepsilon_{z}(x)}^{2}\left\{\frac{1}{80}+\frac{\left(x_{0}-\bar{x}\right)}{\sum_{i=1}^{80}\left(x_{i}-\bar{x}\right)^{2}}\right\} \\
& u^{2}\left(\hat{\varepsilon}_{z}\left(y_{0}\right)\right)=\sigma_{\varepsilon_{z}(y)}^{2}\left\{\frac{1}{80}+\frac{\left(y_{0}-\bar{y}\right)}{\sum_{i=1}^{80}\left(y_{i}-\bar{y}\right)^{2}}\right\} \\
& u^{2}\left(\hat{\alpha}_{x y}\right)=\sigma_{\alpha_{x y}}^{2}\left\{\frac{6}{5}\right\}
\end{aligned}
$$

The combined standard uncertainties of the estimated errors about the mean at a given regressor point are given by the square roots of

$$
\begin{aligned}
u_{c p}^{2}\left(\hat{E}_{x}\left(x_{0}, y_{0}\right)\right)= & y_{0}^{2} u^{2}\left(\hat{\varepsilon}_{z}\left(y_{0}\right)\right)+u^{2}\left(\hat{\delta}_{x}\left(y_{0}\right)\right)+y_{0}^{2} u^{2}\left(\hat{\varepsilon}_{z}\left(x_{0}\right)\right) \\
& +u^{2}\left(\hat{\delta}_{x}\left(x_{0}\right)\right)+y_{0}^{2} u^{2}\left(\hat{\alpha}_{x y}\right) \\
u_{c p}^{2}\left(\hat{E}_{x}\left(x_{0}, y_{0}\right)\right)= & u^{2}\left(\hat{\delta}_{y}\left(y_{0}\right)\right)+x_{0}^{2} u^{2}\left(\hat{\varepsilon}_{z}\left(x_{0}\right)\right)+u^{2}\left(\hat{\delta}_{y}\left(x_{0}\right)\right)
\end{aligned}
$$

where the subscript $c p$ indicates the combined standard uncertainty about the mean at a point $\left(x_{0}, y_{0}\right)$. However, in order to estimate a confidence interval of a future error response one must include the fact that the actual observed errors vary about their true means with estimated variances given by

$$
\begin{aligned}
& u_{c m}^{2}\left(\bar{E}_{x}\left(x_{0}, y_{0}\right)\right)=y_{0}^{2} \sigma_{\varepsilon_{z}(y)}^{2}+\sigma_{\delta_{x}(y)}^{2}+y_{0}^{2} \sigma_{\varepsilon_{z}(x)}^{2}+\sigma_{\delta_{x}(x)}^{2}+y_{0}^{2} \sigma_{\alpha_{x y}}^{2} \\
& u_{c m}^{2}\left(\bar{E}_{y}\left(x_{0}, y_{0}\right)\right)=\sigma_{\delta_{v}(y)}^{2}+x_{0}^{2} \sigma_{\varepsilon_{z}(x)}^{2}+\sigma_{\delta_{y}(x)}^{2}
\end{aligned}
$$

where the subscript $\mathrm{cm}$ refers to the combined standard uncertainty about the mean $\bar{E}$. The combined standard uncertainty for a future error response is then computed by the square root of

$$
\begin{aligned}
& u_{c o}^{2}\left(E_{x}\left(x_{0}, y_{0}\right)\right)=u_{c m}^{2}\left(\bar{E}_{x}\left(x_{0}, y_{0}\right)\right)+u_{c p}^{2}\left(\hat{E}_{x}\left(x_{0}, y_{0}\right)\right) \\
& u_{c o}^{2}\left(E_{y}\left(x_{0}, y_{0}\right)\right)=u_{c m}^{2}\left(\bar{E}_{y}\left(x_{0}, y_{0}\right)\right)+u_{c p}^{2}\left(\hat{E}_{y}\left(x_{0}, y_{0}\right)\right)
\end{aligned}
$$

where the subscript $c o$ refers to a future observation of the errors. These estimated variances are given in tables A1 to A3 in Appendix A for the peripheral hole centers and for thirty-six evenly spaced points around the inner and outer rings of the circular slot on the part in Figure 2. 
The prediction error at $\left(x_{0}, y_{0}\right)$ can be estimated by substituting (27) through (30) into (31) and using a coverage factor of 2 to write

$$
\begin{aligned}
& E_{x}\left(x_{0}, y_{0}\right) \pm 2 \sqrt{u_{c o}^{2}\left(E_{x}\left(x_{0}, y_{0}\right)\right)} \\
& E_{y}\left(x_{0}, y_{0}\right) \pm 2 \sqrt{u_{c o}^{2}\left(E_{y}\left(x_{0}, y_{0}\right)\right)}
\end{aligned}
$$

A table of the expanded confidence intervals given by equation (32) is given in appendix A for all of the peripheral holes numbered in Figure 5 below. Tables A4 to A6 give the prediction intervals for the peripheral hole centers and the evenly spaced points on the inner and outer rings.

\subsection{Linear Distance Uncertainties}

Estimating distances between hole centers is a planar problem so we will only be concerned with the $\mathrm{x}$ and $\mathrm{y}$ errors at the hole centers. Suppose then that two points, $\left(x_{1}, y_{1}\right)$ and $\left(x_{2}, y_{2}\right)$, are given on a part, such as the centers of two drilled holes. Each of these points has an error associated with it, given by $\left(E_{x}\left(x_{1}, y_{1}\right), E_{y}\left(x_{1}, y_{1}\right)\right)$ and $\left(E_{x}\left(x_{2}, y_{2}\right), E_{y}\left(x_{2}, y_{2}\right)\right)$. The length, $L$, is then computed from

$$
L^{2}=\left(x_{1}+E_{x}\left(x_{1}, y_{1}\right)-x_{2}-E_{x}\left(x_{2}, y_{2}\right)\right)^{2}+\left(y_{1}+E_{y}\left(x_{1}, y_{1}\right)-y_{2}-E_{y}\left(x_{2}, y_{2}\right)\right)^{2}
$$

and the nominal length, $L_{0}$, is computed from

$$
L_{0}^{2}=\left(x_{1}-x_{2}\right)^{2}+\left(y_{1}-y_{2}\right)^{2} \text {. }
$$

Since the variance of the actual length is approximately the variance of the estimated length, i.e. $u_{c o}^{2}\left(L_{a}\right) \approx u_{c o}^{2}(L)$, then, using equations (33) and (34), the estimated variance of the actual length is given by (see Appendix D)

$$
\begin{aligned}
u_{c o}^{2}(L)=\left[\frac{\left(x_{1}-x_{2}\right)}{L_{0}}\right]^{2}\left(u_{c o}^{2}(\right. & \left.\left.E_{x}\left(x_{1}, y_{1}\right)\right)+u_{c o}^{2}\left(E_{x}\left(x_{2}, y_{2}\right)\right)\right) \\
+ & {\left[\frac{\left(y_{1}-y_{2}\right)}{L_{0}}\right]^{2}\left(u_{c o}^{2}\left(E_{y}\left(x_{1}, y_{1}\right)\right)+u_{c o}^{2}\left(E_{y}\left(x_{2}, y_{2}\right)\right)\right) }
\end{aligned}
$$

The validity of this equation depends on the independence of the errors $E_{x}\left(x_{1}, y_{1}\right), E_{x}\left(x_{2}, y_{2}\right), E_{y}\left(x_{1}, y_{1}\right), E_{y}\left(x_{2}, y_{2}\right)$. 
Using equation (35) three length uncertainties are estimated. These uncertainties are compared with uncertainties obtained from measuring the parts on a CMM. More distance uncertainties could be computed but the authors felt that the lengths chosen reflect the essential nature of the part uncertainties in general. The lengths chosen are the center-to-center lengths from hole number three (3) to hole number nine (9), from hole nine (9) to hole fifteen (15), and finally from hole three (3) to hole fifteen (15). The predicted point uncertainties for each of the three points are taken from Table A1 in the appendix, along with the nominal center locations. The estimated length is then computed using equation (33). The error uncertainties are also taken from Table A1 and the length uncertainty is computed by equation (35). The expanded prediction interval is computed using a coverage factor of two. The results are given in Tables 3 and 4 below.

\begin{tabular}{|c|c|c|c|c|c|}
\hline \multicolumn{7}{|c|}{ X Axis } \\
\hline Hole & $\begin{array}{c}\text { Nominal } \\
(\mathrm{mm})\end{array}$ & $\begin{array}{c}\text { Error } \\
(\mu \mathrm{m})\end{array}$ & $\begin{array}{c}\text { Variance } \\
(\mu \mathrm{m})^{2}\end{array}$ & $\begin{array}{c}\text { Uncertainty } \\
(\mu \mathrm{m})\end{array}$ & $\begin{array}{c}\text { Expanded } \\
\text { Uncertainty } \\
(\mu \mathrm{m})\end{array}$ \\
\hline 3 & 10 & 1.15 & 6.86 & 2.62 & 5.24 \\
\hline 9 & 10 & 5.04 & 20.96 & 4.58 & 9.16 \\
\hline 15 & 140 & 2.07 & 20.83 & 4.56 & 9.12 \\
\hline \multicolumn{7}{|c|}{ Y Axis } \\
\hline $\begin{array}{c}\text { Hole } \\
\text { Number }\end{array}$ & $\begin{array}{c}\text { Nominal } \\
(\mathrm{mm})\end{array}$ & $\begin{array}{c}\text { Error } \\
(\mu \mathrm{m})\end{array}$ & $\begin{array}{c}\text { Variance } \\
(\mu \mathrm{m})^{2}\end{array}$ & $\begin{array}{c}\text { Uncertainty } \\
(\mu \mathrm{m})\end{array}$ & $\begin{array}{c}\text { Expanded } \\
\text { Uncertainty } \\
(\mu \mathrm{m})\end{array}$ \\
\hline 3 & 10 & 1.63 & 22.60 & 4.75 & 9.50 \\
\hline 9 & 140 & -0.75 & 22.55 & 4.75 & 9.50 \\
\hline 15 & 140 & -1.43 & 31.23 & 5.59 & 11.18 \\
\hline
\end{tabular}

Table 3: Line End-Point Uncertainties

\begin{tabular}{|c|c|c|c|c|c|c|}
\hline \multicolumn{2}{|c|}{ Length } & Uncertainty \\
\hline & $\begin{array}{c}\text { Nominal } \\
(\mathrm{mm})\end{array}$ & $\begin{array}{c}\text { Estimated } \\
(\mathrm{mm})\end{array}$ & Error $(\mathrm{mm})$ & $\begin{array}{c}\text { Variance } \\
(\mu \mathrm{m})^{2}\end{array}$ & $\begin{array}{c}\text { Uncertainty } \\
(\mu \mathrm{m})\end{array}$ & $\begin{array}{c}\text { Expanded } \\
\text { Uncertainty } \\
(\mu \mathrm{m})\end{array}$ \\
\hline $3-9$ & 130 & 129.998 & -0.002 & 45.1 & 6.72 & 13.44 \\
\hline $9-15$ & 130 & 129.997 & -0.003 & 41.8 & 6.47 & 12.94 \\
\hline $3-15$ & 183.848 & 183.846 & -0.002 & 40.7 & 6.38 & 12.76 \\
\hline
\end{tabular}

Table 4: Line Length Uncertainties

These tables are consistent in that the uncertainties squared of the lengths between hole centers is less than the sum of the squares of the component uncertainties. 


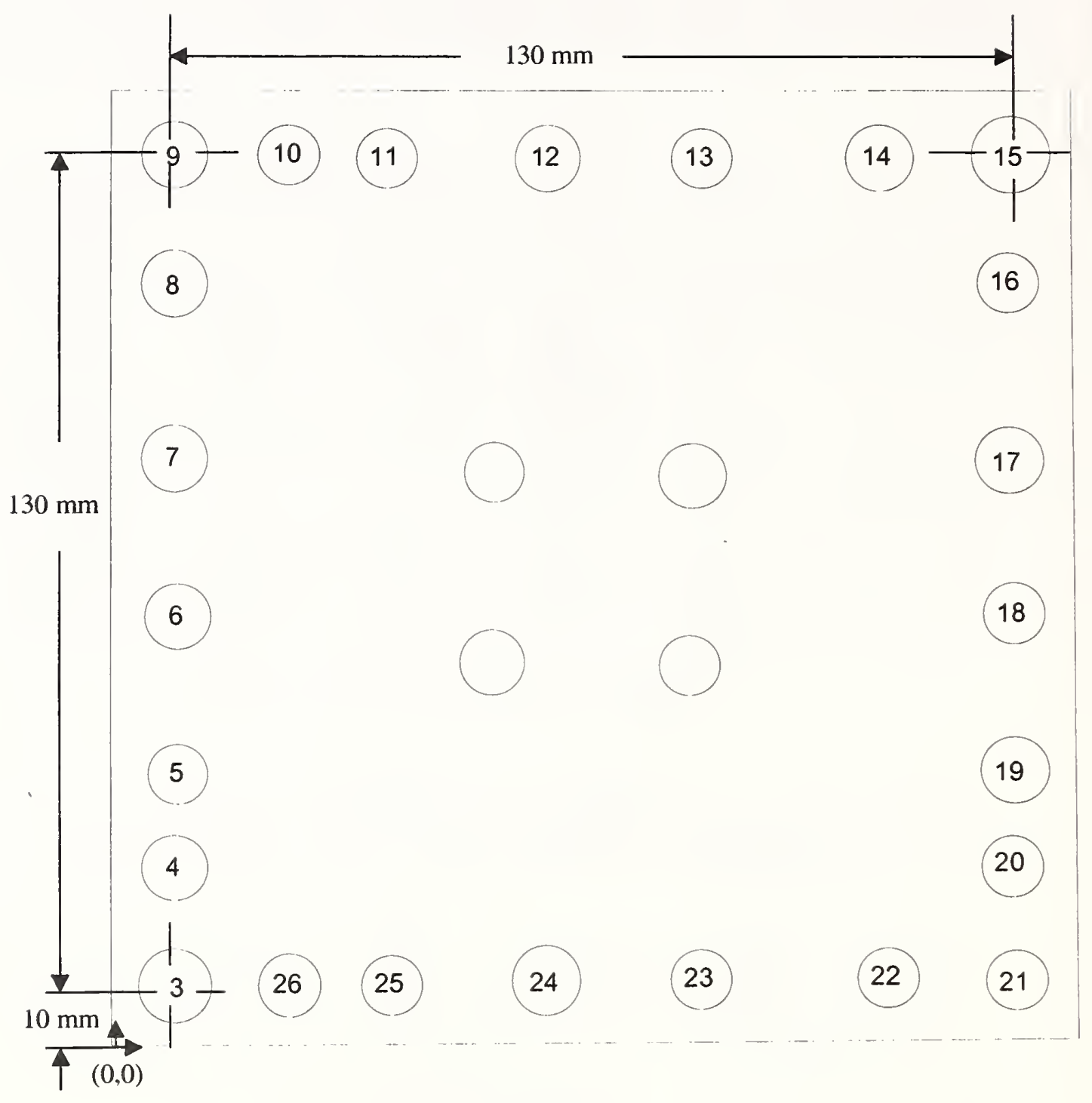




\subsection{Orthogonality Uncertainties}

If the part shown in Figure 2 and Figure 11 were ideal then the line through holes 9 through 15 would lie at right angles to the lines through holes 9 through 3 . However, real parts seldom, if ever, satisfy this property. In general there is a small angular difference between the actual angle that the two lines form and a right angle. This is termed an orthogonality error. Each copy of the same part will have a slightly different orthogonality error. The uncertainty in the distribution of these orthogonality errors is the topic of this section.

Since each of the hole centers has a point uncertainty this means that there is error in both the $x$ and $y$ positions of the center. This fact introduces a problem with finding the best line through the centers of the holes. Assume that we are given points $\left(x_{1}, y_{1}\right), \cdots,\left(x_{N}, y_{N}\right)$ and we wish to find the least squares line through the points. The assumption behind the least squares estimation of coefficients is that the linear first order model can be written as $y=\beta_{0}+\beta_{1} x+\varepsilon$ where the $\varepsilon$ term represents the deviation in the $y$ variable from the line. Thus all of the error in the approximation is assumed to be relegated to the $y$ variable and the $x$ variable is assumed to have no error. The problem of fitting equations to data in which both variables are subject to error, see e.g. Mandel [28]. The relevant methods are called errors in variables.

In this report we will use two different approaches. The first is a technique suggested by Coleman and Steele[25] in which the uncertainties in the least squares coefficients $\beta_{0}, \beta_{1}$ are connected to the uncertainties in the data points themselves. The second is a Monte Carlo approach in which the $\mathrm{x}$ and $\mathrm{y}$ distributions of the hole centers are sampled a large number of times, horizontal and vertical lines fit to the resulting points, and angular differences from right angles computed. The uncertainty in this large sample of orthogonality errors can then be computed.

In the first of the two methods (Coleman and Steele[25]) the assumption is made that the points $\left(x_{1}, y_{1}\right), \cdots,\left(x_{N}, y_{N}\right)$ are given data points and the usual least squares estimates of the slope and intercept are given by

$$
\begin{aligned}
& \beta_{1}=\frac{N \sum_{i=1}^{N} x_{i} y_{i}-\sum_{i=1}^{N} x_{i} \sum_{i=1}^{N} y_{i}}{N \sum_{i=1}^{N}\left(x_{i}^{2}\right)-\left(\sum_{i=1}^{N} x_{i}\right)^{2}} \\
& \beta_{0}=\frac{\sum_{i=1}^{N}\left(x_{i}^{2}\right) \sum_{i=1}^{N} y_{i}-\sum_{i=1}^{N} x_{i} \sum_{i=1}^{N}\left(x_{i} y_{i}\right)}{N \sum_{i=1}^{N}\left(x_{i}^{2}\right)-\left(\sum_{i=1}^{N} x_{i}\right)^{2}}
\end{aligned}
$$

Each of these coefficients can be thought of as functions of the data points so that 


$$
\begin{aligned}
& \beta_{1}=\beta_{1}\left(x_{1}, \cdots, x_{N}, y_{1}, \cdots, y_{N}\right) \\
& \beta_{0}=\beta_{0}\left(x_{1}, \cdots, x_{N}, y_{1}, \cdots, y_{N}\right)
\end{aligned}
$$

Using the propagation of uncertainties formula one gets

$$
\begin{aligned}
& u_{c o}^{2}\left(\beta_{1}\right)=\sum_{i=1}^{N}\left(\frac{\partial \beta_{1}}{\partial x_{i}}\right)^{2} u_{c o}^{2}\left(E_{x}\left(\hat{x}_{i}, \hat{y}_{i}\right)\right)+\sum_{i=1}^{N}\left(\frac{\partial \beta_{1}}{\partial y_{i}}\right)^{2} u_{c o}^{2}\left(E_{y}\left(\hat{x}_{i}, \hat{y}_{i}\right)\right) \\
& u_{c o}^{2}\left(\beta_{0}\right)=\sum_{i=1}^{N}\left(\frac{\partial \beta_{0}}{\partial x_{i}}\right)^{2} u_{c o}^{2}\left(E_{x}\left(\hat{x}_{i}, \hat{y}_{i}\right)\right)+\sum_{i=1}^{N}\left(\frac{\partial \beta_{0}}{\partial y_{i}}\right)^{2} u_{c o}^{2}\left(E_{y}\left(\hat{x}_{i}, \hat{y}_{i}\right)\right)
\end{aligned}
$$

where we assume that each point is the sum of a nominal point plus an error term of the form

$$
\begin{aligned}
& x_{i}=\hat{x}_{i}+E_{x}\left(\hat{x}_{i}, \hat{y}_{i}\right) \\
& y_{i}=\hat{y}_{i}+E_{y}\left(\hat{x}_{i}, \hat{y}_{i}\right)
\end{aligned}
$$

To get the uncertainties on the right hand side of (38) one uses the fact that

$$
\begin{aligned}
& u_{c o}^{2}\left(x_{i}\right)=u_{c o}^{2}\left(\hat{x}_{i}+E_{x}\left(\hat{x}_{i}, \hat{y}_{i}\right)\right)=u_{c o}^{2}\left(E_{x}\left(\hat{x}_{i}, \hat{y}_{i}\right)\right) \\
& u_{c o}^{2}\left(y_{i}\right)=u_{c o}^{2}\left(\hat{y}_{i}+E_{y}\left(\hat{x}_{i}, \hat{y}_{i}\right)\right)=u_{c o}^{2}\left(E_{y}\left(\hat{x}_{i}, \hat{y}_{i}\right)\right)
\end{aligned}
$$

The orthogonality errors only require computing slope differences so that we only need to compute the partial derivatives of the slope $\beta_{1}$. These are given by

$$
\begin{aligned}
& \frac{\partial \beta_{1}}{\partial x_{k}}=\frac{\left[N \sum_{i=1}^{N}\left(x_{i}^{2}\right)-\left(\sum_{i=1}^{N} x_{i}\right)^{2}\right]\left[N y_{k}-\sum_{i=1}^{N} y_{i}\right]-2\left[N \sum_{i=1}^{N} x_{i} y_{i}-\sum_{i=1}^{N} x_{i} \sum_{i=1}^{N} y_{i}\right]\left[N x_{k}-\sum_{i=1}^{N} x_{i}\right]}{\left[N \sum_{i=1}^{N}\left(x_{i}^{2}\right)-\left(\sum_{i=1}^{N} x_{i}\right)^{2}\right]^{2}} \\
& \frac{\partial \beta_{1}}{\partial y_{k}}=\frac{N x_{k}-\sum_{i=1}^{N} x_{i}}{N \sum_{i=1}^{N}\left(x_{i}^{2}\right)-\left(\sum_{i=1}^{N} x_{i}\right)^{2}}
\end{aligned}
$$

where $\left(x_{i}, y_{i}\right)$ are given by (39). For the case of the vertical lines between hole centers one fits $x$ against $y$ and the roles of $x$ and $y$ in (41) reverse.

The fitted horizontal and vertical lines will take the form 


$$
\begin{aligned}
& y=\beta_{0, h}+\beta_{1, h} x \\
& x=\beta_{0, v}+\beta_{1, v} y
\end{aligned}
$$

Since the slopes are small and the tangent of a small angle is approximately the angle in radians one may equate the slopes with angles. But in order to preserve the sign convention with respect to the horizontal axis the slope of the vertical line in (42) must have its sign changed. Thus the two angles are given by

$$
\begin{aligned}
& \theta_{1}=\beta_{1, h} \\
& \theta_{2}=-\beta_{1, v}
\end{aligned}
$$

and the difference, or orthogonality error, is given by

$$
\Delta \theta=\theta_{2}-\theta_{1}
$$

The uncertainty of the orthogonality is computed as

$$
u_{c o}^{2}(\Delta \theta)=u_{c o}^{2}\left(\theta_{2}\right)+u_{c o}^{2}\left(\theta_{1}\right)=u_{c o}^{2}\left(\beta_{1, v}\right)+u_{c o}^{2}\left(\beta_{1, h}\right)
$$

where the last two uncertainties are computed using (38), (39) and (41).

The uncertainty of the orthogonality of the part was estimated using the horizontal holes $3,26,25,24,23,22,21$ and the vertical holes 3, 4, 5, 6, 7, 8, 9 shown in Figure 5. No expansion factor is used here.

\begin{tabular}{|c|c|}
\hline Analytic Estimate of Orthogonality & Standard Uncertainty \\
\hline-5.10 & 11.09 \\
\hline
\end{tabular}

Table 5: Analytic Estimates of Orthogonality Uncertainty in arc sec. The Uncertainty is not Expanded.

A second approach to estimating the uncertainty of the orthogonality error is by means of a Monte Carlo simulation. To generate an orthogonality error angle twenty eight (28) random samples were selected from a normal distribution with zero mean and unit standard deviation, since there were fourteen holes used to estimate orthogonality. There were then two random numbers associated with each hole, one for $x$ and one for $y$, designated by $R_{x}, R_{y}$. For each of the fourteen hole centers the following simulated points were computed

$$
\begin{aligned}
& x=\hat{x}+E_{x}(\hat{x}, \hat{y})+R_{x} u_{c o}\left(E_{x}(\hat{x}, \hat{y})\right) \\
& y=\hat{y}+E_{y}(\hat{x}, \hat{y})+R_{y} u_{c o}\left(E_{y}(\hat{x}, \hat{y})\right)
\end{aligned}
$$


The horizontal and vertical least squares lines through the appropriate new hole centers were computed using (36) for the horizontal lines and the appropriate equations for the vertical lines. For each horizontal and vertical line combination $\Delta \theta$ was computed using (42) through (44). This process was repeated a large number of times, $M$, and the estimated standard deviation $\hat{\sigma}$ was computed. The prediction uncertainty was given by

$$
u_{c o}^{2}(\Delta \theta)=\hat{\sigma}^{2}\left(1+\frac{1}{M}\right)
$$

The results from a simulation with $\mathrm{M}=1000$ is given in the table below.

\begin{tabular}{|c|c|c|}
\hline $\begin{array}{c}\text { Mean Orthogonality } \\
(\operatorname{arc~sec})\end{array}$ & $\begin{array}{c}\text { Sample Standard } \\
\text { Deviation }(\operatorname{arcsec})\end{array}$ & $\begin{array}{c}\text { Standard } \\
\text { Uncertainty }(\operatorname{arc~sec})\end{array}$ \\
\hline-4.68 & 11.02 & 11.03 \\
\hline
\end{tabular}

Table 6: Orthogonality Uncertainty. The Uncertainty is not Expanded.

The figure below shows the distribution of the orthogonality samples.

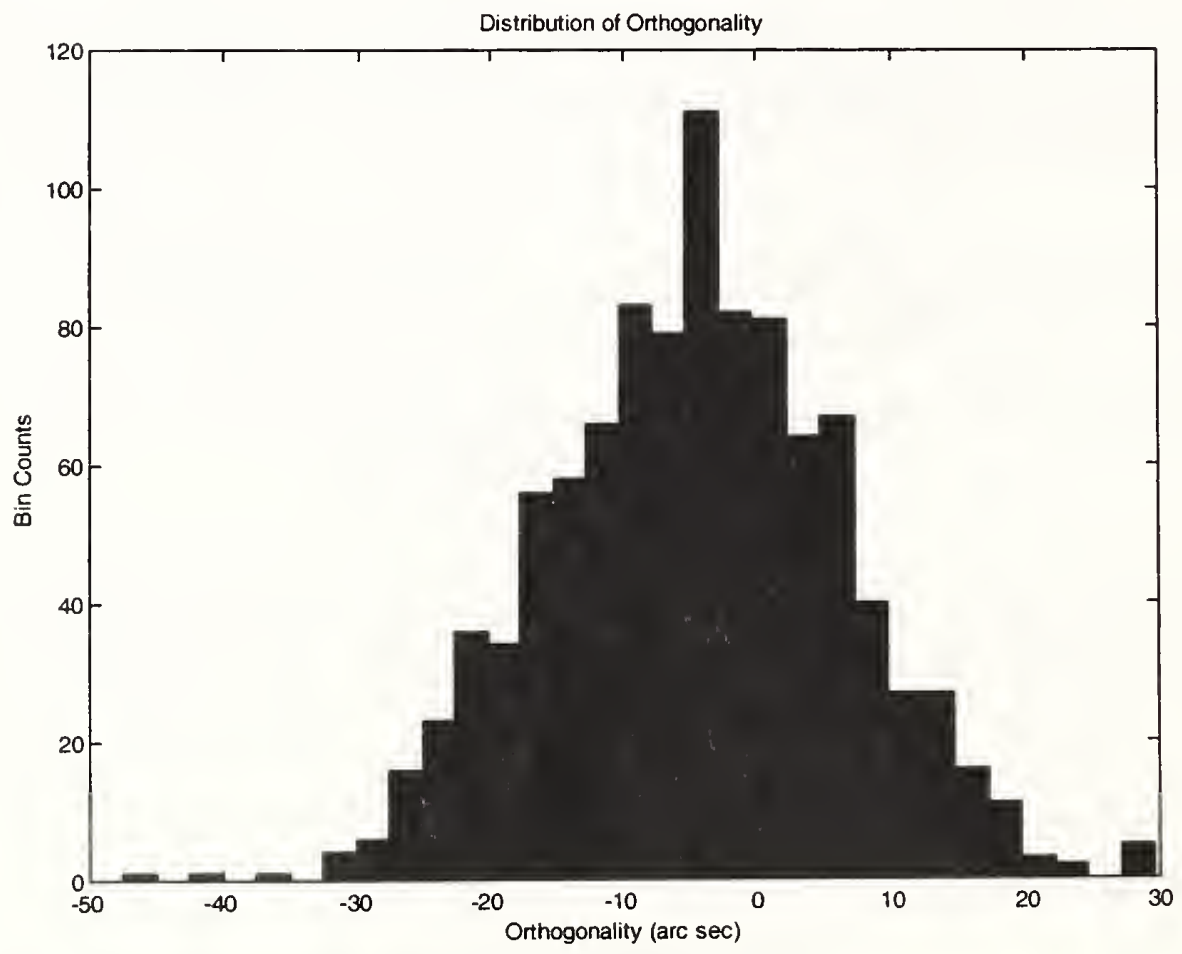

Figure 12: Distribution of the Orthogonalities for 1000 samples. 


\subsection{Circularity Uncertainties}

In ISO 230-4 [29] on circular tests for numerically controlled machine tools circular deviation is defined as the minimum radial separation of two concentric circles enveloping the path produced by the machine tool when programmed to move on the circular path defined by its diameter (or radius), the position of its center and its orientation in the working zone. Optionally the circular deviation may be evaluated as the maximum radial range around the least squares circle. The first definition requires computing the minimum zone circles which can be formulated as a linearly constrained optimization problem. The algorithm for computing the minimum zone circles is sufficiently complex that, for practical purposes, the approach of selecting a least squares circle provides a tool that can be used in a Monte Carlo simulation to estimate the uncertainty of the circular deviation or circularity. The algorithm used here to fit the least squares circle is the Marquardt-Levenberg, based on an algorithm described in Nash [30]. A discussion of the algorithm is given in Appendix F.

In order to compare the estimated uncertainties with the results of measurements of the parts on a CMM, the same nominal points on the inner and outer walls of the circular slot feature of the parts were selected. There were thirty six points (36) selected on each wall around the circular profile. This meant ten degrees between each nominal point. The nominal points were designated as $\left(\hat{x}_{1}, \hat{y}_{1}\right), \cdots,\left(\hat{x}_{36}, \hat{y}_{36}\right)$. The estimated circularity and its uncertainty were calculated by a Monte Carlo simulation. First one thousand random numbers were sampled for each point from a normal distribution with a mean of zero and standard deviation of one and designated $R_{x}(i, 1), \cdots, R_{x}(i, 1000)$ for $i=1, \cdots, 36$. Another one thousand samples were selected from the same distribution for each point and were designated $R_{y}(i, 1), \cdots, R_{y}(i, 1000)$ for $i=1, \cdots, 36$. For each group of thirty-six random numbers, new $\mathrm{x}$ and y points were generated using (46). Thus, for the kth Monte Carlo simulation from one to a thousand the new points were computed as

$$
\begin{aligned}
& x_{i}=\hat{x}_{i}+E_{x}\left(\hat{x}_{i}, \hat{y}_{i}\right)+R_{x}(i, k) u_{c o}\left(E_{x}\left(\hat{x}_{i}, \hat{y}_{i}\right)\right) \\
& y_{i}=\hat{y}_{i}+E_{y}\left(\hat{x}_{i}, \hat{y}_{i}\right)+R_{y}(i, k) u_{c o}\left(E_{y}\left(\hat{x}_{i}, \hat{y}_{i}\right)\right)
\end{aligned}
$$

Next, a least squares circle was fit through these points using the Marquardt-Levenberg nonlinear optimization procedure. This produced the best fit center for the data. The distance from this point to each of the thirty-six new points was computed and the circularity was computed as the maximum of these distances minus the minimum. This procedure was repeated a thousand times. The distribution of the circularities is given in the histograms in Figures 13 and 14. The corresponding prediction uncertainty for a future sample is given by

$$
u_{c o}^{2}(C)=\hat{\sigma}^{2}\left(1+\frac{1}{1000}\right)
$$

where $\hat{\sigma}^{2}$ is the sample variance 


\begin{tabular}{|c|c|}
\hline Mean Circularity $(\mathrm{mm})$ & Standard Uncertainty $(\mathrm{mm})$ \\
\hline 0.0179 & 0.0031 \\
\hline
\end{tabular}

Table 7: Circularity Uncertainty for Inner Circle Feature

Using a coverage factor of two the prediction interval for the inner circular slot edge, based on the simulation results is

$$
0.0117=0.0179-2(0.0031) \leq c \leq 0.0179+2(0.0031)=0.0241
$$

\begin{tabular}{|c|c|}
\hline Mean Circularity $(\mathrm{mm})$ & $\begin{array}{c}\text { Standard } \\
\text { Uncertainty }(\mathrm{mm})\end{array}$ \\
\hline 0.0180 & 0.0031 \\
\hline
\end{tabular}

Table 8: Circularity Uncertainty for Outer Circle Feature

Using a coverage factor of two the prediction interval for the outer circular slot edge, based on the simulation results is

$$
0.0118=0.0180-2(0.0031) \leq c \leq 0.0180+2(0.0031)=0.0242
$$

These results are in millimeters. The next sample taken would be expected to fall within the range (50) or (51) with a $95 \%$ confidence. 


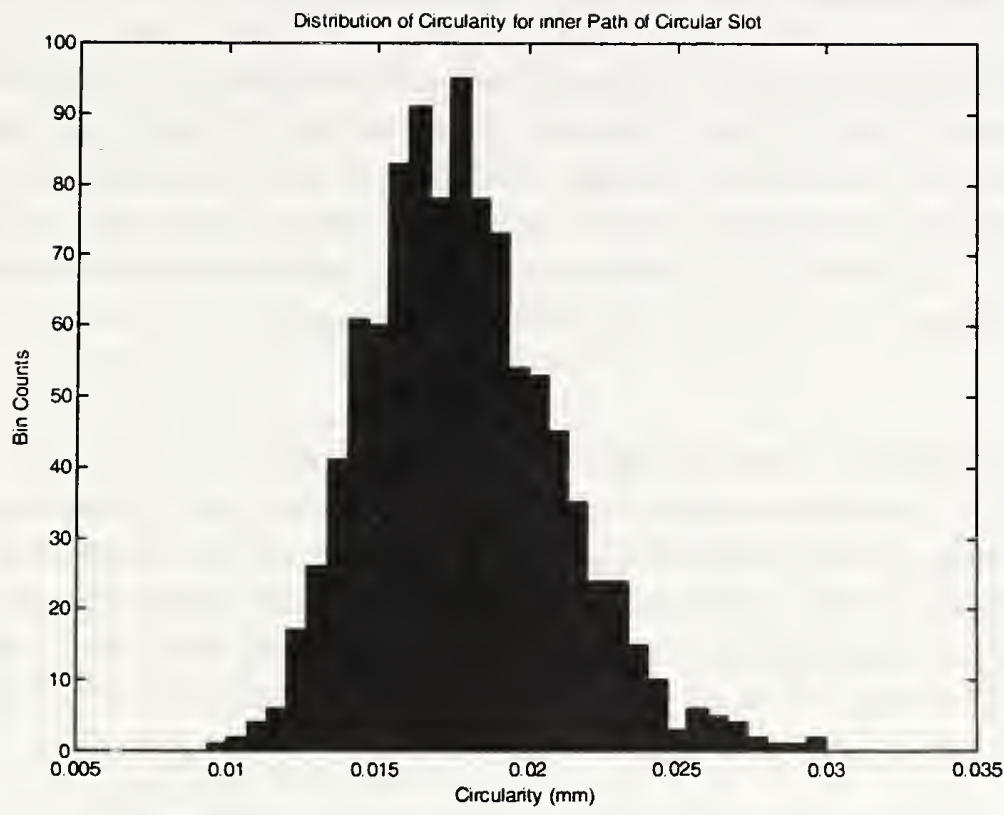

Figure 13: Histogram of the Sampled Circularity for 1000 Samples of the Inner Circle Feature Circularity.

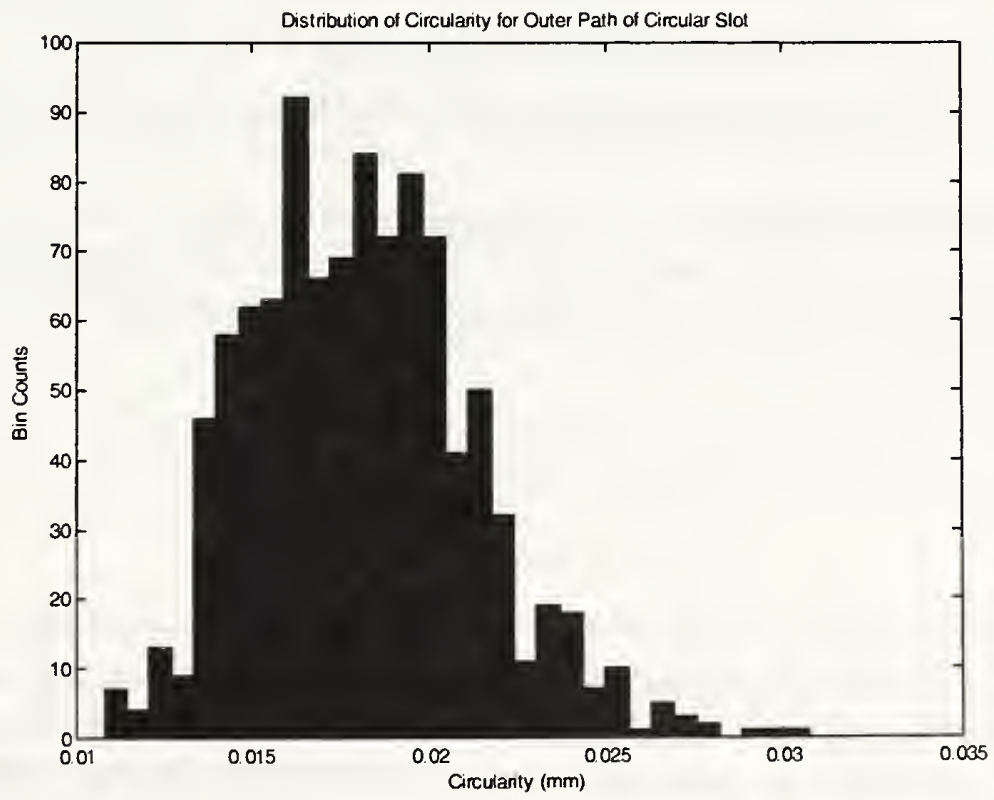

Figure 14: Histogram of the Sampled Circularity for 1000 Samples of the Outer Circle Feature Circularity. 


\subsection{Part Uncertainties by Coordinate Measuring Machine Measurements}

Twenty one parts made according to Figure 2 were measured on a CMM. The following point locations were measured: the hole center locations for the drilled portion of the holes, the hole centers of the milled portion of the holes, thirty six evenly spaced points along the edge of the outer ring of the circular slot and thirty six evenly spaced points along the edge of the inner circle. Five repeat measurements for each of these points were made on part numbers one through four, while two repeats were performed on the other parts.

In this section an analysis of variance procedure is explained that isolates the manufacturing error from the coordinate measuring machine error. Manufacturing and measurement uncertainties are estimated. The analysis of variance procedure is applied to estimate the uncertainties of the locations of the hole centers for both drilled and milled holes as well as to estimate the orthogonality and circularity. An estimate of the uncertainty of the distance between features is also developed

\subsection{Hole Center Location Uncertainties for Manufactured Part}

The following notation will be used to estimate the manufactured part uncertainties:

1. $E_{x}^{m}, E_{y}^{m} \quad$ - Measured Hole Location Errors along the $\mathrm{X}$ and $\mathrm{Y}$ axes.

2. $E_{x}^{a}, E_{y}^{a} \quad$ - Actual Hole Location Errors along the $\mathrm{X}$ and $\mathrm{Y}$ axes.

3. $\eta_{x}, \eta_{y} \quad$ - Hole Location Measurement Process Errors along the $\mathrm{X}$ and $\mathrm{Y}$ axes.

The main assumption made here is that the actual hole location errors due to the manufacturing process and the measurement process errors are uncorrelated. Therefore, their corresponding variances can be added to estimate the variances of the measured hole location errors.

$$
\begin{aligned}
& V\left(E_{x}^{m}\right)=V\left(E_{x}^{a}\right)+V\left(\eta_{x}\right) \\
& V\left(E_{y}^{m}\right)=V\left(E_{y}^{a}\right)+V\left(\eta_{y}\right)
\end{aligned}
$$

If the variances of the measurement process errors can be shown to be small relative to the variances of the measured hole location errors then it is reasonable to suppose that the measured error variance is a good approximation of the actual manufactured hole error variance. That is if $V\left(\eta_{x}\right) \ll V\left(E_{x}^{m}\right)$ then $V\left(E_{x}^{a}\right) \approx V\left(E_{x}^{m}\right)$ and similarly for $y$.

For each machined part, the errors in hole positions are measured by the CMM relative to a part coordinate system located at the lower left corner of the inner $150 \mathrm{~mm} \mathrm{X} 150 \mathrm{~mm}$ square shown in Figure 2. The $X$ and $Y$ locations of the centers of each drilled and milled hole on each of the twenty-one parts were measured a multiple number of times. 
Associated with each hole center one can form two analysis of variance tables, as shown below, one for the $\mathrm{X}$ measurements and one for the $\mathrm{Y}$ measurements. The table represents all of the location measurement errors for the same hole on each of the parts. The columns representing the repeated measurements are the errors from the nominal measured by the CMM. The column of measurement means is the column of row means for the repeated error measurements for the part number of that row. The degrees of freedom are then listed in a column. Finally, the column of measurement uncertainties is the column of standard deviations of the repeated hole location error measurements for that row. The column of measurement means itself has a grand mean and a variance. These will be taken as the manufacturing error and its variance for the $\mathrm{X}$ error for that hole. That is, these give estimates of the manufacturing process uncertainties. The column of measurement standard deviations has a variance, called the pooled variance, which will be taken as an estimate of the uncertainty of the measurements. This uncertainty gives an estimate of the measurement process uncertainty. Once the manufacturing and measurement uncertainties have been estimated, the part uncertainties can be computed from the previous formulas.

\begin{tabular}{|c|c|c|c|c|c|c|}
\hline & & Repeat & Measurements & & & \\
\hline Part \# & $\mathbf{R}_{1}$ & $\ldots$ & $\mathbf{R}_{\mathbf{n}}$ & $\begin{array}{c}\text { Mean } \\
\text { (Manufacturing } \\
\text { Error) }\end{array}$ & $\begin{array}{l}\text { Degrees } \\
\quad \text { of } \\
\text { Freedom }\end{array}$ & $\begin{array}{c}\text { Standard } \\
\text { Deviations } \\
\text { (Metrology } \\
\text { Uncertainties) }\end{array}$ \\
\hline 1 & $m_{11}$ & $\cdots$ & $m_{1 n_{1}}$ & $\mu_{1}$ & $n_{1}-1$ & $s_{1}$ \\
\hline 2 & $m_{21}$ & $\ldots$ & $m_{2 n_{2}}$ & $\mu_{2}$ & $n_{2}-1$ & $s_{2}$ \\
\hline \multirow{4}{*}{$\dddot{21}$} & $\ldots$ & $\ldots$ & $\ldots$ & $\ldots$ & $\ldots$ & $\ldots$ \\
\hline & $m_{21,1}$ & $\cdots$ & $m_{21, n_{21}}$ & $\mu_{21}$ & $n_{21}-1$ & $s_{21}$ \\
\hline & & & & $\bar{\mu}$ & $\sum_{i=1}^{21}\left(n_{i}-1\right)$ & \\
\hline & & & $\mathbf{F}$ & $\mathbf{V}_{\mathrm{p}}(\mu)$ & & $\mathrm{V}_{\mathrm{p}}(s)$ \\
\hline
\end{tabular}

Table 9: Analysis of Variance Table for CMM Measurements

This analysis of variance template will be used for estimating uncertainties for the hole centers, the part orthogonalities and circularities. The analysis of variance techniques used are based on the discussions in Dixon and Massey [31] and Mood and Graybill [32]. The notation used in Table 9 is as follows:

$m_{i j}$ - The $j$-th repetition of measurement of the $i$-th part for under consideration.

$\mu_{i}$ - The mean of the repeated measurements for part $i$. 
$s_{i}$ - Standard Deviation of the repeated measurements for part $i$.

$d f=\sum_{i=1}^{21}\left(n_{i}-1\right)-$ Total degrees of freedom

$\mathrm{V}_{\mathrm{p}}(\mu)=\frac{\sum_{i=1}^{21}\left(n_{i}\right)\left(\mu_{i}-\bar{\mu}\right)^{2}}{21-1}-$ Estimate of the between part uncertainty.

$\mathrm{V}_{\mathrm{p}}(s)=\frac{\sum\left(n_{i}-1\right) s_{i}^{2}}{d f}-$ Estimate of the within part uncertainty.

The ratio $F=V_{p}(\mu) / V_{p}(s)$ is used to determine whether there is a significant difference between the two variance estimates (Montgomery and Peck [27], Chapter 2). For the cases of concern here, the test value for the $\mathrm{F}$ distribution at the $95 \%$ level with 20 degrees of freedom for $V_{p}(\mu)$ and 34 (i.e., $\left.54-20\right)$ degrees of freedom for $V_{p}(s)$, since there are 54 total measurements for each hole center, over all of the parts, is approximately 1.89 . Since most tables give values for 30 and 40 degrees of freedom for $V_{p}(s)$ the value above is an interpolation. The reader is referred to Dixon and Massey [31] for a discussion of the analysis of variance for a one-way fixed effects classification model.

At this point we need to introduce some further terminology. Let

$$
N=\sum_{i=1}^{21} n_{i}
$$

be the total number of measurements over all the parts. Then the pooled mean, called the mean manufacturing error or grand mean, is given by

$$
\bar{\mu}=\frac{\sum_{i=1}^{21} n_{i} \mu_{i}}{N} \text {. }
$$

The pooled standard deviation is

$$
s_{p}=\sqrt{V_{p}(s)}
$$

An estimate of the standard uncertainty of the grand mean is given by 


$$
u=\frac{s_{p}}{\sqrt{N}}
$$

An estimate of the uncertainty of a future measurement sample is given by

$$
u_{f}=\left(\sqrt{1+\frac{1}{N}}\right) s_{p}
$$

The corresponding expanded uncertainty of a future measurement will then be taken as

$$
U_{f}=2 u_{f}
$$

Summary tables of these quantities are given in Tables B1 through B4 in Appendix B for the measurement uncertainties of each of the peripheral holes for all of the parts. Tables $\mathrm{B} 1$ and B2 summarize the results for the $\mathrm{X}$ and $\mathrm{Y}$ measurements of the drilled holes and Tables B3 and B4 summarize the results for the $\mathrm{X}$ and $\mathrm{Y}$ measurements of the milled holes. Both the drilled and milled holes have the same nominal centers. The first column of the tables gives the estimates in micrometers of the mean manufacturing error of the hole center. The second column gives the standard uncertainties of the error. The third column gives the uncertainty of a new measurement of the hole center and finally the fourth column gives an expanded uncertainty of this measurement.

Tables B.5 through B.8 in Appendix B give a summary of the analysis of variance tables for all of the manufacturing errors of all holes for all of the parts. The hole numbers are given in Figure 11.

Figures $15 \mathrm{a}$ and $15 \mathrm{~b}$ below show the mean measured errors for the centers of the three drilled holes numbered 3,9 and 15. These three holes represent the lower left hole, the upper left hole and the upper right hole respectively. These holes will be used in the next section to evaluate uncertainties in length measurements. The first thing that can be noted about the measurements is that part 13 shows a significant negative $\mathrm{x}$ mean error for all three drilled holes compared to the other parts. This appears to be reflected in the $y$ mean errors for that part also. These plots reflect the numbers in tables C1, C2, C5, C6, C9 and C10 in Appendix C. Notice also the significant center location errors for parts 3, 19, 21 and 27 (whose stamped part blank was mistakenly machined in place of part 20).

Figure 16b shows sharp error difference for the $\mathrm{Y}$ measurements of milled holes 9 and 15 on parts 6 and 21 . This is confirmed by looking at tables C8 and C12. 


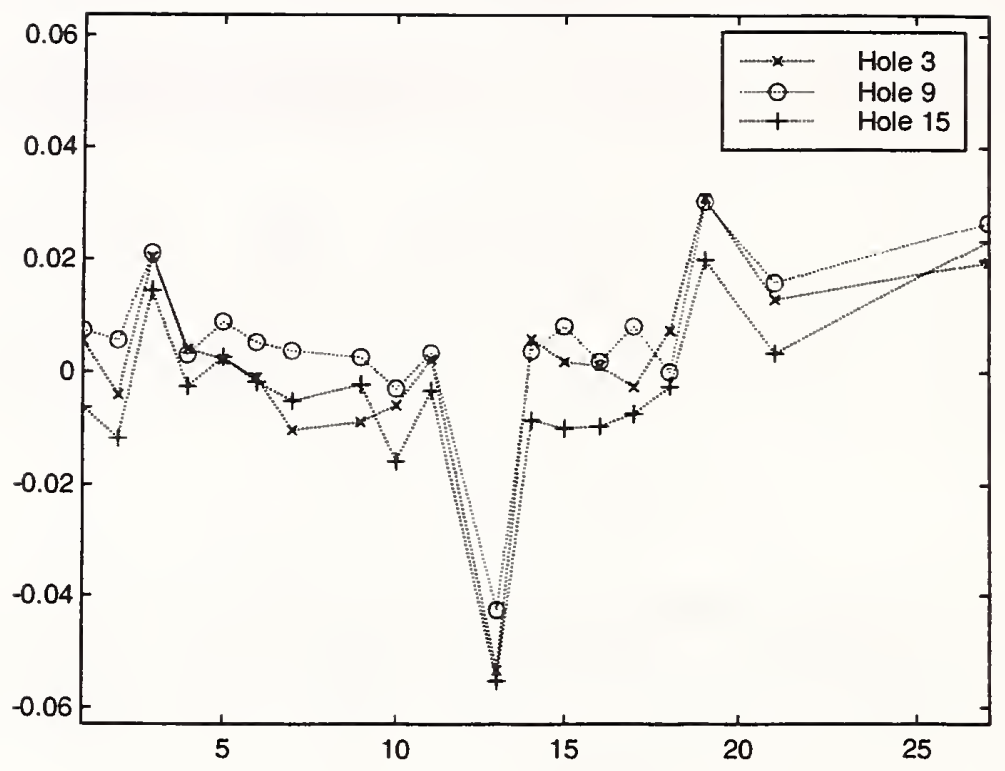

Figure 15a: Mean X Errors for the Centers of the Drilled Holes. Vertical Axis represents Errors in mm. Horizontal Axis represents Part Numbers.

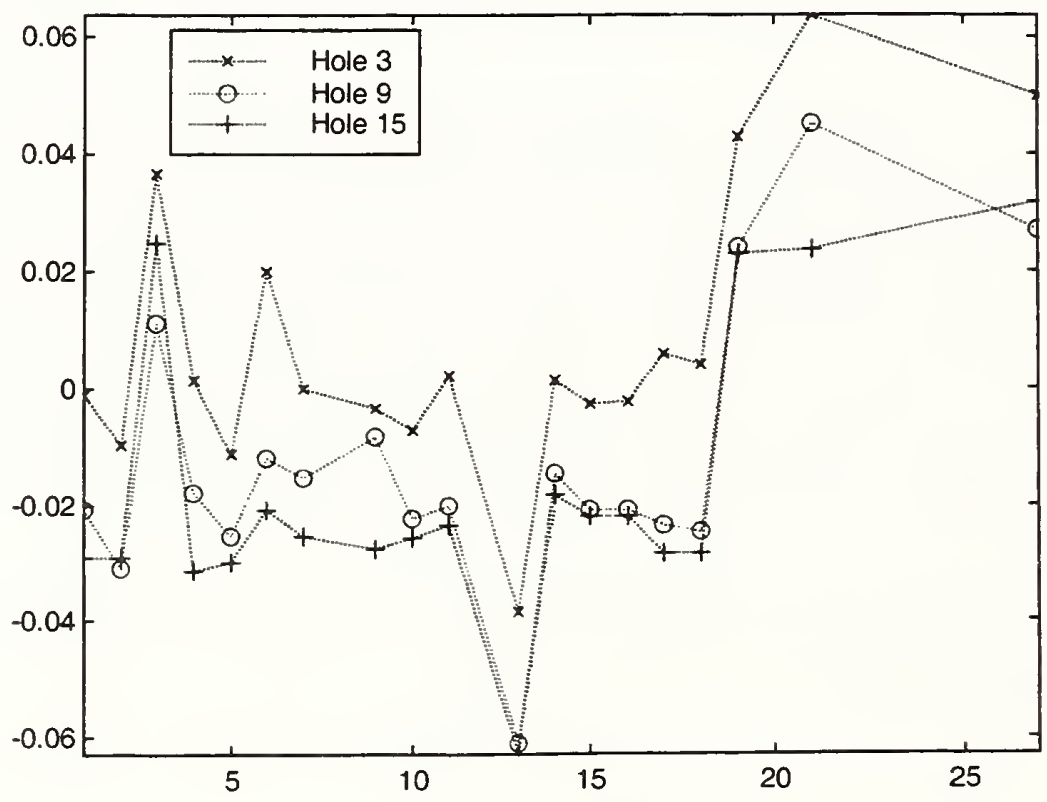

Figure15b: Mean Y Errors for the Centers of the Drilled Holes. Vertical Axis represents Errors in mm. Horizontal Axis represents Part Numbers. 


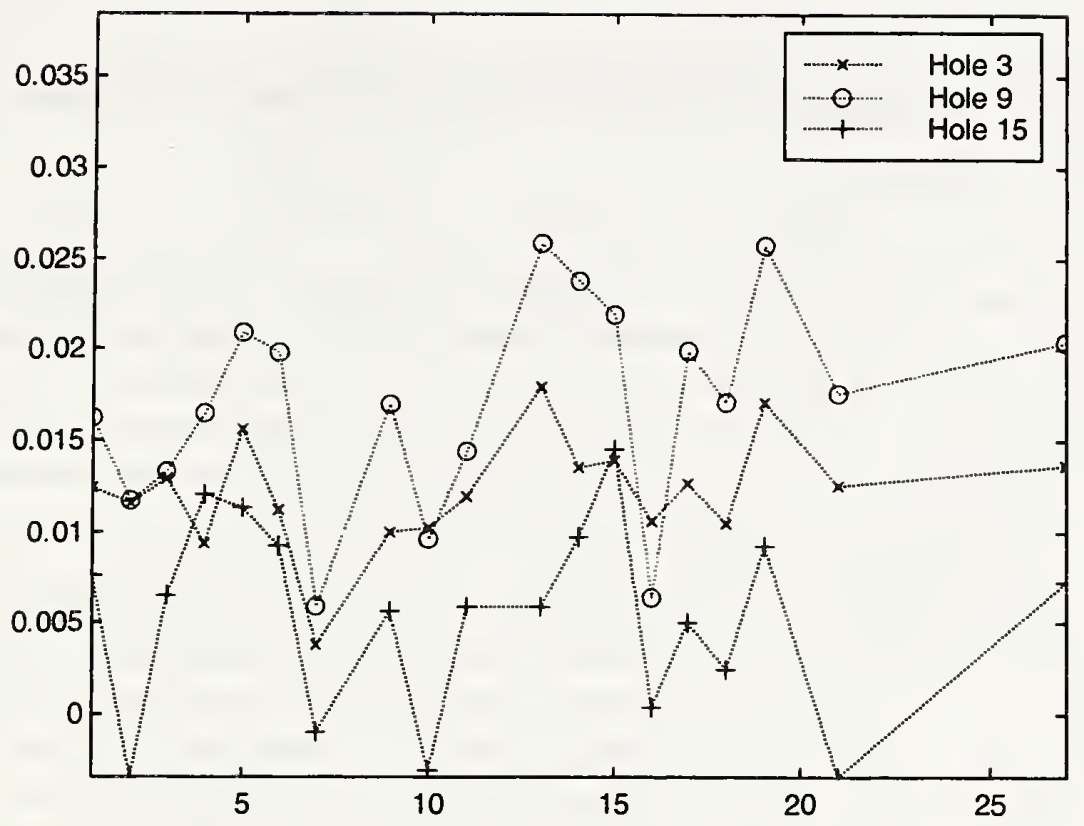

Figure 16a: Mean X Errors for the Centers of the Milled Holes. The Vertical Axis represents Errors in mm. The Horizontal Axis represents Part Numbers.

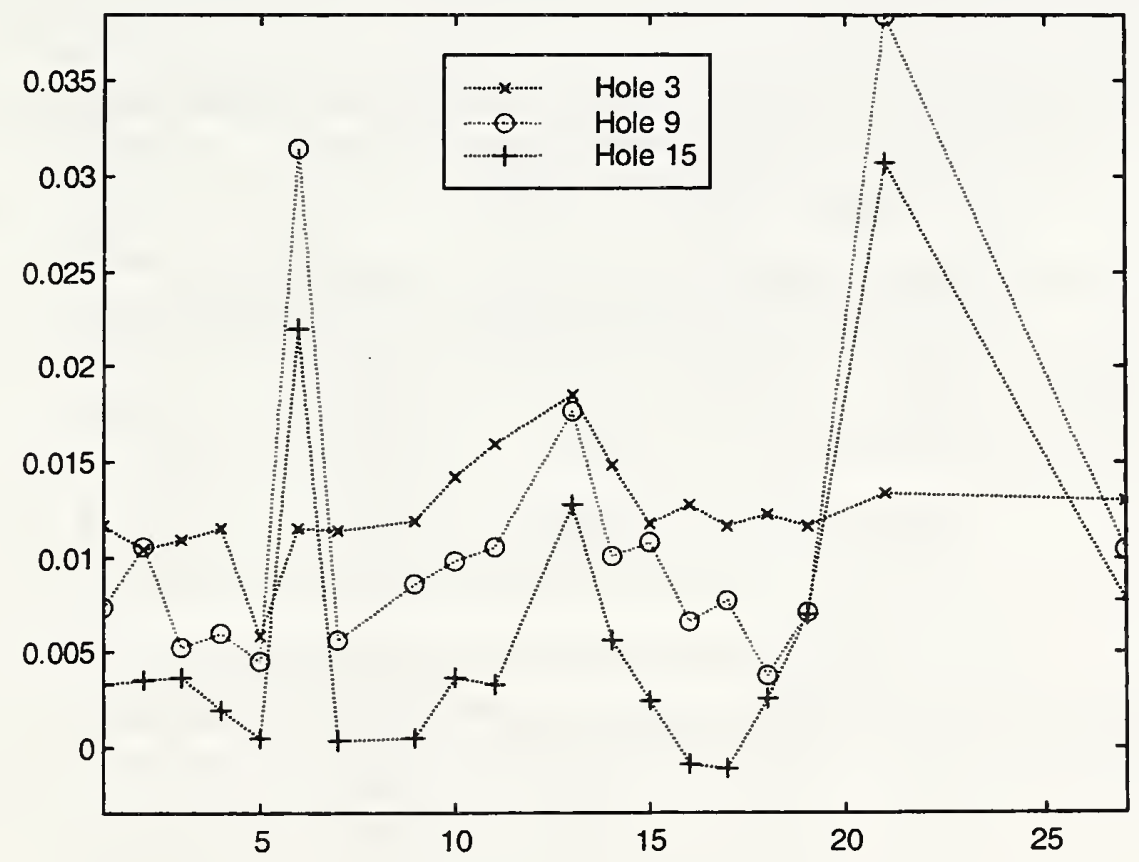

Figure 16b: Mean Y Errors for the Centers of the Milled Holes. The Vertical Axis represents Errors in mm. The Horizontal Axis represents Part Numbers. 


\subsection{Estimating the Uncertainty of a Machined Length Feature from CMM Measurements}

The lengths and uncertainties of these lengths will be examined for the distances between three holes on the parts machined. The summary statistics of the measured errors and uncertainties are given for the three hole center features in Tables 10 and 11. The error variance estimates given in Tables 10 and 11 are computed as the pooled variance of the mean $\left(V_{p}(\mu)\right)$. The measurement variance estimates are computed as the pooled variance of the estimated measurement variances $\left(V_{p}(s)\right)$. The uncertainty estimates are computed as the square roots of the variance estimates. Table 10 gives the results for the drilled hole centers for feature holes 3,9 , and 15 , while Table 11 gives the results for the milled square hole centers for the same feature holes. The tables give the nominal coordinates of the hole centers, relative to the part origin in the lower left corner. Since the measurement of the feature errors are composed of both manufacturing and CMM measurement errors, the tables then give the manufacturing error, variance and uncertainty of the part feature as well as the CMM measurement variance and uncertainty for each feature. The data show that the CMM measurement uncertainties are one to two orders of magnitude less than the manufacturing uncertainties. This verifies the assumption that $V\left(\eta^{x}\right)<<V\left(E_{m}^{x}\right)$, and similarly for the $\mathrm{Y}$ errors. Thus measured variances of hole location errors and variances of actual location errors can taken as the same. For the purpose of this study, then, the measurement mean for each hole will be taken as an estimate of the manufacturing error for that hole and the measurement uncertainty in Table 9 above will be taken as the measurement uncertainty for each hole.

\begin{tabular}{|c|c|c|c|c|c|c|}
\hline \multicolumn{7}{|c|}{ Summary Drilled Hole Statistics } \\
\hline & \multicolumn{4}{|c|}{$\bar{X}$ Axis Location } & \multicolumn{2}{|c|}{ CMM Measurement } \\
\hline Hole & Nominal & Error & Variance & Uncertainty & Variance & Uncertainty \\
\hline Number & $(\mathrm{mm})$ & $(\mu m)$ & $(\mu m)^{2}$ & $(\mu m)$ & $(\mu m)^{2}$ & $(\mu m)$ \\
\hline 3 & 10 & 2.73 & 641 & 25.3 & 1.10 & 1.05 \\
\hline$\overline{9}$ & 10 & 4.99 & 511 & 22.61 & 1.19 & 1.09 \\
\hline 15 & 140 & -4.52 & 566 & 23.79 & 0.710 & 0.843 \\
\hline & \multicolumn{4}{|c|}{ Y Axis Location } & \multicolumn{2}{|c|}{ CMM Measurement } \\
\hline Hole & Nominal & Error & Variance & Uncertainty & Variance & Uncertainty \\
\hline Number & $(\mathrm{mm})$ & $(\mu m)$ & $(\mu m)^{2}$ & $(\mu m)$ & $(\mu m)^{2}$ & $(\mu m)$ \\
\hline 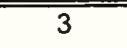 & 10 & 2.70 & 1371 & 37.03 & 0.743 & 0.862 \\
\hline 9 & 140 & 2.70 & $\overline{1925}$ & 43.87 & 0.678 & 0.823 \\
\hline 15 & 140 & 2.70 & 2410 & 49.09 & 0.982 & 0.991 \\
\hline
\end{tabular}

Table 10: Uncertainty Statistics for Drilled Holes 3, 9, and 15. The Uncertainties are not Expanded Uncertainties. 


\begin{tabular}{|c|c|c|c|c|c|c|}
\hline \multicolumn{7}{|c|}{ Summary Milled Hole Statistics } \\
\hline & \multicolumn{4}{|c|}{$X$ Axis Location } & \multicolumn{2}{|c|}{ CMM Measurement } \\
\hline Hole & Nominal & Error & Variance & Uncertainty & Variance & Uncertainty \\
\hline Number & $(\mathrm{mm})$ & $(\mu m)$ & $(\mu m)^{2}$ & $(\mu m)$ & $(\mu m)^{2}$ & $(\mu m)$ \\
\hline 3 & 10 & 11.23 & 86.92 & 9.32 & 1.39 & 1.18 \\
\hline 9 & $\overline{10}$ & 14.79 & 158.37 & 12.58 & 0.834 & 0.91 \\
\hline 15 & 140 & 3.63 & 202.31 & 14.22 & 1.92 & 1.39 \\
\hline & \multicolumn{4}{|c|}{ Y Axis Location } & \multicolumn{2}{|c|}{ CMM Measurement } \\
\hline Hole & Nominal & Error & Variance & Uncertainty & Variance & Uncertainty \\
\hline Number & $(\mathrm{mm})$ & $(\mu m)$ & $(\mu m)^{2}$ & $(\mu m)$ & $(\mu m)^{2}$ & $(\mu m)$ \\
\hline 3 & 10 & 12.84 & 80.80 & 8.99 & 0.30 & 0.55 \\
\hline 9 & 140 & 12.84 & 274.91 & 16.58 & 0.19 & 0.44 \\
\hline 15 & 140 & 12.84 & 417.45 & 20.43 & 0.33 & 0.57 \\
\hline
\end{tabular}

Table 11: Uncertainty Statistics for Milled Holes 3, 9, and 15. The Uncertainties are not Expanded Uncertainties.

Tables 12 and 13 give the actual lengths and variances of the three hole center to hole center lengths for the three line lengths for the drilled and milled holes. These are computed using equations (33) and (35) and the values from tables 10 and 11.

\begin{tabular}{|c|c|c|c|c|c|}
\hline \multicolumn{7}{|c|}{ Manufactured Length between Drilled Holes } \\
\hline & Nominal & Actual & Actual & Actual & Actual \\
\hline Hole-Hoie & Length & Length & Error & Variance & Uncertainty \\
\hline & $(\mathrm{mm})$ & $(\mathrm{mm})$ & $(\mu \mathrm{m})$ & $(\mu \mathrm{m})^{2}$ & $(\mu \mathrm{m})$ \\
\hline 3 to 9 & 130 & 130.0000 & 0.00 & 3296 & 57.41 \\
\hline 9 to 15 & 130 & 129.9905 & -9.51 & 1077 & 32.82 \\
\hline 3 to 15 & 183.84776 & 183.8426 & -5.12 & 2494 & 49.94 \\
\hline
\end{tabular}

\section{Table 12: Manufactured Length Uncertainties Between Drilled} Hole Centers. The Uncertainties are not Expanded Uncertainties.

These tables indicate that the uncertainties associated with drilling operations tend to be larger than those for milling operations. A possible explanation for this may be the fact that a drill bit has a tendency to hop slightly before the flutes bite into the material being machined. 


\begin{tabular}{|c|c|c|c|c|c|}
\hline \multicolumn{7}{|c|}{ Manufactured Length between Milled Hole Centers } \\
\hline \hline & Nominal & Actual & Actual & Actual & Actual \\
\hline Hole-Hole & Length & Length & Error & Variance & Uncertainty \\
\hline & $(\mathrm{mm})$ & $(\mathrm{mm})$ & $(\mu \mathrm{m})$ & $(\mu \mathrm{m})^{2}$ & $(\mu \mathrm{m})$ \\
\hline \hline 3 to 9 & 130 & 130.0000 & 0.00 & 355.71 & 18.86 \\
\hline 9 to 15 & 130 & 129.9888 & -11.16 & 360.68 & 18.99 \\
\hline 3 to 15 & 183.84776 & 183.8424 & -5.40 & 393.74 & 19.84 \\
\hline
\end{tabular}

Table 13: Manufactured Length Uncertainties Between Milled Hole Centers. The Uncertainties are not Expanded Uncertainties.

\subsection{Estimating the Uncertainty of Machined Part Orthogonality from CMM Measurements}

From Tables B5 through B8 it is clear that the center locations of milled holes have lower manufacturing errors. The peripheral milled hole centers were selected as points to be used for estimating orthogonality. The milled holes were designed to have their nominal centers form lines parallel to the edges of the parts. Two nominally orthogonal lines of holes (the bottom row and left side row) were selected to estimate the uncertainties in the orthogonality of these two lines of holes. All of the twenty-one parts had the milled hole centers measured on a high precision CMM with repeated measurements of each part. The first four parts had five repeated center measurements and the rest of the parts had two repeated measurements. The procedure of estimating orthogonality was as follows:

For the centers of the holes along the $Y$-axis a least squares fit of the line form $y=m x+$ $b$ was made for each of the repetitions for each of the parts. This produced a table of slope values for $\mathrm{m}$. Since the deviation of $\mathrm{m}$ from 0 was small the values of $\mathrm{m}$ could be used as angle estimates since for small angles $\tan (a) \approx a$ in radians and $m$ is the tangent of the slope angle. Next the vertical line of hole centers was fit with an equation of the form $x=m y+b$. The sign of the resulting slope had to be reversed and then it could be added to the horizontal slope to determine the orthogonality error. This calculation is similar to that leading to equations (42) to (44). Table Gl was produced. The grand mean represents the mean of all of the orthogonality estimates, including repetitions and is properly weighted by the degrees of freedom. The uncertainty of the means is the manufacturing uncertainty and the uncertainty of the standard deviations is the CMM measurement uncertainty.

We will summarize the results in Table 14 below. The error means and variances come from Table G1, while the other entries are based on the formulas in Section 5.1. 


\begin{tabular}{|c|c|c|c|}
\hline $\begin{array}{c}\text { Mean } \\
\text { Manufacturing } \\
\text { Error }(\operatorname{arc} \text { sec) }\end{array}$ & $\begin{array}{c}\text { Variance of the } \\
\text { Manufacturing } \\
\text { Error }(\operatorname{arcsec})^{2}\end{array}$ & $\begin{array}{c}\text { Variance of the } \\
\text { Metrology } \\
\text { Uncertainties } \\
(\operatorname{arc~sec})^{2}\end{array}$ & \\
\hline-1.059 & 80.285 & 8.768 & \\
\hline $\begin{array}{c}\text { Pooled Standard } \\
\text { Deviation of the } \\
\text { Manufacturing } \\
\text { Error }(\operatorname{arc} \text { sec) }\end{array}$ & $\begin{array}{c}\text { Pooled Standard } \\
\text { Uncertainty } \\
(\text { arc sec) }\end{array}$ & $\begin{array}{c}\text { Uncertainty of a } \\
\text { Future } \\
\text { Orthogonality } \\
\text { Estimate } \\
(\operatorname{arc~sec})\end{array}$ & $\begin{array}{c}\text { Expanded } \\
\text { Uncertainty of } \\
\text { a Future } \\
\text { Orthogonality } \\
\text { Estimate } \\
(\operatorname{arc~sec})\end{array}$ \\
\hline 8.96 & 1.22 & 9.05 & 18.10 \\
\hline
\end{tabular}

\section{Table 14: Summary of the Orthogonality Statistics from CMM Measurements}

Note that the variance of the metrology uncertainties is an order of magnitude less than the variance of the manufacturing error so that the measured and manufacturing variances can be considered approximately equal.

\subsection{Estimating the Uncertainty of a Machined Part Circularity from CMM Measurements}

On each of the parts a circular slot was milled with an inner and outer radius (see Figure 2). The inner surface of the slot was milled counterclockwise and the outer surface was milled clockwise. Thirty seven equally space points on each surface were measured on the CMM and the resulting radii from the best fit center were reported. Again five repeated measurements were made on the first four parts and two on each of the others. Based on the thirty seven measured points on each surface a value for the circularity could be computed as the difference between the largest and the smallest radius of the thirty seven points. From these calculations Table $\mathrm{H} 1$ and Table $\mathrm{H} 2$ were prepared. Tables 15 and 16 below summarize the statistics. Terminology is given in Section 5.1. Note that there are fifty four circularity estimates for each table.

\begin{tabular}{|c|c|c|c|}
\hline $\begin{array}{c}\text { Mean Manufacturing } \\
\text { Error }(\mu \mathrm{m})\end{array}$ & $\begin{array}{c}\text { Variance of the } \\
\text { Manufacturing Errors } \\
(\mu \mathrm{m})^{2}\end{array}$ & $\begin{array}{c}\text { Variance of the } \\
\text { Metrology } \\
\text { Uncertainties }(\mu \mathrm{m})^{2}\end{array}$ & \\
\hline 20.986 & 7.378 & 3.130 & \\
\hline $\begin{array}{c}\text { Pooled Standard } \\
\text { Deviation of the } \\
\text { Manufacturing Errors } \\
(\mu \mathrm{m})\end{array}$ & $\begin{array}{c}\text { Pooled Standard } \\
\text { Uncertainty }(\mu \mathrm{m})\end{array}$ & $\begin{array}{c}\text { Uncertainty of a New } \\
\text { Circularity Estimate } \\
(\mu \mathrm{m})\end{array}$ & $\begin{array}{c}\text { Expanded } \\
\text { Uncertainty of a New } \\
\text { Circularity Estimate } \\
(\mu m)\end{array}$ \\
\hline 2.716 & 0.370 & 2.743 & 5.486 \\
\hline
\end{tabular}

Table 15: Summary Statistics for Inner Circle of Slot 


\begin{tabular}{|c|c|c|c|}
\hline $\begin{array}{c}\text { Mean Manufacturing } \\
\text { Error }(\mu \mathrm{m})\end{array}$ & $\begin{array}{c}\text { Variance of the } \\
\text { Manufacturing Errors } \\
(\mu \mathrm{m})^{2}\end{array}$ & $\begin{array}{c}\text { Variance of the } \\
\text { Metrology } \\
\text { Uncertainties }(\mu \mathrm{m})^{2}\end{array}$ & \\
\hline 26.018 & 35.836 & 2.556 & \\
\hline $\begin{array}{c}\text { Pooled Standard } \\
\text { Deviation of the } \\
\text { Manufacturing Errors } \\
(\mu \mathrm{m})\end{array}$ & $\begin{array}{c}\text { Pooled Standard } \\
\text { Uncertainty }(\mu \mathrm{m})\end{array}$ & $\begin{array}{c}\text { Uncertainty of a New } \\
\text { Circularity Estimate } \\
(\mu \mathrm{m})\end{array}$ & $\begin{array}{c}\text { Encertainty of a New } \\
\text { Circularity Estimate } \\
(\mu \mathrm{m})\end{array}$ \\
\hline 5.986 & 0.815 & 6.046 & 12.092 \\
\hline
\end{tabular}

Table 16: Summary Statistics for Outer Circle of Slot

Note that the variance of measurements of the inner wall of the circular wall is less than the variance of the manufacturing errors in Table 15. Several factors could have accounted for this. The inner and outer walls of the circular slot were cut in opposite directions. Direction of cut may have had an effect in leaving small debris. The inner walls might not have been cleaned sufficiently. Table 16 shows the measurement variance to be an order of magnitude less than the variance of the manufacturing errors. 


\subsection{Comparative Results}

\subsection{Comparison of Hole-Location Errors and Uncertainties}

When we compare the predicted errors computed from LBB measurements for the peripheral holes given in Table A1, the mean errors measured by the CMM shown in Tables B1 through B4 tend to be larger. The manufacturing uncertainties for a given feature measurement shown in Tables B5 through B8 are significantly greater than those predicted by the LBB measurements. These latter are the square roots of the variances given in the last two columns of Table Al.

The signs of the errors for both the predicted errors and the measured errors tend to be consistent for the drilled holes. This does not mean that they are all the same but that they in general cluster in the same groups. For the $\mathrm{x}$-machine errors the signs cluster negatively between holes twenty-five and fourteen, whereas for the y-machine errors they cluster between nineteen and six. The consistency does not seem to hold for the milled holes.

From Table A1, the range of the predicted variances $\mathrm{x}$-errors based upon the LBB measurements falls between $6.81 \mu \mathrm{m}^{2}$ and $20.96 \mu \mathrm{m}^{2}$. For the y-errors the predicted variances fall between $22.37 \mu \mathrm{m}^{2}$ and $31.29 \mu \mathrm{m}^{2}$. For the parts measured by the CMM the variances are significantly higher. These are given in column two of Tables B5 through B8. For the $\mathrm{x}$-machine errors for the drilled holes the error variances fall

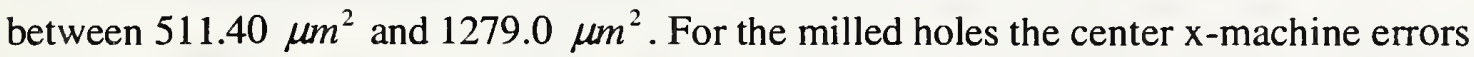
range from $86.92 \mu \mathrm{m}^{2}$ to $211.42 \mu \mathrm{m}^{2}$. The $\mathrm{y}$-machine error variances tend to be larger. For the drilled holes the $y$-machine error variances fall between $1310.32{\mu \mathrm{m}^{2}}^{2}$ and $2489.11 \mathrm{\mu m}^{2}$. For the milled holes the $y$-machine error variances fall between 78.77 $\mu m^{2}$ and $427.54 \mu m^{2}$. We can note here that the $y$-machine error variances are in general greater than the $\mathrm{x}$-machine error variances in both the model prediction and CMM measurement cases.

A question arises at this point. If we only knew the variances (uncertainties) from the model predictions is there some multiple that could be used to estimate conservatively the actual manufacturing variances (uncertainties) of the parts for the given machining center? In order to estimate this relation we can start by considering the ratios between the lower limits of the manufacturing error variances and the model predicted variances. For the drilled holes the lower limit ratio for $\mathrm{x}$-machine errors (511.40/6.81) gives 75.1. The upper limit ratio (1279.0/20.96) gives 61.0. For the milled holes the lower $\mathrm{x}$-machine error ratio is $\mathbf{1 2 . 7 6}$ and the upper ratio is 10.1 . For the $y$-machine error variances for the drilled holes the lower limit ratio (1310.32/22.37) is 58.57 and the upper ratio (2489.11) is 79.55. Similarly for the milled holes the lower ratio is 3.52 and the upper is 13.66 . These ratios are not immediately revealing. However, since we are looking for relations between the uncertainties which are the square roots of the variances we wish to examine 
the square roots of these ratios. Taking square roots we can see that for the $x$-errors in the drilled case the ratios fall between 7.81 and 8.67 whereas in the milled case they fall between 3.17 and 3.57. Similarly in the y-error cases they fall between 7.65 and 8,91 for the drilled holes and 1.88 and 3.70 for the milled holes. These ranges suggest that, if we wished to estimate the actual machining operation uncertainties for the machining center used, then, to be conservative, we could take an uncertainty multiple of 9 for drilling operations and 4 for milling operations.

\subsection{Comparison of Length Uncertainties}

The uncertainties associated with the three hole center-to-center lengths are summarized in Table 17 below. The drilled hole uncertainty range is computed from Table 12 by expanding the uncertainties in that table. The mean length error is obtained by subtracting the nominal length from the actual length given in the table. Twice the length uncertainty given in Table 12 was then added and subtracted from the mean length error to give the uncertainty range. The table shows the upper and lower bounds for the uncertainty range. The uncertainties for the milled hole center-to-center lengths are also given in Table 17. These have been computed by expanding uncertainty data given in Table 4. The average ratio of the drilled hole-to-hole range to the comparable model range is 7.2 while the average for the similar ratios for the milled holes is 2.96 .

\begin{tabular}{|c|c|c|c|c|}
\hline \multicolumn{5}{|c|}{ Drilled Hole Expanded Uncertainty Range } \\
\hline Center-to-Center & Lower Uncertainty & Mean Length & Upper Uncertainty & Range \\
\hline Lines & Bound $(\mu m)$ & Error $(\mu m)$ & Bound $(\mu m)$ & $(\mu m)$ \\
\hline 3 to 9 & -114.82 & 0.00 & 114.82 & 229.64 \\
\hline 9 to 15 & -75.15 & -9.51 & 56.13 & 131.28 \\
\hline 3 to 15 & -105.00 & -5.12 & 94.76 & 199.76 \\
\hline \multicolumn{5}{|c|}{ Milled Hole Expanded Uncertainty Range } \\
\hline Center-to-Center & Lower Uncertainty & Mean Length & Upper Uncertainty & Range Width \\
\hline Lines & Bound $(\mu m)$ & Error $(\mu m)$ & Bound $(\mu m)$ & $(\mu m)$ \\
\hline 3 to 9 & -37.72 & 0.00 & 37.72 & 75.44 \\
\hline 9 to 15 & -49.14 & -11.16 & 26.82 & 75.96 \\
\hline 3 to 15 & -45.08 & -5.40 & 34.28 & 79.36 \\
\hline \multicolumn{5}{|c|}{ Expanded Uncertainty Estimates Based on LBB Machine Metrology } \\
\hline Center-to-Center & Lower Uncertainty & Mean Length & Upper Uncertainty & Range Width \\
\hline Lines & Bound $(\mu m)$ & Error $(\mu m)$ & Bound $(\mu m)$ & $(\mu m)$ \\
\hline 3 to 9 & -15 & 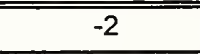 & 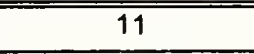 & 26 \\
\hline 9 to 15 & -16 & -3 & 10 & 26 \\
\hline 3 to 15 & -15 & -1.8 & 11 & 26 \\
\hline
\end{tabular}

Table 17: A Comparison of the Upper and Lower Expanded Uncertainty Limits for the Hole-to-Hole Lengths based on the CMM Measurements and the Model Estimates Based on the LBB Machine Measurements. 
The next observation relates to the ratio of the measured length uncertainties to the computed length uncertainties. The work of Wilhelm, Srinivasan and Farabaugh [4] showed that the position errors of the test part holes fell in general within two standard deviations of the measured machine errors. Their work however was conducted under controlled laboratory conditions. In terms of expanded uncertainties this would allow for approximately four standard deviations. The parts in this study were not milled under controlled conditions, but under ordinary shop environment conditions. The results of this study suggest that for the machining center used the potential length errors of manufactured parts could fall as far away as seven standard deviations of the measured machine errors for drilled holes and three for milled holes. This conclusion can only be considered tentative.

\subsection{Comparison of Orthogonality Uncertainties.}

The mean orthogonality error from Tables 5 and 6 is -4.89 arc sec and the average expanded uncertainty is $22.12 \mathrm{arc} \mathrm{sec}$. These are based on the analytic and Monte Carlo methods of estimating orthogonality from the machine tool model and LBB measurements. From Table 14 the mean manufacturing orthogonality error from the CMM measurements is -1.06 arc sec with an expanded uncertainty of 18.1 arc sec. In this case the model estimates over-predicted the orthogonality error but did produce the same direction of error. Similarly the model results over-predicted the expanded uncertainty. Note that both the errors and uncertainties were both discrepant by about 4 arc sec.

\subsection{Comparison of Circularity Uncertainties}

The first circularity errors and uncertainties to be considered are those predicted by the machine model. The mean circularity error for the inner circle feature from Table 7 is $17.9 \mu \mathrm{m}$ while the expanded uncertainty if $6.2 \mu \mathrm{m}$. For the outer circle Table 8 shows these to be $18.1 \mu \mathrm{m}$ and $6.2 \mu \mathrm{m}$ respectively. The results from the CMM measured parts show that for the inner circle the mean circularity error is $20.99 \mu \mathrm{m}$ and the expanded uncertainty is $5.49 \mu \mathrm{m}$. For the outer circle the circularity error is $26.02 \mu \mathrm{m}$ and the expanded uncertainty is $12.09 \mu \mathrm{m}$. From these results it appears that the values from the model are closer to the CMM measurements for the inner circle, at least in terms of uncertainty. There is one fact that might have some relevance here although it would be hard to determine the actual effect. The inner circle was milled in a counterclockwise fashion, whereas the outer circle was milled in a clockwise fashion. 


\subsection{Conclusions}

There are a number of conclusions that can be drawn from this study. The first and foremost is that machining uncertainties can be estimated for production machines. These estimates of course only apply to the individual machine being studied, however it would be interesting to do a parallel study on a production machine in the same family and determine whether there are any commonalities.

The law of Propagation of Uncertainties provides a means of estimating both point location and length uncertainties when combined with an adequate kinematic model of the machine tool under study. There are uncertainties, such as for circularity, where the law cannot be applied directly. These uncertainties occur in cases where there are no clearly understood functional relationships between quantities that would allow the law to be applied. In these cases some form of simulation or Monte Carlo technique must be applied to estimate the uncertainties.

Setting up and calibrating the particular LBB for measuring the machine tool component errors was cumbersome, but it did provide measurements for all of the components necessary to model the machine tool. It was possible to take all of the measurements in a reasonably short time without changing fixtures for each component measurement.

Although the original plan was to cut a larger number of parts, the twenty-one parts that were finally produced provided adequate data to estimate uncertainties in the machining. This makes it feasible to consider developing a procedure to estimate the uncertainties of a new machine tool by performing a machine tool characterization, cutting a reasonably small set of reference parts, measuring the parts and then developing an uncertainty table for that machine. This table could be used by a part designer as a tool in any parts designed for production on that machine. This possibility is reinforced by the fact that there seem to be computable relations between uncertainties estimated from characterization and the actual production uncertainties.

\subsection{Acknowledgements}

The authors wish to thank the many members of the NIST staff who participated in various ways to make this project a success. Bruce $\mathrm{R}$. Borchardt did the painstaking measurements of the manufactured parts on a CMM. Robert R. Clary, a machinist, was instrumental in running the vertical machining center during the measurement of the machine with the laser ball bar but also during the machining of the parts. M. Alkan Donmez supervised the overall project and provide invaluable consulting on machine metrology. Richard Rhorer played an important part in the early design of the experiment and part design. Johannes A. Soons designed the final part selected, provided machine tool programming and metrology consultation. 


\subsection{References}

1. International Organization for Standardization, Guide to the Expression of Uncertainty in Measurement.

2. Taylor, B. N., Kuyatt, C. E., "Guidelines for Evaluating and Expressing the Uncertainty of NIST Measurement Results", NIST Technical Note 1297, National Institute of Standards and Technology, Gaithersburg, MD, 20899, 1994.

3. American National Standards Institute, "American National Standard for Expressing Uncertainty - U.S. Guide to the Expression of Uncertainty in Measurement", ANSI/NCSL Z540-2-1997.

4. Wilhelm, R.G., Srinivasan, N., Farabaugh, F., "Part Form Errors Predicted from Machine Tool Performance Measurements", Annals of the CIRP, 46, 1997, 471-474.

5. Chatterjee, S., "An Assessment of Quasi-Static and Operational Errors in NC Machine Tools", J. of Manuf. Syst., 16, 1, 1997, 59-68.

6. Shin, Y. C., Wei, Y., "A statistical analysis of positional errors of a multiaxis machine tool," Precision Engineering, 14, 1992, 139-146.

7. Kaminski, J., Crafoord, R., "Position Accuracy of Drilled Holes", Annals of the CIRP, 40, 1991, 503-506.

8. Lehtihet, E. A., Gunasena, U. N., "Statistical Models for the Relationship between Production Errors and the Position Tolerance of a Hole", Annals of the CIRP, Vol. 39, 1990, 569-572.

9. Lee, S. J., Eman, K. F. and Wu, S. M., "An Analysis of the Drill Wandering Motion", Journ. of Eng. for Ind., Vol. 109, 1987, 297-305.

i0. Fujii, H., Marui, E., Ema, S., "Whirling Vibration in Drilling. Part 1: Cause of Vibration and Role of Chisel Edge", Journ. of Eng. for Ind., Vol. 108, 1986, 157162.

11. Fujii, H., Marui, E., Ema, S., "Whirling Vibration in Drilling. Part 2: Influence of Drill Geometries, Particularly of the Drill Flank, on the Initiation of Vibration", Journ. of Eng. for Ind., Vol. 108, 1986, 163-168.

12. Fujii, H., Marui, E., Ema, S., "Whirling Vibration in Drilling. Part 3: Vibration Analysis in Drilling Workpiece with a Pilot Hole", Journ. of Eng. for Ind., Vol. 110, 1988, 315-321.

13. Magrab, E. B., Gilsinn, D. E., "Buckling Loads and Natural Frequencies of Drill Bits and Fluted Cutters", Journ. of Eng. for Ind., Vol. 106, 1984, 196-204.

14. Shen, Y., Duffie, N.A., "An Uncertainty Analysis Method for Coordinate Referencing in Manufacturing Systems", J. of Eng. for Ind., Vol. 117, 1995, 42-48.

15. Shen, Y., Duffie, N. A., "Uncertainties in the Acquisition and Utilization of Coordinate Frames in Manufacturing Systems", Annals of the CIRP, 40, 1, 1991, 527-530.

16. Bauer, W.F., "The Monte Carlo Method", J. Soc. Indust. Appl. Math., 6,4, 1958, 438451.

17. Yau, H., "Evaluation and uncertainty analysis of vectorial tolerances", Precision Engineering, Vol. 20, 1997, 123-137. 
18. Phillips, S.D., Borchardt, B., Estler, W.T., Buttress, J., "The estimation of measurement uncertainty of small circular features measured by coordinate measuring machines", Precision Engineering, Vol. 22, 1998, 87-97.

19. ASME B5.54-1992, Methods for Performance Evaluation of Computer Numerically Controlled Machining Centers, The American Society of Mechanical Engineers, New York, 1993.

20. Kakino, Y., Ihara, Y., Nakatsu, Y., "The Measurement of Motion Errors of NC Machine Tools and Diagnosis of their Origins by Using Telescoping Magnetic Ball Bar Method", Annals of the CIRP, Vol. 36, 1987, 377-380.

21. Ziegert, J.C., Mize, C.D., "The laser ball bar: anew instrument for machine tool metrology", Precision Engineering, 16, 1994, 259-267.

22. Schmitz, T., Ziegert, J., "Premachining computer numerical control contour validation", Precision Engineering, 22, 1998, 10-18.

23. Srinivasa, N., Ziegert, J. C., "Automated measurement and compensation of thermally induced error maps in machine tools", Precision Engineering, 19, 1996, 112-132.

24. Donmez, M.A., A General Methodology for Machine Tool Accuracy Enhancement: Theory, Application and Implementation, Ph.D. Dissertation, Purdue University, 1985.

25. Coleman, H. W., Steele, W. G., Experimentation and Uncertainty Analysis for Engineers, John Wiley \& Sons, Inc., New York, 1999.

26. Wheeler, A.J., Ganji, A.R., Introduction to Engineering Experimentation, Prentice Hall, Englewood Cliffs, 1996.

27. Montgomery, D. C., Peck, E. A., Introduction to Linear Regression Analysis, John Wiley \& Sons, Inc., New York, 1992.

28. Mandel, J., "Fitting Straight Lines When Both Variables are Subject to Error", J. of Quality Technology, 16, 1984, 1-14.

29. International Organization for Standardization, "Test code for machine tools - Part 4: Circular Tests for Numerically Controlled Machine Tools, 1996.

30. Nash, J.C., Compact Numerical Methods for Computers: linear algebra and function minimisation, John Wiley \& Sons, New York 1979.

31. Dixon, W.J., Massey, Jr., F. J., Introduction to Statistical Analysis, McGraw-Hill Book Company, Inc., New York, 1957.

32. Mood, A. M., Graybill, F. A., Introduction to the Theory of Statistics, McGraw-Hill Book Company, Inc., New York, 1963.

33. Dennis, Jr., J.E., Schnabel, R.B., Numerical Methods for Unconstrained Optimization and Nonlinear Equations, Prentice-Hall, Inc., Englewood Cliffs, New Jersey 1983 


\section{APPENDIX A: Model Based Estimates of Point Error Variances and Confidence Intervals}

This appendix contains tables of uncertainty estimates of the machine tool errors for the peripheral hole centers and selected points on the inner and outer radii of the circular slot based on the prediction formulas (31) and (32). Table Al contains the predicted machine errors using equation (13) and the error component regression models with coefficients from Table 2. Table A2 and A3 contain the same information for the inner and outer radii points of the circular slot. Tables A4, A5, and A6 give the $95 \%$ prediction interval estimates for the location of the points.

\begin{tabular}{|c|c|c|c|c|c|c|c|}
\hline \multicolumn{8}{|c|}{ Hole Center Error Uncertainty Estimates for the Next Center Sample } \\
\hline & $\begin{array}{c}\text { Hole } \\
\text { Number }\end{array}$ & $\begin{array}{l}\text { Hole } \\
\text { Center } \\
x(\mathrm{~mm})\end{array}$ & $\begin{array}{l}\text { Hole } \\
\text { Center } \\
y(\mathrm{~mm})\end{array}$ & $\begin{array}{l}\text { Machine } x- \\
\text { Error } \\
(\mu \mathrm{m})\end{array}$ & $\begin{array}{c}\text { Machine y- } \\
\text { Error } \\
(\mu \mathrm{m})\end{array}$ & $\begin{array}{c}\text { Prediction } \\
\text { Variance } \\
\text { x-Error } \\
(\mu \mathrm{m} \text { sqr.) }\end{array}$ & $\begin{array}{l}\text { Prediction } \\
\text { Variance } \\
\text { y-Error } \\
\text { ( } \mu \mathrm{m} \text { sqr.) }\end{array}$ \\
\hline & & $\bar{x}$ & $\mathbf{y}$ & $E_{x}$ & $E_{y}$ & $u_{c o}^{2}\left(E_{x}\right)$ & $u_{c o}^{2}\left(E_{y}\right)$ \\
\hline 1 & 3 & 10 & 10 & 1.15 & 1.63 & 6.86 & 22.60 \\
\hline 2 & 26 & 28 & 10 & 0.80 & 1.47 & 6.84 & 22.84 \\
\hline 3 & 25 & 43 & 10 & 0.52 & 1.36 & 6.83 & 23.26 \\
\hline 4 & 24 & 68 & 10 & 0.04 & 1.20 & 6.82 & 24.45 \\
\hline 5 & 23 & 92 & 10 & -0.42 & 1.09 & 6.81 & 26.15 \\
\hline 6 & 22 & 120 & 10 & -0.96 & 0.99 & 6.82 & 28.85 \\
\hline 7 & 21 & 140 & 10 & -1.34 & 0.95 & 6.84 & 31.29 \\
\hline 8 & 20 & 140 & 28 & -0.76 & 0.62 & 7.29 & 31.18 \\
\hline 9 & 19 & 140 & 43 & -0.30 & 0.35 & 8.03 & 31.12 \\
\hline 10 & 18 & 140 & 68 & 0.41 & -0.11 & 9.99 & 31.06 \\
\hline 11 & 17 & 140 & 92 & 1.03 & -0.55 & 12.74 & 31.06 \\
\hline 12 & 16 & 140 & 120 & 1.67 & -1.06 & 17.03 & 31.13 \\
\hline 13 & 15 & 140 & 140 & 2.07 & -1.43 & 20.83 & 31.23 \\
\hline 14 & 14 & 120 & 140 & 2.53 & -1.39 & 20.76 & 28.79 \\
\hline 15 & 13 & 92 & 140 & 3.17 & -1.29 & 20.72 & 26.09 \\
\hline 16 & 12 & 68 & 140 & 3.72 & -1.17 & 20.74 & 24.39 \\
\hline 17 & 11 & 43 & 140 & 4.29 & -1.01 & 20.80 & 23.21 \\
\hline 18 & 10 & 28 & 140 & 4.63 & -0.90 & 20.86 & 22.78 \\
\hline 19 & 9 & 10 & 140 & 5.04 & -0.75 & 20.96 & 22.55 \\
\hline 20 & 8 & 10 & 120 & 4.57 & -0.38 & $17 . \overline{13}$ & 22.45 \\
\hline 21 & 7 & 10 & 92 & 3.83 & 0.13 & 12.81 & 22.37 \\
\hline 22 & 6 & 10 & 68 & 3.12 & 0.57 & 10.04 & 22.37 \\
\hline 23 & 5 & 10 & 43 & 2.32 & 1.02 & 8.06 & 22.43 \\
\hline 24 & 4 & 10 & 28 & 1.80 & 1.30 & 7.32 & 22.50 \\
\hline
\end{tabular}

Table A1: This Table Contains the Nominal Locations in Part Measurement Coordinates, the Predicted Machine Error at the Hole Centers, and the Prediction Variances for the Next Sample. 


\begin{tabular}{|c|c|c|c|c|c|c|}
\hline \multicolumn{7}{|c|}{ Point Error Uncertainty Estimates for the Next Inner Circle Point Sample } \\
\hline & $\begin{array}{c}\text { Point } \\
x(\mathrm{~mm})\end{array}$ & $\begin{array}{c}\text { Point } \\
\text { y }(\mathrm{mm})\end{array}$ & $\begin{array}{c}\text { Machine } \\
\text { x-Error } \\
(\mu \mathrm{m})\end{array}$ & $\begin{array}{c}\text { Machine } \\
\text { y-Error } \\
(\mu \mathrm{m})\end{array}$ & 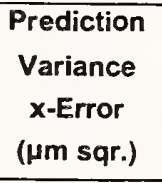 & $\begin{array}{c}\text { Prediction } \\
\text { Variance } \\
y \text {-Error } \\
\text { ( } \mu \mathrm{m} \text { sqr.) } \\
\end{array}$ \\
\hline & $x$ & $y$ & $E_{x}$ & $E$ & $u_{c o}^{2}\left(E_{x}\right)$ & $u_{c o}^{2}\left(E_{y}\right)$ \\
\hline 1 & 119.5 & 75 & 1.03 & -0.20 & 10.68 & 28.56 \\
\hline 2 & 118.82 & 82.73 & 1.25 & -0.34 & 11.54 & 28.48 \\
\hline 3 & 116.82 & 90.22 & 1.48 & -0.47 & 12.47 & 28.27 \\
\hline 4 & 113.54 & 97.25 & 1.73 & -0.59 & 13.41 & 27.93 \\
\hline 5 & 109.09 & 103.6 & 1.98 & -0.69 & 14.32 & 27.49 \\
\hline 6 & 103.6 & 109.09 & 2.23 & -0.77 & 15.15 & 26.98 \\
\hline 7 & 97.25 & 113.54 & 2.47 & -0.83 & 15.86 & 26.41 \\
\hline 8 & 90.22 & 116.82 & 2.70 & -0.86 & 16.40 & 25.83 \\
\hline 9 & 82.73 & 118.82 & 2.92 & -0.86 & 16.74 & 25.26 \\
\hline 10 & 75 & 119.5 & 3.11 & -0.83 & 16.87 & 24.73 \\
\hline 11 & 67.27 & 118.82 & 3.26 & -0.78 & 16.76 & 24.24 \\
\hline 12 & 59.78 & 116.82 & 3.38 & -0.70 & 16.43 & 23.82 \\
\hline 13 & 52.75 & 113.54 & 3.46 & -0.60 & 15.89 & 23.47 \\
\hline 14 & 46.4 & 109.09 & 3.49 & -0.47 & 15.19 & 23.19 \\
\hline 15 & 40.91 & 103.6 & 3.47 & -0.33 & 14.36 & 22.98 \\
\hline 16 & 36.46 & 97.25 & 3.40 & -0.19 & 13.45 & 22.83 \\
\hline 17 & 33.18 & 90.22 & 3.28 & -0.03 & 12.51 & 22.73 \\
\hline 18 & 31.18 & 82.73 & 3.11 & 0.12 & 11.59 & 22.67 \\
\hline 19 & 30.5 & 75 & 2.90 & 0.27 & 10.71 & 22.65 \\
\hline 20 & 31.18 & 67.27 & 2.66 & 0.40 & 9.93 & 22.68 \\
\hline 21 & 33.18 & 59.78 & 2.39 & 0.52 & 9.25 & 22.74 \\
\hline 22 & 36.46 & 52.75 & 2.10 & 0.63 & 8.69 & 22.85 \\
\hline 23 & 40.91 & 46.4 & 1.81 & 0.71 & 8.24 & 23.01 \\
\hline 24 & 46.4 & 40.91 & 1.52 & 0.77 & 7.90 & 23.22 \\
\hline 25 & 52.75 & 36.46 & 1.24 & 0.81 & 7.65 & 23.51 \\
\hline 26 & 59.78 & 33.18 & 1.00 & 0.83 & 7.49 & 23.86 \\
\hline 27 & 67.27 & 31.18 & 0.78 & 0.82 & 7.40 & 24.28 \\
\hline 28 & 75 & 30.5 & 0.61 & 0.79 & 7.37 & 24.77 \\
\hline 29 & 82.73 & 31.18 & 0.47 & 0.74 & 7.39 & 25.30 \\
\hline 30 & 90.22 & 33.18 & 0.39 & 0.67 & 7.48 & 25.87 \\
\hline 31 & 97.25 & 36.46 & 0.36 & 0.58 & 7.64 & 26.45 \\
\hline 32 & 103.6 & 40.91 & 0.37 & 0.48 & 7.88 & 27.01 \\
\hline 33 & 109.09 & 46.4 & 0.43 & 0.36 & 8.22 & 27.52 \\
\hline 34 & 113.54 & 52.75 & 0.53 & 0.23 & 8.66 & 27.95 \\
\hline 35 & 116.82 & 59.78 & 0.67 & 0.09 & 9.22 & 28.28 \\
\hline 36 & 118.82 & 67.27 & 0.83 & -0.05 & 9.90 & 28.49 \\
\hline
\end{tabular}

Table A2: This Table Contains the Same Data as Table A1 for Inner Circle Points. 


\begin{tabular}{|c|c|c|c|c|c|c|}
\hline \multicolumn{7}{|c|}{ Point Error Uncertainty Estimates for the Next Outer Circle Point Sample } \\
\hline & $\begin{array}{c}\text { Point } \\
\text { x (mm) }\end{array}$ & $\begin{array}{c}\text { Point } \\
y(\mathrm{~mm})\end{array}$ & $\begin{array}{c}\text { Machine } \\
x \text {-Error } \\
(\mu \mathrm{m})\end{array}$ & $\begin{array}{c}\text { Machine } \\
\text { y-Error } \\
\text { (رm) }\end{array}$ & $\begin{array}{c}\text { Prediction } \\
\text { Variance } \\
\text { x-Error } \\
\text { ( } \mu \mathrm{m} \text { sqr.) }\end{array}$ & $\begin{array}{c}\text { Prediction } \\
\text { Variance } \\
\text { y-Error } \\
\text { ( } \mu \mathrm{mr} \text { sqr.) }\end{array}$ \\
\hline & $x$ & y & $E_{x}$ & $E_{y}$ & $u_{c o}^{2}\left(E_{x}\right)$ & $u_{c o}^{2}\left(E_{y}\right)$ \\
\hline 1 & 130.5 & 75 & 0.80 & -0.22 & 10.69 & 29.84 \\
\hline 2 & 129.66 & 84.64 & 1.07 & -0.40 & 11.79 & 29.74 \\
\hline 3 & 127.15 & 93.98 & 1.35 & -0.56 & 12.98 & 29.45 \\
\hline 4 & 123.06 & 102.75 & 1.65 & -0.71 & 14.21 & 28.99 \\
\hline 5 & 117.52 & 110.67 & 1.96 & -0.84 & 15.42 & 28.39 \\
\hline 6 & 110.67 & 117.52 & 2.27 & -0.95 & 16.54 & 27.70 \\
\hline 7 & 102.75 & 123.06 & 2.57 & -1.02 & 17.49 & 26.95 \\
\hline 8 & 93.98 & 127.15 & 2.85 & -1.06 & 18.23 & 26.19 \\
\hline 9 & 84.64 & 129.66 & 3.12 & -1.07 & 18.69 & 25.45 \\
\hline 10 & 75 & 130.5 & 3.35 & -1.04 & 18.86 & 24.78 \\
\hline 11 & 65.36 & 129.66 & 3.55 & -0.97 & 18.71 & 24.18 \\
\hline 12 & 56.02 & 127.15 & 3.71 & -0.87 & 18.26 & 23.68 \\
\hline 13 & 47.25 & $\overline{123.06}$ & 3.81 & -0.73 & 17.54 & 23.28 \\
\hline 14 & 39.33 & 117.52 & 3.85 & -0.58 & 16.59 & 22.97 \\
\hline 15 & 32.48 & 110.67 & 3.83 & -0.40 & 15.48 & 22.75 \\
\hline 16 & 26.94 & 102.75 & 3.75 & -0.21 & 14.27 & 22.60 \\
\hline 17 & 22.85 & 93.98 & 3.60 & -0.02 & 13.04 & 22.51 \\
\hline 18 & 20.34 & 84.64 & 3.40 & 0.17 & 11.84 & 22.46 \\
\hline 19 & 19.5 & 75 & 3.13 & 0.36 & 10.74 & 22.45 \\
\hline 20 & 20.34 & 65.36 & 2.82 & 0.52 & 9.77 & 22.47 \\
\hline 21 & 22.85 & 56.02 & 2.48 & 0.67 & 8.96 & 22.53 \\
\hline 22 & 26.94 & 47.25 & 2.12 & 0.80 & 8.31 & 22.63 \\
\hline 23 & 32.48 & 39.33 & 1.74 & 0.90 & 7.82 & 22.78 \\
\hline 24 & 39.33 & 32.48 & 1.38 & 0.98 & 7.47 & 23.01 \\
\hline 25 & 47.25 & 26.94 & 1.03 & 1.02 & 7.24 & 23.32 \\
\hline 26 & 56.02 & 22.85 & 0.72 & 1.04 & 7.10 & 23.73 \\
\hline 27 & 65.36 & 20.34 & 0.45 & 1.03 & 7.02 & 24.23 \\
\hline 28 & 75 & 19.5 & 0.23 & 0.99 & 7.00 & 24.83 \\
\hline 29 & 84.64 & 20.34 & 0.08 & 0.93 & 7.02 & 25.50 \\
\hline 30 & 93.98 & 22.85 & -0.02 & 0.84 & 7.09 & 26.23 \\
\hline 31 & 102.75 & 26.94 & -0.06 & 0.73 & 7.23 & 26.99 \\
\hline 32 & 110.67 & 32.48 & -0.04 & 0.61 & 7.46 & 27.73 \\
\hline 33 & 117.52 & 39.33 & 0.04 & 0.46 & 7.80 & 28.42 \\
\hline 34 & 123.06 & 47.25 & 0.17 & 0.30 & 8.28 & 29.01 \\
\hline 35 & 127.15 & 56.02 & 0.34 & 0.13 & 8.92 & 29.46 \\
\hline 36 & 129.66 & 65.36 & 0.56 & -0.04 & 9.73 & 29.75 \\
\hline
\end{tabular}

Table A3: This Table Contains the Same Data as Table A1 for Outer Circle Points. 


\begin{tabular}{|c|c|c|c|c|c|c|c|c|c|}
\hline \multicolumn{10}{|c|}{ Expanded Prediction Intervals for Hole Center Errors With Coverage Factor 2} \\
\hline & $\begin{array}{c}\text { Hole } \\
\text { Number }\end{array}$ & $\begin{array}{c}\text { Hole } \\
\text { Center } \\
x(\mathrm{~mm})\end{array}$ & $\begin{array}{l}\text { Hole } \\
\text { Center } \\
\text { y (mm) }\end{array}$ & $\begin{array}{c}\text { Machine } \\
\text { x-Error } \\
(\mu \mathrm{m})\end{array}$ & $\begin{array}{c}\text { Machine } \\
\text { y-Error } \\
(\mu \mathrm{m})\end{array}$ & $\begin{array}{l}\text { Lower Limit } \\
x-\text { Error } \\
(\mu \mathrm{m})\end{array}$ & $\begin{array}{l}\text { Upper Limit } \\
\text { x-Error } \\
(\mu \mathrm{m})\end{array}$ & $\begin{array}{c}\text { Lower Limit } \\
y \text {-Error } \\
(\mu \mathrm{m})\end{array}$ & $\begin{array}{c}\text { Upper Limit } \\
y \text {-Error } \\
(\mu \mathrm{m})\end{array}$ \\
\hline & & $\bar{x}$ & $\begin{array}{ll}y \\
\end{array}$ & $E_{x}$ & $E_{y}$ & & & & \\
\hline 1 & 3 & 10 & 10 & 1.15 & 1.63 & -4.09 & 6.39 & -7.88 & 11.13 \\
\hline 2 & 26 & 28 & 10 & 0.80 & 1.47 & -4.43 & 6.03 & -8.08 & 11.03 \\
\hline 3 & 25 & 43 & 10 & 0.52 & 1.36 & -4.71 & 5.74 & -8.29 & 11.01 \\
\hline 4 & 24 & 68 & 10 & 0.04 & 1.20 & -5.19 & 5.26 & -8.69 & 11.09 \\
\hline 5 & 23 & 92 & 10 & -0.42 & 1.09 & -5.64 & 4.80 & -9.14 & 11.31 \\
\hline 6 & 22 & 120 & 10 & -0.96 & 0.99 & -6.18 & 4.26 & -9.75 & 11.73 \\
\hline 7 & 21 & 140 & 10 & -1.34 & 0.95 & -6.57 & 3.89 & -10.24 & 12.14 \\
\hline 8 & 20 & 140 & 28 & -0.76 & 0.62 & -6.16 & 4.64 & -10.55 & 11.79 \\
\hline 9 & 19 & 140 & 43 & -0.30 & 0.35 & -5.96 & 5.37 & -10.81 & 11.50 \\
\hline 10 & 18 & 140 & 68 & 0.41 & -0.11 & -5.91 & 6.74 & -11.26 & 11.03 \\
\hline 11 & 17 & 140 & 92 & 1.03 & -0.55 & -6.11 & 8.17 & -11.70 & 10.60 \\
\hline 12 & 16 & 140 & 120 & 1.67 & -1.06 & -6.59 & 9.92 & -12.22 & 10.10 \\
\hline 13 & 15 & 140 & 140 & 2.07 & -1.43 & -7.06 & 11.20 & -12.60 & 9.75 \\
\hline 14 & 14 & 120 & 140 & 2.53 & -1.39 & -6.59 & 11.64 & -12.12 & 9.35 \\
\hline 15 & 13 & 92 & 140 & 3.17 & -1.29 & -5.94 & 12.27 & -11.51 & 8.93 \\
\hline 16 & 12 & 68 & 140 & 3.72 & -1.17 & -5.39 & 12.82 & -11.05 & 8.71 \\
\hline 17 & 11 & 43 & 140 & 4.29 & -1.01 & -4.83 & 13.41 & -10.65 & 8.62 \\
\hline 18 & 10 & 28 & 140 & 4.63 & -0.90 & -4.50 & 13.77 & -10.45 & 8.64 \\
\hline 19 & 9 & 10 & 140 & 5.04 & -0.75 & -4.11 & 14.20 & -10.25 & 8.75 \\
\hline 20 & 8 & 10 & 120 & 4.57 & -0.38 & -3.71 & 12.85 & -9.86 & 9.09 \\
\hline 21 & 7 & 10 & 92 & 3.83 & 0.13 & -3.33 & 10.98 & -9.33 & 9.59 \\
\hline 22 & 6 & 10 & 68 & 3.12 & 0.57 & -3.22 & 9.46 & -8.89 & 10.03 \\
\hline 23 & 5 & 10 & 43 & 2.32 & 1.02 & -3.36 & 8.00 & -8.45 & 10.49 \\
\hline 24 & 4 & 10 & 28 & 1.80 & 1.30 & -3.61 & 7.21 & -8.19 & 10.78 \\
\hline
\end{tabular}

Table A4: 95\% Prediction Intervals for the Peripheral Holes. 


\begin{tabular}{|c|c|c|c|c|c|c|c|c|}
\hline & & xpandec & liction Inte & for Inner & le Point Errc & Vith Covera & ctor 2 & \\
\hline $\begin{array}{l}\text { Point } \\
\text { Index }\end{array}$ & $\begin{array}{c}\text { Point } \\
x(\mathrm{~mm})\end{array}$ & $\begin{array}{l}\text { Point } \\
y(\mathrm{~mm})\end{array}$ & 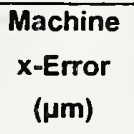 & $\begin{array}{c}\text { Machine } \\
\text { y-Error } \\
\text { (pm) }\end{array}$ & $\begin{array}{c}\text { Lower Limit } \\
\text { x-Error } \\
(\mu \mathrm{m})\end{array}$ & 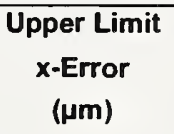 & $\begin{array}{c}\text { Lower Limit } \\
\text { y-Error } \\
(\mu \mathrm{m})\end{array}$ & $\begin{array}{l}\text { Upper Limit } \\
\text { y-Error } \\
(\mu \mathrm{m})\end{array}$ \\
\hline & $x$ & $\mathbf{y}$ & $E_{x}$ & $E_{y}$ & & & & \\
\hline 1 & 119.5 & 75 & 1.03 & -0.20 & -5.50 & 7.57 & -10.89 & 10.49 \\
\hline 2 & 118.82 & 82.73 & 1.25 & -0.34 & -5.55 & 8.04 & -11.01 & 10.34 \\
\hline 3 & \begin{tabular}{|l|}
116.82 \\
\end{tabular} & 90.22 & 1.48 & -0.47 & -5.58 & 8.55 & -11.10 & 10.17 \\
\hline 4 & \begin{tabular}{|l|}
113.54 \\
\end{tabular} & 97.25 & 1.73 & -0.59 & -5.59 & 9.05 & -11.16 & 9.98 \\
\hline 5 & 109.09 & 103.6 & 1.98 & -0.69 & -5.59 & 9.55 & -11.18 & 9.80 \\
\hline 6 & 103.6 & 109.09 & 2.23 & -0.77 & -5.56 & 10.01 & -11.16 & 9.62 \\
\hline 7 & 97.25 & 113.54 & 2.47 & -0.83 & -5.49 & 10.44 & -11.11 & 9.45 \\
\hline 8 & 90.22 & 116.82 & 2.70 & -0.86 & -5.40 & 10.80 & -11.02 & 9.31 \\
\hline 9 & 82.73 & 118.82 & 2.92 & -0.86 & -5.27 & 11.10 & -10.91 & 9.19 \\
\hline 10 & 75 & 119.5 & 3.11 & -0.83 & -5.11 & 11.32 & -10.78 & 9.11 \\
\hline 11 & 67.27 & 118.82 & 3.26 & -0.78 & -4.92 & 11.45 & -10.63 & 9.07 \\
\hline 12 & 59.78 & 116.82 & 3.38 & -0.70 & -4.72 & 11.49 & -10.46 & 9.06 \\
\hline 13 & 52.75 & 113.54 & 3.46 & -0.60 & -4.51 & 11.43 & -10.29 & 9.09 \\
\hline 14 & 46.4 & 109.09 & 3.49 & -0.47 & -4.31 & 11.28 & -10.10 & 9.16 \\
\hline 15 & 40.91 & 103.6 & 3.47 & -0.33 & -4.11 & 11.05 & -9.92 & 9.25 \\
\hline 16 & 36.46 & 97.25 & 3.40 & -0.19 & -3.94 & 10.73 & -9.74 & 9.37 \\
\hline 17 & 33.18 & 90.22 & 3.28 & -0.03 & -3.80 & 10.35 & -9.57 & 9.50 \\
\hline 18 & 31.18 & 82.73 & 3.11 & 0.12 & -3.70 & 9.92 & -9.40 & 9.64 \\
\hline 19 & 30.5 & 75 & 2.90 & 0.27 & -3.64 & 9.45 & -9.25 & 9.79 \\
\hline 20 & 31.18 & 67.27 & 2.66 & 0.40 & -3.64 & 8.96 & -9.12 & 9.93 \\
\hline 21 & 33.18 & 59.78 & 2.39 & 0.52 & -3.70 & 8.47 & -9.01 & 10.06 \\
\hline 22 & 36.46 & 52.75 & 2.10 & 0.63 & -3.79 & 7.99 & -8.93 & 10.19 \\
\hline 23 & 40.91 & 46.4 & 1.81 & 0.71 & -3.93 & 7.55 & -8.88 & 10.30 \\
\hline 24 & 46.4 & 40.91 & 1.52 & 0.77 & -4.10 & 7.14 & -8.87 & 10.41 \\
\hline 25 & 52.75 & 36.46 & 1.24 & 0.81 & -4.29 & 6.78 & -8.88 & 10.51 \\
\hline 26 & 59.78 & 33.18 & 1.00 & 0.83 & -4.48 & 6.47 & -8.94 & 10.60 \\
\hline 27 & 67.27 & 31.18 & 0.78 & 0.82 & -4.66 & 6.22 & -9.03 & 10.68 \\
\hline 28 & 75 & 30.5 & 0.61 & 0.79 & -4.82 & 6.03 & -9.16 & 10.74 \\
\hline 29 & 82.73 & 31.18 & 0.47 & 0.74 & -4.96 & 5.91 & -9.32 & 10.80 \\
\hline 30 & \begin{tabular}{|l}
90.22 \\
\end{tabular} & 33.18 & 0.39 & 0.67 & -5.08 & 5.86 & -9.50 & 10.84 \\
\hline 31 & \begin{tabular}{|l|}
97.25 \\
\end{tabular} & 36.46 & 0.36 & 0.58 & -5.17 & 5.89 & -9.71 & 10.87 \\
\hline 32 & 103.6 & 40.91 & 0.37 & 0.48 & -5.24 & 5.98 & -9.92 & 10.87 \\
\hline 33 & \begin{tabular}{|l|}
109.09 \\
\end{tabular} & 46.4 & $\overline{0.43}$ & 0.36 & -5.31 & 6.16 & -10.14 & 10.85 \\
\hline 34 & 113.54 & 52.75 & 0.53 & 0.23 & -5.36 & 6.41 & -10.35 & 10.80 \\
\hline 35 & \begin{tabular}{|l|}
116.82 \\
\end{tabular} & 59.78 & 0.67 & 0.09 & -5.41 & 6.74 & -10.55 & 10.73 \\
\hline 36 & \begin{tabular}{|l|}
118.82 \\
\end{tabular} & 67.27 & 0.83 & -0.05 & -5.46 & 7.13 & -10.73 & 10.62 \\
\hline
\end{tabular}

Table A 5: 95\% Prediction Intervals for Inner Circle Points 


\begin{tabular}{|c|c|c|c|c|c|c|c|c|}
\hline \multicolumn{9}{|c|}{ Expanded Prediction Intervals for Outer circle Point Errors With Coverage Factor 2} \\
\hline & $\begin{array}{c}\text { Point } \\
x(\mathrm{~mm})\end{array}$ & $\begin{array}{l}\text { Point } \\
y(\mathrm{~mm})\end{array}$ & $\begin{array}{c}\text { Machine } \\
\text { x-Error } \\
(\mathrm{erm})\end{array}$ & $\begin{array}{c}\text { Machine } \\
\text { y-Error } \\
(\mu \mathrm{m})\end{array}$ & $\begin{array}{l}\text { Lower Limit } \\
\text { x-Error } \\
(\mu \mathrm{m})\end{array}$ & $\begin{array}{l}\text { Upper Limit } \\
\text { x-Error } \\
(\mu \mathrm{m})\end{array}$ & $\begin{array}{l}\text { Lower Limit } \\
y \text {-Error } \\
(\mu \mathrm{m})\end{array}$ & $\begin{array}{l}\text { Upper Limit } \\
y \text {-Error } \\
(\mu \mathrm{m})\end{array}$ \\
\hline & $\mathbf{x}$ & y & $E_{x}$ & $E_{y}$ & & & & \\
\hline 1 & 130.5 & 75 & 0.80 & -0.22 & -5.74 & 7.34 & -11.15 & 10.70 \\
\hline 2 & 129.66 & 84.64 & 1.07 & -0.40 & -5.80 & 7.93 & -11.30 & 10.51 \\
\hline 3 & 127.15 & 93.98 & 1.35 & -0.56 & -5.85 & 8.56 & -11.42 & 10.29 \\
\hline 4 & 123.06 & 102.75 & 1.65 & -0.71 & -5.89 & 9.19 & -11.48 & 10.05 \\
\hline 5 & \begin{tabular}{|l|}
117.52 \\
\end{tabular} & 110.67 & 1.96 & -0.84 & -5.89 & 9.81 & -11.50 & 9.81 \\
\hline 6 & \begin{tabular}{|l|}
110.67 \\
\end{tabular} & 117.52 & 2.27 & -0.95 & -5.87 & 10.40 & -11.47 & 9.58 \\
\hline 7 & \begin{tabular}{|l|}
102.75 \\
\end{tabular} & 123.06 & 2.57 & -1.02 & -5.80 & 10.93 & -11.40 & 9.36 \\
\hline 8 & 93.98 & 127.15 & 2.85 & -1.06 & -5.69 & 11.39 & -11.30 & 9.17 \\
\hline 9 & 84.64 & 129.66 & 3.12 & -1.07 & -5.53 & 11.76 & -11.16 & 9.02 \\
\hline 10 & 75 & 130.5 & 3.35 & -1.04 & -5.33 & 12.04 & -10.99 & 8.92 \\
\hline 11 & 65.36 & 129.66 & 3.55 & -0.97 & -5.10 & 12.20 & -10.80 & 8.87 \\
\hline 12 & 56.02 & 127.15 & 3.71 & -0.87 & -4.84 & 12.25 & -10.60 & 8.87 \\
\hline 13 & 47.25 & 123.06 & 3.81 & -0.73 & -4.57 & 12.18 & -10.38 & 8.92 \\
\hline 14 & 39.33 & 117.52 & 3.85 & -0.58 & -4.29 & 12.00 & -10.16 & 9.01 \\
\hline 15 & 32.48 & 110.67 & 3.83 & -0.40 & -4.03 & 11.70 & -9.94 & 9.14 \\
\hline 16 & 26.94 & 102.75 & 3.75 & -0.21 & -3.80 & 11.31 & -9.72 & 9.30 \\
\hline 17 & 22.85 & 93.98 & 3.60 & -0.02 & -3.62 & 10.83 & -9.51 & 9.47 \\
\hline 18 & 20.34 & 84.64 & 3.40 & 0.17 & -3.49 & 10.28 & -9.31 & 9.65 \\
\hline 19 & 19.5 & 75 & 3.13 & 0.36 & -3.42 & 9.69 & -9.12 & 9.83 \\
\hline 20 & 20.34 & 65.36 & 2.82 & 0.52 & -3.43 & 9.08 & -8.96 & 10.01 \\
\hline 21 & 22.85 & 56.02 & 2.48 & 0.67 & -3.50 & 8.47 & -8.82 & 10.17 \\
\hline 22 & 26.94 & 47.25 & 2.12 & 0.80 & -3.65 & 7.88 & -8.71 & 10.31 \\
\hline 23 & 32.48 & 39.33 & 1.74 & 0.90 & -3.85 & 7.34 & -8.64 & 10.45 \\
\hline 24 & 39.33 & 32.48 & 1.38 & 0.98 & -4.09 & 6.84 & -8.62 & 10.57 \\
\hline 25 & 47.25 & 26.94 & 1.03 & 1.02 & -4.35 & 6.41 & -8.64 & 10.68 \\
\hline 26 & 56.02 & 22.85 & 0.72 & 1.04 & -4.61 & 6.05 & -8.70 & 10.78 \\
\hline 27 & 65.36 & 20.34 & 0.45 & 1.03 & -4.85 & 5.75 & -8.82 & 10.87 \\
\hline 28 & 75 & 19.5 & 0.23 & 0.99 & -5.06 & 5.52 & -8.97 & 10.96 \\
\hline 29 & 84.64 & 20.34 & 0.08 & 0.93 & -5.22 & 5.37 & -9.17 & 11.03 \\
\hline 30 & 93.98 & 22.85 & -0.02 & 0.84 & -5.35 & 5.30 & -9.40 & 11.09 \\
\hline 31 & 102.75 & 26.94 & -0.06 & 0.73 & -5.44 & 5.32 & -9.66 & 11.12 \\
\hline 32 & \begin{tabular}{|l|}
110.67 \\
\end{tabular} & 32.48 & -0.04 & 0.61 & -5.50 & 5.43 & -9.93 & 11.14 \\
\hline 33 & \begin{tabular}{|l|}
117.52 \\
\end{tabular} & 39.33 & 0.04 & 0.46 & -5.54 & 5.63 & -10.20 & 11.12 \\
\hline 34 & \begin{tabular}{|l|}
123.06 \\
\end{tabular} & 47.25 & 0.17 & 0.30 & -5.58 & 5.93 & -10.47 & 11.07 \\
\hline 35 & 127.15 & 56.02 & 0.34 & 0.13 & -5.63 & 6.32 & -10.72 & 10.99 \\
\hline 36 & \begin{tabular}{|l|}
129.66 \\
\end{tabular} & 65.36 & 0.56 & -0.04 & -5.68 & 6.79 & -10.95 & 10.86 \\
\hline
\end{tabular}

Table A6: 95\% Prediction Intervals for the Outer Circle Points. 


\section{APPENDIX B: Uncertainty Estimates for Hole Centers Based on CMM Measurements of Parts}

Tables B.1.and B.2. contain the uncertainty estimates for all of the drilled hole center errors. Tables B.3. and B.4. contain the uncertainty estimates for all milled hole center errors. The computations are described in Section 5.1. The results are based on pooled estimates over all of the manufactured parts.

\begin{tabular}{|c|c|c|c|c|}
\hline \multicolumn{5}{|c|}{ Summary Table } \\
\hline \multicolumn{5}{|c|}{$\begin{array}{l}\text { Drilled Hole X-Measurement Uncertainties ( } \mu \mathrm{m} \text { ) } \\
\text { CMM Measurements (All Parts) }\end{array}$} \\
\hline Hole \# & $\begin{array}{c}\text { Manufacturing } \\
\text { Error }\end{array}$ & $\begin{array}{l}\text { Standard } \\
\text { Uncertainty }\end{array}$ & $\begin{array}{c}\text { Uncertainty } \\
\text { of a new } \\
\text { Measurement }\end{array}$ & $\begin{array}{c}\text { Expanded } \\
\text { Uncertainty } \\
\text { of a new } \\
\text { Measurement }\end{array}$ \\
\hline 3 & 2.73 & 0.14 & 1.06 & 2.12 \\
\hline 26 & 0.10 & 0.16 & 1.21 & 2.42 \\
\hline 25 & -0.43 & 0.12 & 0.89 & 1.78 \\
\hline 24 & -1.88 & 0.16 & 1.19 & 2.38 \\
\hline 23 & -5.33 & 0.31 & 2.32 & 4.64 \\
\hline 22 & -6.31 & 0.14 & 1.05 & 2.09 \\
\hline 21 & -8.13 & 0.12 & 0.93 & 1.85 \\
\hline 20 & -6.85 & 0.10 & 0.74 & 1.48 \\
\hline 19 & -6.94 & 0.09 & 0.70 & 1.41 \\
\hline 18 & -4.86 & 0.13 & 0.93 & 1.86 \\
\hline 17 & -4.88 & 0.09 & 0.69 & 1.37 \\
\hline 16 & -2.94 & 0.12 & 0.87 & 1.74 \\
\hline 15 & -4.52 & 0.11 & 0.85 & 1.70 \\
\hline 14 & -2.05 & 0.11 & 0.85 & 1.71 \\
\hline 13 & 1.61 & 0.67 & 4.99 & 9.98 \\
\hline 12 & 1.23 & 0.54 & 4.04 & 8.07 \\
\hline 11 & 3.02 & 0.15 & 1.11 & 2.22 \\
\hline 10 & 5.49 & 0.17 & 1.28 & 2.56 \\
\hline 9 & 4.99 & 0.15 & 1.10 & 2.20 \\
\hline 8 & 6.46 & 0.17 & 1.25 & 2.49 \\
\hline 7 & 1.30 & 0.14 & 1.04 & 2.08 \\
\hline 6 & 3.83 & 0.17 & 1.25 & 2.50 \\
\hline 5 & 3.60 & 0.17 & 1.24 & 2.49 \\
\hline 4 & 2.70 & 0.17 & 1.24 & 2.48 \\
\hline
\end{tabular}

Table B.1: Summary of Uncertainty Estimates for Drilled Hole XErrors. These are based on pooled estimates over all parts. 


\begin{tabular}{|c|c|c|c|c|}
\hline \multicolumn{5}{|c|}{ Summary Table } \\
\hline \multicolumn{5}{|c|}{$\begin{array}{l}\text { Drilled Hole Y-Measurement Uncertainties ( } \mu \mathrm{m} \text { ) } \\
\text { CMM Measurements (All Parts) }\end{array}$} \\
\hline Hole \# & $\begin{array}{c}\text { Manufacturing } \\
\text { Error }\end{array}$ & $\begin{array}{c}\text { Standard } \\
\text { Uncertainty }\end{array}$ & $\begin{array}{l}\text { Uncertainty } \\
\text { of a new } \\
\text { Measurement }\end{array}$ & $\begin{array}{c}\text { Expanded } \\
\text { Uncertainty } \\
\text { of a new } \\
\text { Measurement }\end{array}$ \\
\hline 3 & 8.05 & 0.12 & 0.87 & 1.74 \\
\hline 26 & 6.32 & 0.12 & 0.87 & 1.74 \\
\hline 25 & 9.14 & 0.13 & 0.94 & 1.87 \\
\hline 24 & 9.33 & 0.11 & 0.81 & 1.62 \\
\hline 23 & 12.29 & 0.39 & 2.90 & 5.80 \\
\hline 22 & 5.90 & 0.16 & 1.17 & 2.34 \\
\hline 21 & 6.10 & 0.13 & 0.98 & 1.96 \\
\hline 20 & 0.99 & 0.09 & 0.64 & 1.28 \\
\hline 19 & -2.05 & 0.10 & 0.71 & 1.41 \\
\hline 18 & -5.61 & 0.12 & 0.92 & 1.85 \\
\hline 17 & -9.61 & 0.10 & 0.74 & 1.48 \\
\hline 16 & -13.97 & 0.13 & 0.96 & 1.92 \\
\hline 15 & -16.45 & 0.13 & 1.00 & 2.00 \\
\hline 14 & -14.26 & 0.13 & 0.95 & 1.91 \\
\hline 13 & -13.09 & 1.18 & 8.74 & 17.49 \\
\hline 12 & -12.01 & 0.93 & 6.91 & 13.82 \\
\hline 11 & -11.51 & 0.16 & 1.19 & 2.39 \\
\hline 10 & -9.56 & 0.15 & 1.13 & 2.25 \\
\hline 9 & -13.58 & 0.11 & 0.83 & 1.66 \\
\hline 8 & -8.68 & 0.15 & 1.10 & 2.21 \\
\hline 7 & -4.57 & 0.14 & 1.03 & 2.05 \\
\hline 6 & -0.63 & 0.14 & 1.00 & 2.00 \\
\hline 5 & 2.45 & 0.13 & 0.93 & 1.87 \\
\hline 4 & 2.86 & 0.13 & 1.00 & 1.99 \\
\hline
\end{tabular}

Table B.2: Summary of Uncertainty Estimates for Drilled Hole Y-Errors. These are based on pooled estimates over all parts. 


\begin{tabular}{|c|c|c|c|c|}
\hline \multicolumn{5}{|c|}{ Summary Table } \\
\hline & \multicolumn{4}{|c|}{$\begin{array}{l}\text { Milled Hole X-Measurement Uncertainties }(\mu \mathrm{m}) \\
\text { CMM Measurements (All Parts) }\end{array}$} \\
\hline Hole \# & $\begin{array}{l}\text { Manufacturing } \\
\text { Error }\end{array}$ & $\begin{array}{c}\text { Standard } \\
\text { Uncertainty }\end{array}$ & $\begin{array}{c}\text { Uncertainty } \\
\text { of a new } \\
\text { Measurement }\end{array}$ & \begin{tabular}{|c} 
Expanded \\
Uncertainty \\
of a new \\
Measurement
\end{tabular} \\
\hline 3 & 11.23 & 0.16 & 1.19 & 2.38 \\
\hline 26 & 9.79 & 0.18 & 1.33 & 2.66 \\
\hline 25 & 7.63 & 0.14 & 1.07 & 2.13 \\
\hline 24 & 5.62 & 0.21 & 1.56 & 3.12 \\
\hline 23 & 2.99 & 0.14 & 1.03 & 2.06 \\
\hline 22 & 0.72 & 0.12 & 0.92 & 1.85 \\
\hline 21 & -1.38 & 0.14 & 1.05 & 2.10 \\
\hline 20 & -1.52 & 0.14 & 1.02 & 2.05 \\
\hline 19 & -1.66 & 0.13 & 0.94 & 1.88 \\
\hline 18 & -2.36 & 0.15 & 1.11 & 2.23 \\
\hline 17 & -0.12 & 0.13 & 0.98 & 1.96 \\
\hline 16 & 2.43 & 0.16 & 1.17 & 2.33 \\
\hline 15 & 3.62 & 0.19 & 1.40 & 2.80 \\
\hline 14 & 6.10 & 0.14 & 1.03 & 2.07 \\
\hline 13 & 8.22 & 0.16 & 1.18 & 2.35 \\
\hline 12 & 10.50 & 0.15 & 1.09 & 2.19 \\
\hline 11 & 12.37 & 0.54 & 4.00 & 7.99 \\
\hline 10 & 13.69 & 0.16 & 1.22 & 2.44 \\
\hline 9 & 14.79 & 0.12 & 0.92 & 1.84 \\
\hline 8 & 14.90 & 0.14 & 1.02 & 2.04 \\
\hline 7 & 15.28 & 0.18 & 1.31 & 2.63 \\
\hline 6 & 15.91 & 0.18 & 1.33 & 2.67 \\
\hline 5 & 14.04 & 0.15 & 1.14 & 2.28 \\
\hline 4 & 12.84 & 0.21 & 1.59 & 3.18 \\
\hline
\end{tabular}

Table B.3: Summary of Uncertainty Estimates for Milled Hole $\mathrm{X}$-Errors. These are based on pooled estimates over all parts. 


\begin{tabular}{|c|c|c|c|c|}
\hline \multicolumn{5}{|c|}{ Summary Table } \\
\hline \multicolumn{5}{|c|}{$\begin{array}{l}\text { Milled Hole Y-Uncertainties in } \mu \mathrm{m} \\
\text { CMM Measurements (All Parts) }\end{array}$} \\
\hline Hole \# & $\begin{array}{c}\text { Manufacturing } \\
\text { Error }\end{array}$ & $\begin{array}{c}\text { Standard } \\
\text { Uncertainty }\end{array}$ & $\begin{array}{l}\text { Uncertainty } \\
\text { of a new } \\
\text { Measurement }\end{array}$ & $\begin{array}{c}\text { Expanded } \\
\text { Uncertainty } \\
\text { of a new } \\
\text { Measurement }\end{array}$ \\
\hline 3 & 111.15 & 0.07 & 0.55 & 1.10 \\
\hline 26 & 11.08 & 0.07 & 0.54 & 1.09 \\
\hline 25 & 10.45 & 0.07 & 0.49 & 0.98 \\
\hline 24 & 9.70 & 0.14 & 1.05 & 2.09 \\
\hline 23 & 9.87 & 0.29 & 2.12 & 4.24 \\
\hline 22 & 8.68 & 0.12 & 0.91 & 1.82 \\
\hline 21 & 7.90 & 0.10 & 0.74 & 1.48 \\
\hline 20 & 6.45 & 0.08 & 0.56 & 1.12 \\
\hline 19 & 6.25 & 0.09 & 0.68 & 1.37 \\
\hline 18 & 7.03 & 0.08 & 0.59 & 1.18 \\
\hline 17 & 7.44 & 0.06 & 0.46 & 0.92 \\
\hline 16 & 6.67 & 0.07 & 0.54 & 1.08 \\
\hline 15 & 4.67 & 0.08 & 0.58 & 1.16 \\
\hline 14 & 5.88 & 0.16 & 1.21 & 2.42 \\
\hline 13 & 8.45 & 1.45 & 10.74 & 21.48 \\
\hline 12 & 8.08 & 0.08 & 0.61 & 1.21 \\
\hline 11 & 8.71 & 0.07 & 0.52 & 1.04 \\
\hline 10 & 8.72 & 0.12 & 0.87 & 1.73 \\
\hline 9 & 9.57 & 0.06 & 0.43 & 0.87 \\
\hline 8 & 11.13 & 0.07 & 0.52 & 1.05 \\
\hline 7 & 12.01 & 0.10 & 0.78 & 1.55 \\
\hline 6 & 11.23 & 0.11 & 0.81 & 1.62 \\
\hline 5 & 9.56 & 0.09 & 0.65 & 1.29 \\
\hline 4 & 9.20 & 0.08 & 0.59 & 1.18 \\
\hline
\end{tabular}

Table B.4: Summary of Uncertainty Estimates for Milled Hole Y-Errors. These are based on pooled estimates over all parts. 
The next four tables are analysis of manufacturing variance tables for all of the drilled and milled holes.

\begin{tabular}{|c|c|c|c|c|c|}
\hline \multicolumn{6}{|c|}{ Analysis of Variance Summary } \\
\hline \multicolumn{6}{|c|}{ Drilled Hole, X-Error } \\
\hline Hole \# & $\begin{array}{c}\text { Manufacturing } \\
\text { Error } \\
\text { Variance } \\
(\mu \mathrm{m} \text { sqr.) }\end{array}$ & $\begin{array}{l}\text { Metrology } \\
\text { Error } \\
\text { Variance } \\
(\mu \mathrm{m} \text { sqr.) }\end{array}$ & F Statistic & $\begin{array}{c}\text { Future } \\
\text { Manufacturing } \\
\text { Uncertainty } \\
(\mu \mathrm{m})\end{array}$ & $\begin{array}{c}\text { Expanded } \\
\text { Future } \\
\text { Manufacturing } \\
\text { Uncertainty } \\
(\mu \mathrm{m}) \\
\end{array}$ \\
\hline 3 & 640.89 & 1.10 & 581.09 & 25.91 & 51.82 \\
\hline 26 & 777.13 & 1.44 & 540.77 & 28.53 & 57.07 \\
\hline 25 & 702.47 & 0.78 & 904.63 & 27.13 & 54.26 \\
\hline 24 & 692.02 & 1.39 & 498.33 & 26.93 & 53.85 \\
\hline 23 & 1279.90 & 5.28 & 242.25 & 36.62 & 73.24 \\
\hline 22 & 706.44 & 1.08 & 656.09 & 27.20 & 54.41 \\
\hline 21 & 626.32 & 0.84 & 742.98 & 25.62 & 51.23 \\
\hline 20 & 661.73 & 0.54 & 1225.84 & 26.33 & 52.66 \\
\hline 19 & 640.13 & 0.49 & 1314.85 & 25.90 & 51.79 \\
\hline 18 & 673.04 & 0.85 & 792.55 & 26.55 & 53.11 \\
\hline 17 & 576.07 & 0.46 & 1250.15 & 24.57 & 49.13 \\
\hline 16 & 597.47 & 0.74 & 805.18 & 25.02 & 50.04 \\
\hline 15 & 566.00 & 0.71 & 797.18 & 24.35 & 48.70 \\
\hline 14 & 574.13 & 0.71 & 804.51 & 24.52 & 49.05 \\
\hline 13 & 622.42 & 24.46 & 25.44 & 25.54 & 51.07 \\
\hline 12 & 563.77 & 15.99 & 35.26 & 24.30 & 48.61 \\
\hline 11 & 606.99 & 1.21 & 500.87 & 25.22 & 50.43 \\
\hline 10 & 634.77 & 1.61 & 393.10 & 25.79 & 51.57 \\
\hline 9 & 511.44 & 1.19 & 430.00 & 23.15 & 46.29 \\
\hline 8 & 638.22 & 1.53 & 417.98 & 25.86 & 51.72 \\
\hline 7 & 736.93 & 1.06 & 696.80 & 27.79 & 55.57 \\
\hline 6 & 624.16 & 1.54 & 406.18 & 25.57 & 51.14 \\
\hline 5 & 613.85 & 1.52 & 404.15 & 25.36 & 50.72 \\
\hline 4 & 716.56 & 1.51 & 473.73 & 27.40 & 54.80 \\
\hline
\end{tabular}

Table B.5.: Summary Analysis of Variances for X-Errors for all Peripheral Drilled Holes along with Manufacturing Uncertainties. 


\begin{tabular}{|c|c|c|c|c|c|}
\hline \multicolumn{6}{|c|}{ Analysis of Variance Summary } \\
\hline \multicolumn{6}{|c|}{ Drilled Hole, Y-Error } \\
\hline Hole \# & $\begin{array}{c}\text { Manufacturing } \\
\text { Error } \\
\text { Variance } \\
(\mu \mathrm{m} \text { sqr.) }\end{array}$ & $\begin{array}{l}\text { Metrology } \\
\text { Error } \\
\text { Variance } \\
\text { ( } \mathrm{m} \text { m sqr.) }\end{array}$ & F Statistic & \begin{tabular}{|c|} 
Future \\
Manufacturing \\
Uncertainty \\
$(\mu \mathrm{m})$
\end{tabular} & $\begin{array}{c}\text { Expanded } \\
\text { Future } \\
\text { Manufacturing } \\
\text { Uncertainty } \\
(\mu \mathrm{m}) \\
\end{array}$ \\
\hline 3 & 1371.01 & 0.74 & 1844.87 & 37.90 & 75.80 \\
\hline 26 & 1376.53 & 0.75 & 1846.50 & 37.97 & 75.95 \\
\hline 25 & 1299.86 & 0.86 & 1507.01 & 36.90 & 73.80 \\
\hline 24 & 1585.27 & 0.64 & 2464.64 & 40.75 & 81.50 \\
\hline 23 & 2489.11 & 8.26 & 301.28 & 51.07 & 102.13 \\
\hline 22 & 1456.46 & 1.34 & 1084.26 & 39.06 & 78.12 \\
\hline 21 & 1583.96 & 0.94 & 1682.07 & 40.74 & 81.47 \\
\hline 20 & 1388.55 & 0.40 & 3461.30 & 38.14 & 76.28 \\
\hline 19 & 1399.56 & 0.49 & 2863.77 & 38.29 & 76.58 \\
\hline 18 & 1959.60 & 0.84 & 2338.42 & 45.31 & 90.62 \\
\hline 17 & 1691.96 & 0.53 & 3167.08 & 42.10 & 84.20 \\
\hline 16 & 1983.36 & 0.91 & 2186.34 & 45.58 & 91.17 \\
\hline 15 & 2410.27 & 0.98 & 2455.54 & 50.25 & 100.50 \\
\hline 14 & 1950.38 & 0.89 & 2186.49 & 45.20 & 90.40 \\
\hline 13 & 1985.83 & 75.08 & 26.45 & 45.61 & 91.22 \\
\hline 12 & 1819.30 & 46.86 & 38.82 & 43.66 & 87.31 \\
\hline 11 & 1576.95 & 1.40 & 1127.49 & 40.65 & 81.29 \\
\hline 10 & 1695.11 & 1.25 & 1359.27 & 42.14 & 84.28 \\
\hline 9 & 1924.78 & 0.68 & 2840.90 & 44.90 & 89.81 \\
\hline 8 & 1765.56 & 1.19 & 1477.68 & 43.01 & 86.01 \\
\hline 7 & 1445.01 & 1.03 & 1397.68 & 38.91 & 77.82 \\
\hline 6 & 1429.39 & 0.99 & 1449.70 & 38.70 & 77.39 \\
\hline 5 & 1310.32 & 0.86 & 1530.73 & 37.05 & 74.10 \\
\hline 4 & 1539.39 & 0.98 & 1578.21 & 40.16 & 80.32 \\
\hline
\end{tabular}

Table B.6.: Summary Analysis of Variances for Y-Errors for all Peripheral Drilled Holes along with Manufacturing Uncertainties. 


\begin{tabular}{|c|c|c|c|c|c|}
\hline \multicolumn{6}{|c|}{ Analysis of Variance Summary } \\
\hline \multicolumn{6}{|c|}{ Milled Hole, X-Error } \\
\hline Hole \# & $\begin{array}{l}\text { Manufacturing } \\
\text { Error } \\
\text { Variance } \\
\text { ( } \mu \mathrm{m} \text { sqr.) }\end{array}$ & $\begin{array}{l}\text { Metrology } \\
\text { Error } \\
\text { Variance } \\
(\mu \mathrm{m} \text { sqr.) }\end{array}$ & F Statistic & $\begin{array}{c}\text { Future } \\
\text { Manufacturing } \\
\text { Uncertainty } \\
(\mu \mathrm{m})\end{array}$ & $\begin{array}{c}\text { Expanded } \\
\text { Future } \\
\text { Manufacturing } \\
\text { Uncertainty } \\
(\mu / \mathrm{m}) \\
\end{array}$ \\
\hline 3 & 86.92 & 1.39 & 62.72 & 9.54 & 19.08 \\
\hline 26 & 102.83 & 1.74 & 59.15 & 10.38 & 20.76 \\
\hline 25 & 110.68 & 1.12 & 99.11 & 10.77 & 21.54 \\
\hline 24 & 132.55 & 2.39 & 55.52 & 11.78 & 23.57 \\
\hline 23 & 142.90 & 1.04 & 137.71 & 12.24 & 24.47 \\
\hline 22 & 179.14 & 0.84 & 213.70 & 13.70 & 27.40 \\
\hline 21 & 186.62 & 1.08 & 172.20 & 13.98 & 27.97 \\
\hline 20 & 166.98 & 1.03 & 162.65 & 13.23 & 26.45 \\
\hline 19 & 191.99 & 0.87 & 220.33 & 14.18 & 28.36 \\
\hline 18 & 168.87 & 1.22 & 138.57 & 13.30 & 26.60 \\
\hline 17 & 196.49 & 0.95 & 207.73 & 14.35 & 28.69 \\
\hline 16 & 189.82 & 1.34 & 141.98 & 14.10 & 28.20 \\
\hline 15 & 202.31 & 1.92 & 105.31 & 14.56 & 29.12 \\
\hline 14 & 176.59 & 1.05 & 168.53 & 13.60 & 27.20 \\
\hline 13 & 189.78 & 1.36 & 139.68 & 14.10 & 28.20 \\
\hline 12 & 171.24 & 1.17 & 145.87 & 13.39 & 26.79 \\
\hline 11 & 211.42 & 15.68 & 13.48 & 14.88 & 29.76 \\
\hline 10 & 172.01 & 1.46 & 117.85 & 13.42 & 26.85 \\
\hline 9 & 158.37 & 0.83 & 189.96 & 12.88 & 25.76 \\
\hline 8 & 166.44 & 1.02 & 163.41 & 13.20 & 26.41 \\
\hline 7 & 136.10 & 1.70 & 80.22 & 11.94 & 23.88 \\
\hline 6 & 109.39 & 1.75 & 62.60 & 10.71 & 21.41 \\
\hline 5 & 102.46 & 1.27 & 80.62 & 10.36 & 20.72 \\
\hline 4 & 118.15 & 2.48 & 47.70 & 11.13 & 22.25 \\
\hline
\end{tabular}

Table B.7.: Summary Analysis of Variances for X-Errors for all Peripheral Milled Holes along with Manufacturing Uncertainties. 


\begin{tabular}{|c|c|c|c|c|c|}
\hline \multicolumn{6}{|c|}{ Analysis of Variance Summary } \\
\hline \multicolumn{6}{|c|}{ Milled Hole, Y-Error } \\
\hline Hole \# & $\begin{array}{c}\text { Manufacturing } \\
\text { Error } \\
\text { Variance } \\
\text { (um sqr.) }\end{array}$ & $\begin{array}{l}\text { Metrology } \\
\text { Error } \\
\text { Variance } \\
\text { ( } \mathrm{m} \text { sqr.) }\end{array}$ & F Statistic & \begin{tabular}{|c|} 
Future \\
Manufacturing \\
Uncertainty \\
$(\mu \mathrm{m})$
\end{tabular} & $\begin{array}{c}\text { Expanded } \\
\text { Future } \\
\text { Manufacturing } \\
\text { Uncertainty } \\
(\mu \mathrm{m}) \\
\end{array}$ \\
\hline 3 & 80.80 & 0.30 & 270.04 & 9.20 & 18.40 \\
\hline 26 & 78.77 & 0.29 & 270.10 & 9.08 & 18.17 \\
\hline 25 & 91.95 & 0.24 & 387.66 & 9.81 & 19.63 \\
\hline 24 & 104.62 & 1.07 & 97.51 & 10.47 & 20.94 \\
\hline 23 & 125.93 & 4.42 & 28.50 & 11.49 & 22.97 \\
\hline 22 & 114.74 & 0.82 & 140.68 & 10.96 & 21.93 \\
\hline 21 & 128.85 & 0.54 & 239.85 & 11.62 & 23.24 \\
\hline 20 & 168.60 & 0.31 & 550.40 & 13.29 & 26.58 \\
\hline 19 & 183.26 & 0.46 & 400.33 & 13.86 & 27.71 \\
\hline 18 & 167.01 & 0.34 & 490.36 & 13.23 & 26.45 \\
\hline 17 & 211.27 & 0.21 & 1020.07 & 14.88 & 29.75 \\
\hline 16 & 288.84 & 0.29 & 1010.57 & 17.40 & 34.79 \\
\hline 15 & 417.45 & 0.33 & 1269.35 & 20.91 & 41.82 \\
\hline 14 & 371.76 & 1.43 & 259.19 & 19.73 & 39.47 \\
\hline 13 & 427.54 & 113.29 & 3.77 & 21.16 & 42.33 \\
\hline 12 & 262.69 & 0.36 & 726.60 & 16.59 & 33.18 \\
\hline 11 & 255.97 & 0.27 & 960.45 & 16.38 & 32.75 \\
\hline 10 & 270.35 & 0.74 & 367.71 & 16.83 & 33.66 \\
\hline 9 & 274.91 & 0.19 & 1483.63 & 16.97 & 33.94 \\
\hline 8 & 224.23 & 0.27 & 833.03 & 15.33 & 30.65 \\
\hline 7 & 157.35 & 0.59 & 266.11 & 12.84 & 25.68 \\
\hline 6 & 106.69 & 0.64 & 166.11 & 10.57 & 21.14 \\
\hline 5 & 99.46 & 0.41 & 242.57 & 10.21 & 20.42 \\
\hline 4 & 108.00 & 0.34 & 316.19 & 10.64 & 21.27 \\
\hline
\end{tabular}

Table B.8.: Summary Analysis of Variances for Y-Errors for all Peripheral Milled Holes along with Manufacturing Uncertainties. 


\section{APPENDIX C: Analysis of Variance for Selected Hole Centers}

This appendix contains the analysis of variance tables for the CMM measurements of the centers of the three drilled and milled holes number 3,9 and 15.

\begin{tabular}{|c|c|c|c|c|c|c|c|c|}
\hline \multicolumn{9}{|c|}{$\begin{array}{l}\text { Analysis of Vaniance Table } \\
\text { Drilled Hole \# } 3\end{array}$} \\
\hline $\begin{array}{l}\text { Part } \\
\#\end{array}$ & \multicolumn{5}{|c|}{$\begin{array}{l}\text { X-Measurement Replications } \\
\qquad(\mu \mathrm{m})\end{array}$} & \multirow{2}{*}{$\begin{array}{c}\text { Mean } \\
\text { (Manufacturing } \\
\text { Error, } \mu \mathrm{m} \text { ) }\end{array}$} & \multirow{2}{*}{$\begin{array}{l}\text { Degrees-of- } \\
\text { Freedom }\end{array}$} & \multirow{2}{*}{$\begin{array}{c}\text { Standard } \\
\text { Deviation } \\
\text { (Metrology } \\
\begin{array}{c}\text { Uncertainty, } \\
\text { Hm) }\end{array} \\
1.25925\end{array}$} \\
\hline 1 & 8.388 & 6.124 & 4.94 & 5.996 & 6.177 & & & \\
\hline 2 & -3.861 & -3.593 & -3.191 & -1.589 & -3.945 & -3.236 & 4 & 0.966609 \\
\hline 3 & 21.613 & 22.459 & 19.837 & 20.361 & 21.42 & 21.138 & 4 & 1.042298 \\
\hline 4 & 5.404 & 4.218 & 5.734 & 4.302 & 4.889 & 4.91 & 4 & 0.665768 \\
\hline 5 & 0.88 & 2.705 & & & & 1.792 & 1 & 1.29003 \\
\hline 6 & -0.417 & -0.191 & & & & -0.304 & 1 & 0.159821 \\
\hline 7 & -11.848 & -12.696 & & & & -12.272 & 1 & 0.599499 \\
\hline 8 & -21.173 & -21.07 & & & & -21.122 & 1 & 0.072832 \\
\hline 9 & -8.784 & -11.428 & & & & -10.106 & 1 & 1.869298 \\
\hline 10 & -6.097 & -4.546 & & & & -5.322 & 1 & 1.096493 \\
\hline 11 & 5.164 & 2.433 & & & & 3.798 & 1 & 1.931337 \\
\hline 12 & 17.726 & 18.735 & & & & 18.23 & 1 & 0.713464 \\
\hline 13 & -51.234 & -52.277 & & & & -51.755 & 1 & 0.73706 \\
\hline$\overline{14}$ & 6.463 & 6.073 & & & & 6.268 & 1 & 0.275809 \\
\hline 15 & 2.642 & 1.146 & & & & 1.894 & 1 & 1.05738 \\
\hline 16 & -0.773 & 1.325 & & & & 0.276 & 1 & 1.483569 \\
\hline 17 & -2.42 & -1.887 & & & & -2.154 & 1 & 0.376961 \\
\hline 18 & 8.539 & 10.633 & & & & 9.586 & 1 & 1.480194 \\
\hline 19 & 29.596 & 29.434 & & & & 29.515 & 1 & 0.114643 \\
\hline 27 & 17.431 & 19.826 & & & & 18.629 & 1 & 1.693294 \\
\hline \multirow[t]{5}{*}{21} & 13.722 & 14.055 & & & & 13.889 & 1 & 0.235346 \\
\hline & \multicolumn{6}{|c|}{ Mean Manufacturing Error (Grand Mean) = } & & \\
\hline & \multirow{2}{*}{\multicolumn{6}{|c|}{$\begin{array}{l}\text { Variance of the Manufacturing Error (Variance of the Means) = } \\
\text { Vaniance of the Metrology Uncertainty (Variance of the Standard Deviations) = }\end{array}$}} & 640.886701 & $\mu \mathrm{m}$ sqr. \\
\hline & & & & & & & & 1.102909 \\
\hline & F Statistic & & 581.0877 & & & & & \\
\hline
\end{tabular}

Table C1: Analysis of Variance Table for X-Measurements of Drilled Hole \# 3 


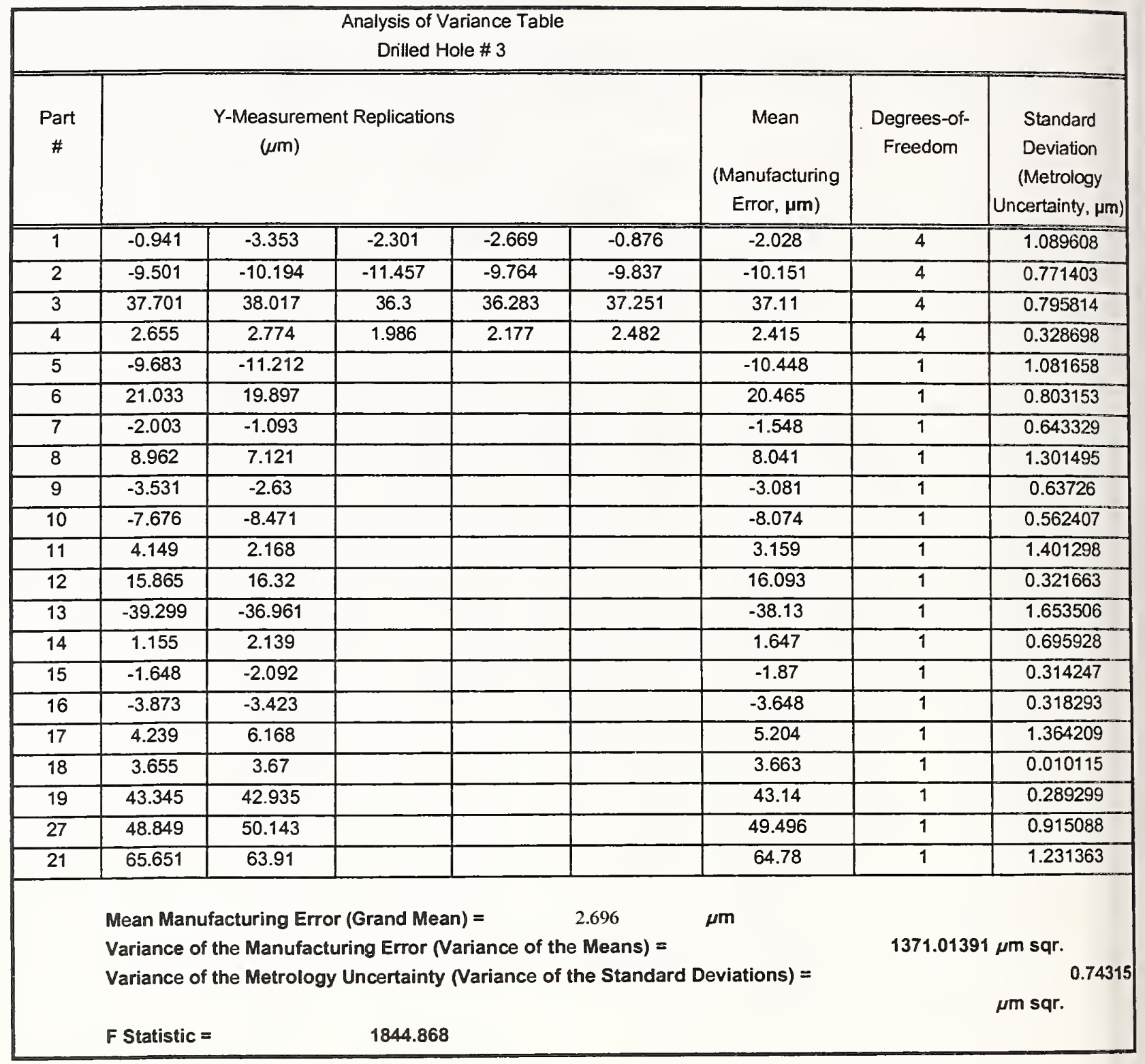

Table C2: Analysis of Variance Table for Y-Measurements of Drilled Hole \#3 


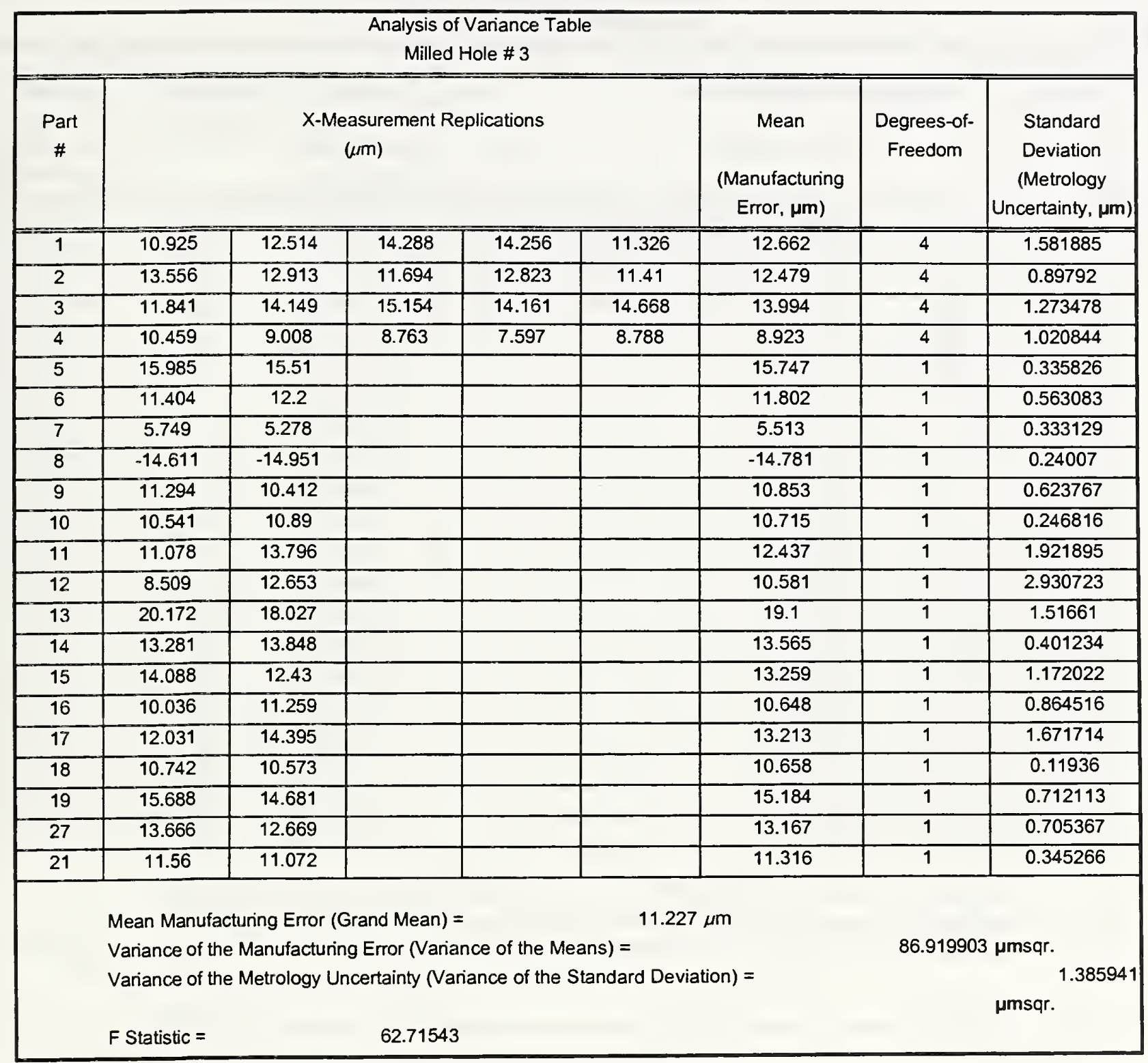

Table C3: Analysis of Variance Table for X-Measurements of Milled Hole \#3 


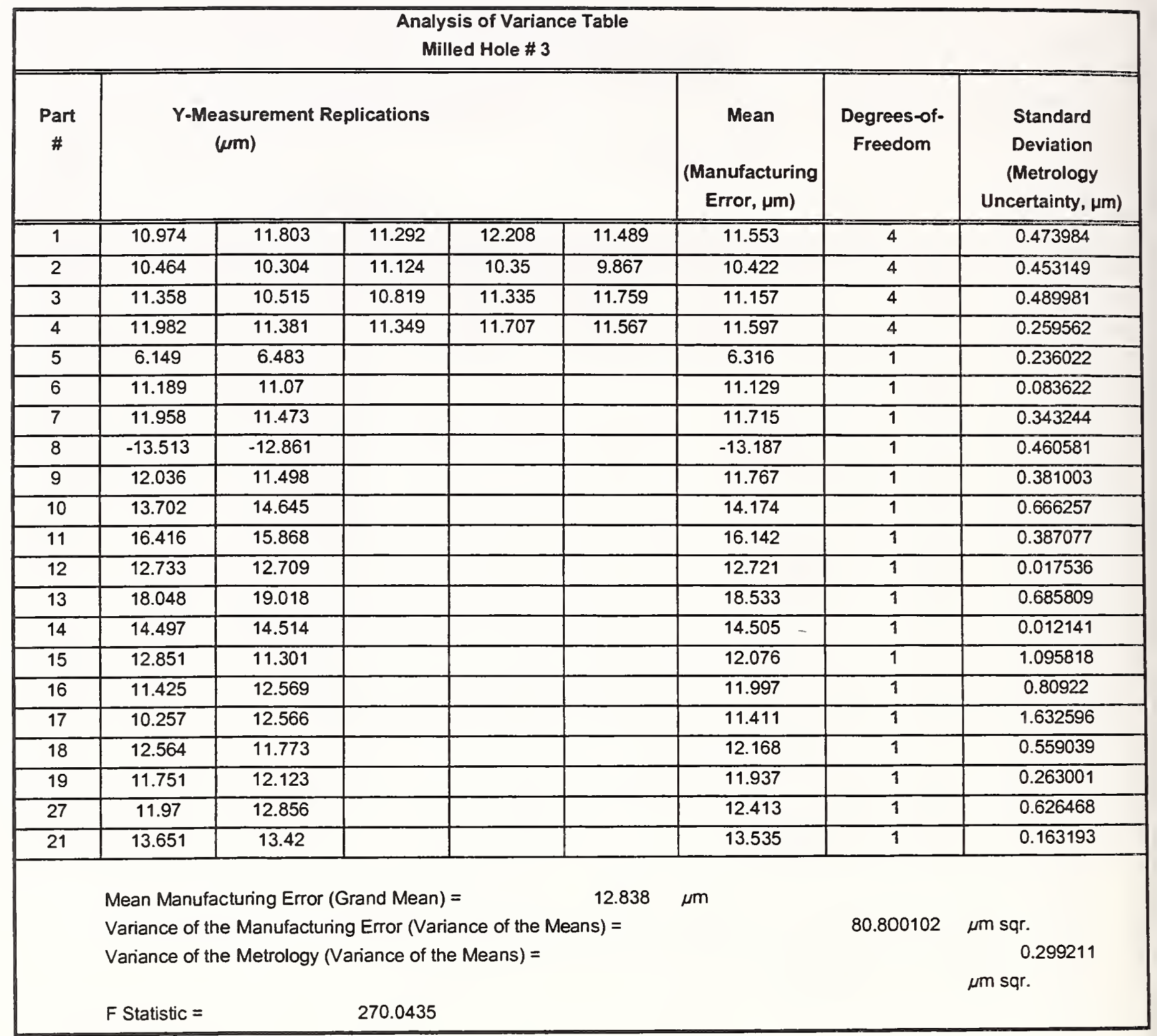

Table C4: Analysis of Variance Table for Y-Measurements of Milled Hole \#3. 


\begin{tabular}{|c|c|c|c|c|c|c|c|c|}
\hline \multicolumn{8}{|c|}{$\begin{array}{c}\text { Analysis of Vaniance Table } \\
\text { Drilled Hole \# } 9\end{array}$} & \multirow[b]{2}{*}{$\begin{array}{c}\text { Standard } \\
\text { Deviation } \\
\text { (Metrology } \\
\text { Uncertainty, } \mu \mathrm{m} \text { ) }\end{array}$} \\
\hline $\begin{array}{c}\text { Part } \\
\#\end{array}$ & \multicolumn{4}{|c|}{$\begin{array}{l}\text { X-Measurement Replications } \\
(\mu \mathrm{m})\end{array}$} & & $\begin{array}{c}\text { Mean } \\
\text { (Manufacturing } \\
\text { Errors, } \boldsymbol{\mu m} \text { ) }\end{array}$ & $\begin{array}{l}\text { Degrees-of- } \\
\text { Freedom }\end{array}$ & \\
\hline 1 & 7.837 & 7.521 & 7.277 & 8.075 & 6.667 & 7.475 & $\overline{4}$ & 0.544309 \\
\hline 2 & 4.903 & $5 . \overline{352}$ & 5.411 & 4.946 & 6.571 & 5.437 & 4 & 0.674551 \\
\hline 3 & 21.018 & 20.875 & 19.423 & 22.19 & 22.438 & 21.189 & 4 & 1.205255 \\
\hline 4 & 3.952 & 2.542 & 3.057 & 1.662 & 3.372 & 2.917 & 4 & 0.867943 \\
\hline 5 & 7.962 & 9.512 & & & & 8.737 & 1 & 1.095818 \\
\hline 6 & 4.37 & 5.79 & & & & 5.08 & 1 & 1.004106 \\
\hline 7 & 3.724 & 3.736 & & & & 3.73 & 1 & 0.008092 \\
\hline 8 & -13.96 & -14.961 & & & & -14.461 & 1 & 0.708068 \\
\hline 9 & 3.099 & 1.667 & & & & 2.383 & 1 & 1.012873 \\
\hline 10 & -2.782 & -3.345 & & & & -3.064 & 1 & 0.398541 \\
\hline 11 & 2.476 & 3.744 & & & & 3.11 & 1 & 0.896884 \\
\hline 12 & -16.38 & -15.505 & & & & -15.943 & 1 & 0.619051 \\
\hline 13 & -43.098 & -41.484 & & & & -42.291 & 1 & 1.141673 \\
\hline 14 & 4.272 & 2.942 & & & & 3.607 & 1 & 0.940718 \\
\hline 15 & 7.968 & 8.286 & & & & 8.127 & 1 & 0.224558 \\
\hline 16 & 3.741 & -0.134 & & & & 1.803 & 1 & 2.740556 \\
\hline 17 & 10.651 & 5.971 & & & & 8.311 & 1 & 3.30903 \\
\hline 18 & 0.651 & -0.635 & & & & 0.008 & 1 & 0.909698 \\
\hline 19 & 29.827 & 30.695 & & & & 30.261 & 1 & 0.613656 \\
\hline 27 & 27.004 & 26.467 & & & & 26.736 & 1 & 0.37966 \\
\hline 21 & 15.547 & 16.31 & & & & 15.928 & 1 & 0.53948 \\
\hline & Mean Man & acturing Err & Grand Me & & 4.985 & $\mu \mathrm{m}$ & & \\
\hline & Variance 0 & he Manufac & ng Error ( & ince of $t$ & eans) = & & 511.4417 & $\mu \mathrm{m}$ sqr. \\
\hline & Variance 0 & he Metrolog & Incertainty & niance of & Standarc & Deviations) = & & $\begin{array}{l}1.189403 \\
\mu \mathrm{m} \text { sqr. }\end{array}$ \\
\hline & F Statistic & & 429.9987 & & & & & \\
\hline
\end{tabular}

Table C5: Analysis of Variance Table for X-Measurements of Drilled Hole \#9 


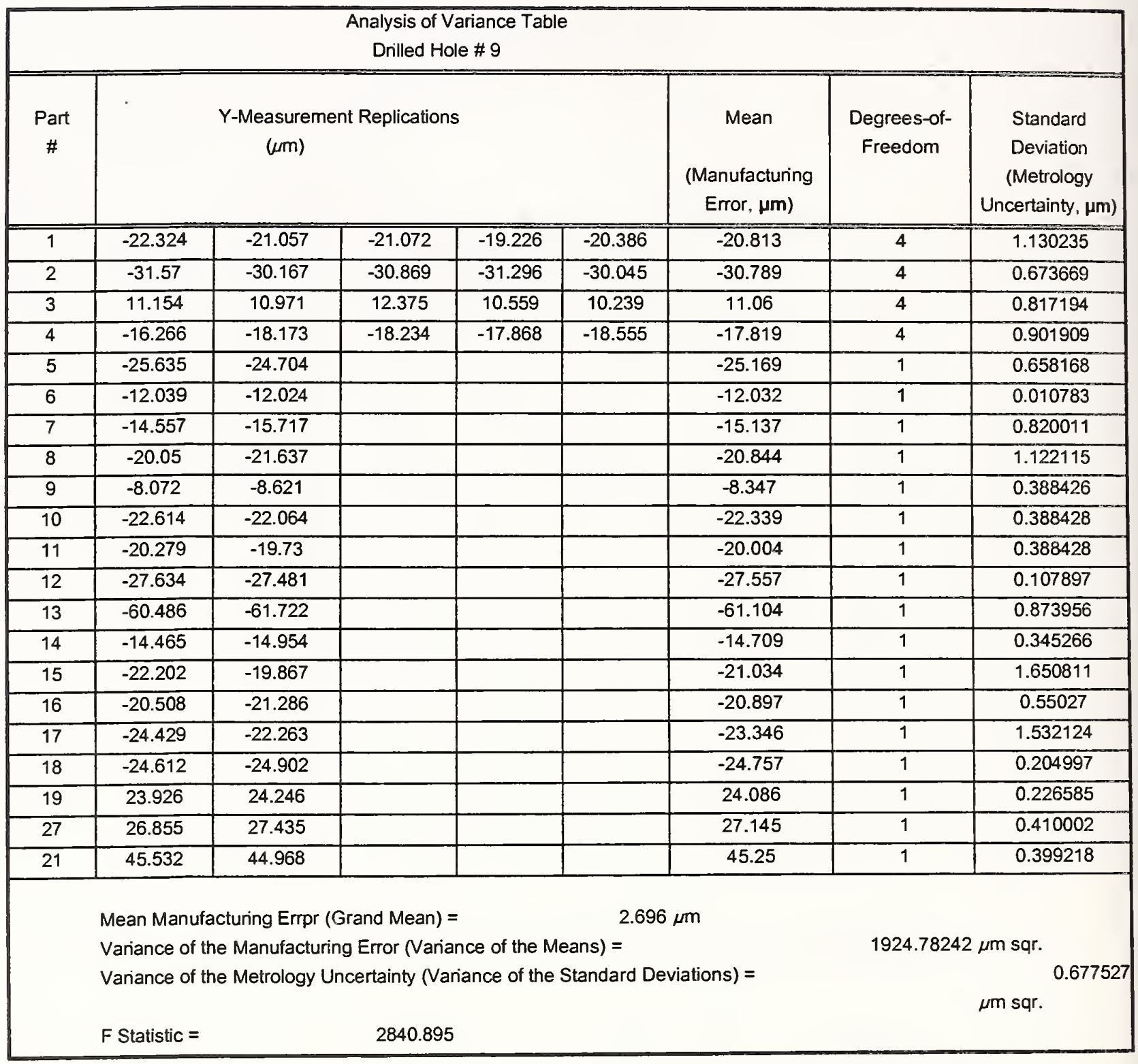

Table C6: Analysis of Variance Table for Y-Measurements of Drilled Hole \#9. 


\begin{tabular}{|c|c|c|c|c|c|c|c|c|}
\hline \multicolumn{6}{|c|}{$\begin{array}{l}\text { Analysis of Vaniance Table } \\
\text { Milled Hole \# } 9\end{array}$} & & & \\
\hline $\begin{array}{c}\text { Part } \\
\#\end{array}$ & \multicolumn{4}{|c|}{$\begin{array}{l}\text { X-Measurement Replications } \\
\text { (um) }\end{array}$} & & $\begin{array}{c}\text { Mean } \\
\text { (Manufacturing } \\
\text { Error, } \mu \mathrm{m} \text { ) }\end{array}$ & $\begin{array}{l}\text { Degrees-of- } \\
\text { Freedom }\end{array}$ & $\begin{array}{c}\text { Standard } \\
\text { Deviation } \\
\text { (Metrology } \\
\text { Uncertainty, } \mu \mathrm{m} \text { ) }\end{array}$ \\
\hline 1 & 16.844 & 17.036 & 15.541 & 14.392 & 17.315 & 16.226 & 4 & 1.230574 \\
\hline 2 & 12.421 & 11.37 & 11.843 & 10.819 & 11.881 & 11.667 & 4 & 0.60236 \\
\hline 3 & 13.545 & 13.164 & 14.556 & 12.291 & 12.893 & 13.29 & 4 & 0.842547 \\
\hline 4 & 16.253 & 14.369 & 17.07 & 17.63 & 17.078 & 16.48 & 4 & 1.278243 \\
\hline 5 & 20.363 & 21.506 & & & & 20.935 & 1 & 0.808548 \\
\hline 6 & 20.476 & 19.172 & & & & 19.824 & 1 & 0.922513 \\
\hline 7 & 5.013 & 6.687 & & & & 5.85 & 1 & 1.184158 \\
\hline 8 & -9.427 & -10.124 & & & & -9.776 & 1 & 0.492952 \\
\hline 9 & 16.628 & 17.302 & & & & 16.965 & 1 & 0.476088 \\
\hline 10 & 9.825 & $9 . \overline{42}$ & & & & 9.623 & 1 & 0.285924 \\
\hline 11 & 13.21 & 15.644 & & & & 14.427 & 1 & 1.720935 \\
\hline 12 & -1.594 & -0.473 & & & & -1.033 & 1 & 0.792361 \\
\hline 13 & 25.29 & 26.453 & & & & 25.871 & 1 & 0.822705 \\
\hline 14 & 23.735 & 23.692 & & & & 23.714 & 1 & 0.030349 \\
\hline 15 & 21.171 & 22.602 & & & & 21.886 & 1 & 1.012195 \\
\hline 16 & 6.42 & 6.26 & & & & 6.34 & 1 & 0.113291 \\
\hline 17 & 19.974 & 19.786 & & & & 19.88 & 1 & 0.132844 \\
\hline 18 & 17.862 & 16.369 & & & & 17.116 & 1 & 1.056029 \\
\hline 19 & 25.863 & 25.488 & & & & 25.675 & 1 & 0.265017 \\
\hline 27 & 20.897 & 19.802 & & & & 20.349 & 1 & 0.774155 \\
\hline 21 & 17.456 & 17.815 & & & & 17.635 & 1 & 0.253561 \\
\hline & Mean Manu & turing Error & and Mear & & 14.7 & & & \\
\hline & Variance of & Manufactu & Error Na & $e$ of the 1 & )$=$ & & 158.37362 & $\mu \mathrm{m}$ sqr. \\
\hline & Variance of & Metrology & sertainty ( & ice of the & idard De & $n s)=$ & & $\mu$ m sqr. $\quad 0.833741$ \\
\hline & F Statistic $=$ & & 189.95 & & & & & \\
\hline
\end{tabular}

Table C7: Analysis of Variance Table for X-Measurements of Milled Hole \#9. 


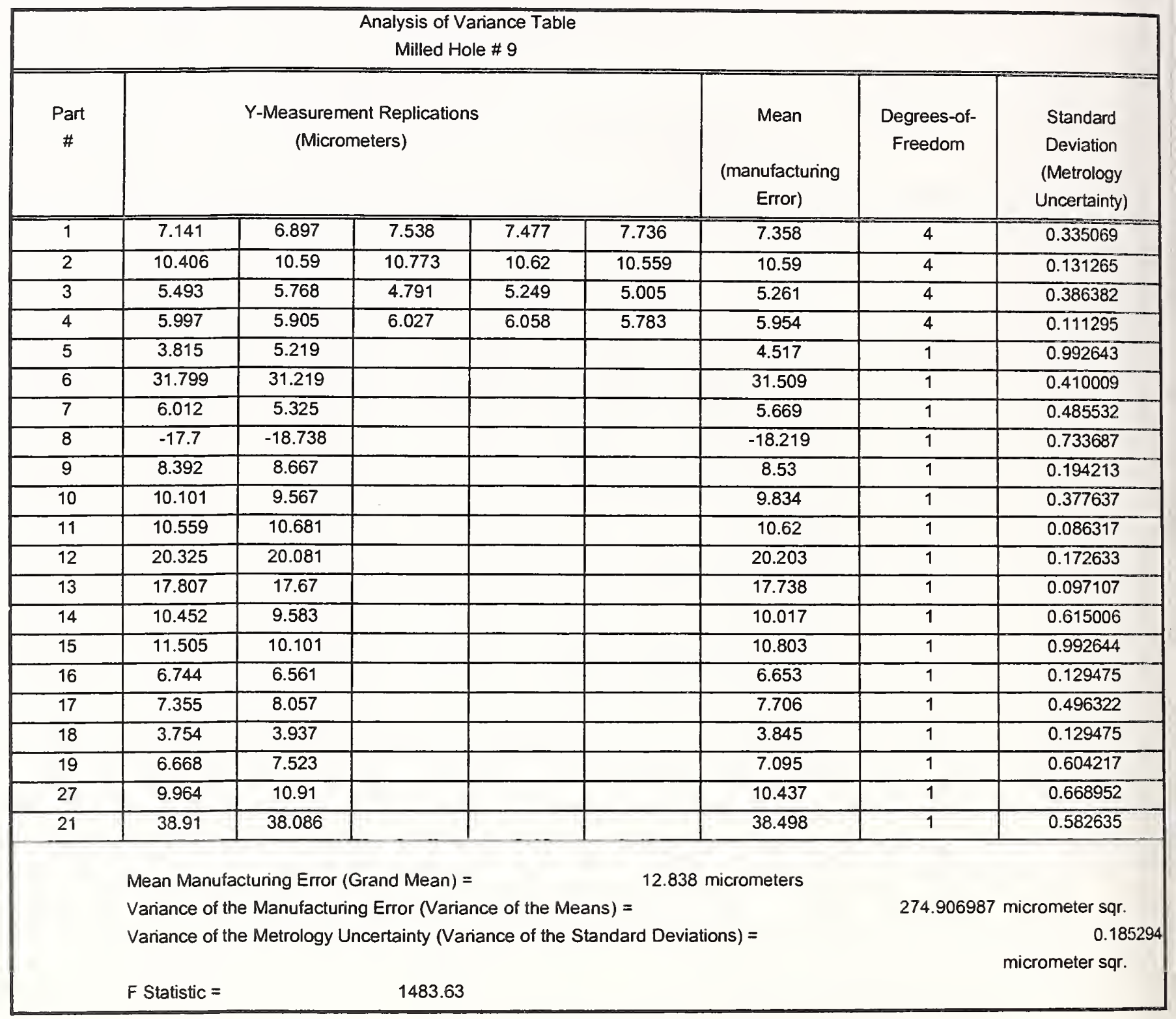

Table C8: Analysis of Variance Table for Y-Measurements of Milled Hole \#9. 


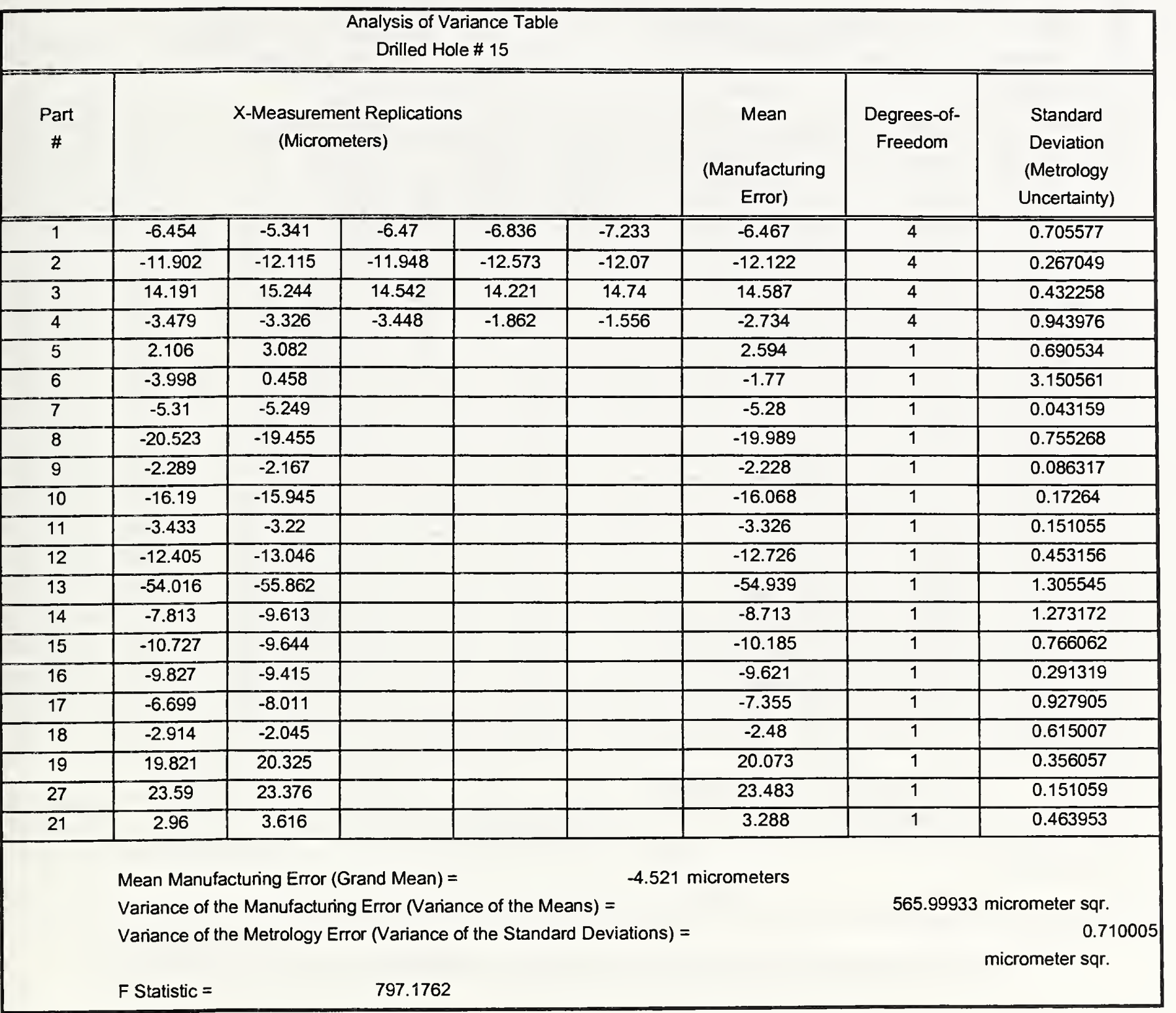

Table C9: Analysis of Variance Table for X-Measurements of Drilled Hole \#15. 


\begin{tabular}{|c|c|c|c|c|c|c|c|c|}
\hline \multicolumn{6}{|c|}{$\begin{array}{l}\text { Analysis of Variance Table } \\
\text { Drilled Hole \# } 15\end{array}$} & & & \\
\hline \multirow{2}{*}{$\begin{array}{c}\text { Part } \\
\# \\
\\
1\end{array}$} & \multicolumn{5}{|c|}{$\begin{array}{l}\text { Y-Measurement Replications } \\
\text { (Micrometers) }\end{array}$} & \multirow{2}{*}{$\begin{array}{c}\text { Mean } \\
\text { (Manufacturing } \\
\text { Error) }\end{array}$} & \multirow{2}{*}{\begin{tabular}{|c|}
$\begin{array}{c}\text { Degrees-of- } \\
\text { Freedom }\end{array}$ \\
4
\end{tabular}} & \multirow{2}{*}{$\begin{array}{c}\begin{array}{c}\text { Standard } \\
\text { Deviation } \\
\text { (Metrology } \\
\text { Uncertainty) }\end{array} \\
0.958113\end{array}$} \\
\hline & -30.075 & $2-29.633$ & -28.046 & -27.893 & "-28.793 & & & \\
\hline 2 & -29.053 & -29.404 & -29.099 & -29.022 & -29.221 & -29.16 & 4 & 0.155985 \\
\hline 3 & 25.436 & 25.787 & 21.469 & 26.031 & 24.796 & 24.704 & 4 & 1.867158 \\
\hline 4 & -31.54 & -31.403 & -31.769 & -31.174 & -31.418 & -31.461 & 4 & 0.217243 \\
\hline 5 & -29.968 & -29.343 & & & & -29.655 & 1 & 0.442373 \\
\hline 6 & -20.737 & -21.133 & & & & -20.935 & 1 & 0.28053 \\
\hline 7 & -25.879 & -25.055 & & & & -25.467 & 1 & 0.582642 \\
\hline 8 & -19.318 & -19.867 & & & & -19.592 & 1 & 0.388421 \\
\hline 9 & -27.069 & -27.847 & & & & -27.458 & 1 & 0.55027 \\
\hline 10 & -25.62 & -25.803 & & & & -25.711 & 1 & 0.129471 \\
\hline 11 & -23.239 & -23.651 & & & & -23.445 & 1 & 0.291314 \\
\hline 12 & -6.256 & -7.462 & & & & -6.859 & 1 & 0.852378 \\
\hline$\overline{13}$ & -63.965 & -61.783 & & & & -62.874 & 1 & 1.542907 \\
\hline 14 & -18.021 & -18.478 & & & & -18.25 & 1 & 0.323685 \\
\hline 15 & -20.981 & -22.766 & & & & -21.873 & 1 & 1.262384 \\
\hline 16 & -22.064 & -21.805 & & & & -21.935 & 1 & 0.183423 \\
\hline 17 & -28.229 & -28.076 & & & & -28.152 & 1 & 0.107897 \\
\hline 17 & -30.289 & -26.321 & & & & -28.305 & 1 & 2.805298 \\
\hline 19 & 22.583 & 23.163 & & & & 22.873 & 1 & 0.410002 \\
\hline 27 & 31.479 & 32.15 & & & & 31.815 & 1 & 0.474744 \\
\hline \multirow[t]{5}{*}{21} & 23.407 & 24.048 & & & & 23.727 & 1 & 0.453164 \\
\hline & \multicolumn{6}{|c|}{ Mean Manufacturing Error (Grand Mean) $=\quad 2.696$} & & \\
\hline & \multicolumn{6}{|c|}{ Variance of the Manufacturing Error (Variance of the Means) = } & 2410.274 & micrometer sqr. \\
\hline & \multicolumn{6}{|c|}{ Variance of the Metrology Uncertainty (Variance of the Standard Deviations) $=$} & & 0.981564 \\
\hline & F Statistic $=$ & & 2455.544 & & & & & \\
\hline
\end{tabular}

Table C10: Analysis of Variance Table for Y-Measurements of Drilled Hole \#15. 
Analysis of Variance Table

Milled Hole \# 15

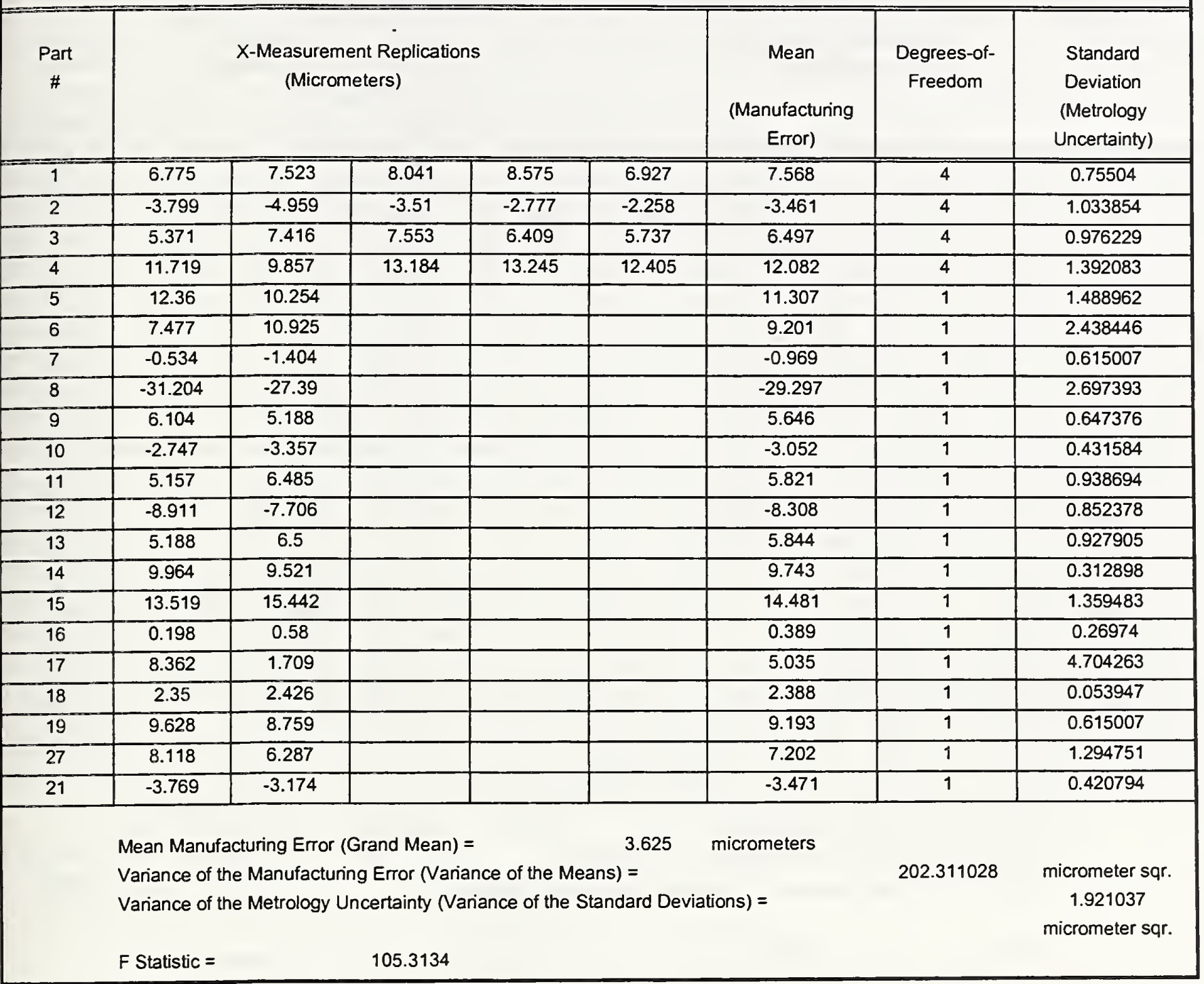

Table C11: Analysis of Variance Table for X-Measurements of Milled Hole \#15. 


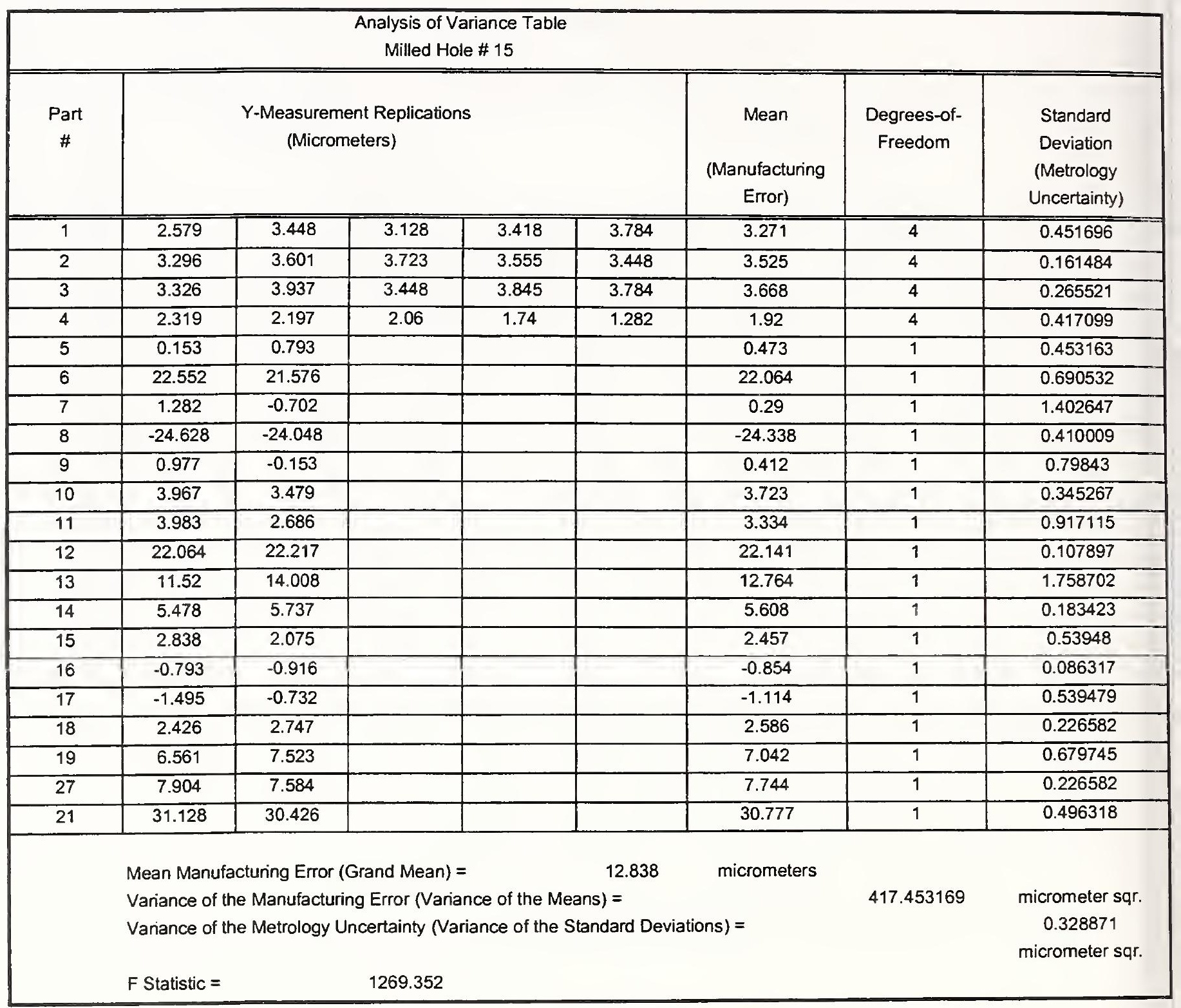

Table C12: Analysis of Variance Table for Y-Measurements of Milled Hole \#15. 


\section{APPENDIX D: Derivation of the Variance of Length Equation}

In this appendix we derive the formula (35). From equation (33), the quantity $L$ is implicitly a function of the four error terms $E_{x}\left(x_{1}, y_{1}\right), E_{x}\left(x_{2}, y_{2}\right), E_{y}\left(x_{1}, y_{1}\right), E_{y}\left(x_{2}, y_{2}\right)$. $L$ can be expanded as a Taylor series around $(0,0,0,0)$ to the first order as

$$
\begin{aligned}
L\left(E_{x}\left(x_{1}, y_{1}\right), E_{x}\left(x_{2}, y_{2}\right), E_{y}\left(x_{1}, y_{1}\right), E_{y}\left(x_{2}, y_{2}\right)\right)= & L(0,0,0,0) \\
& +\frac{\partial L(0,0,0,0)}{\partial E_{x}\left(x_{1}, y_{1}\right)} E_{x}\left(x_{1}, y_{1}\right) \\
& +\frac{\partial L(0,0,0,0)}{\partial E_{x}\left(x_{2}, y_{2}\right)} E_{x}\left(x_{2}, y_{2}\right) \\
& +\frac{\partial L(0,0,0,0)}{\partial E_{y}\left(x_{1}, y_{1}\right)} E_{y}\left(x_{1}, y_{1}\right) \\
& +\frac{\partial L(0,0,0,0)}{\partial E_{y}\left(x_{2}, y_{2}\right)} E_{y}\left(x_{2}, y_{2}\right)
\end{aligned}
$$

By implicit differentiation of (33)

$$
\begin{aligned}
L\left(E_{x}\left(x_{1}, y_{1}\right), E_{x}\left(x_{2}, y_{2}\right), E_{y}\left(x_{1}, y_{1}\right), E_{y}\left(x_{2}, y_{2}\right)\right) & \frac{\partial L}{\partial E_{x}\left(x_{1}, y_{1}\right)}\left(E_{x}\left(x_{1}, y_{1}\right), E_{x}\left(x_{2}, y_{2}\right), E_{y}\left(x_{1}, y_{1}\right), E_{y}\left(x_{2}, y_{2}\right)\right) \\
& =\left(x_{1}+E_{x}\left(x_{1}, y_{1}\right)-x_{2}-E_{x}\left(x_{2}, y_{2}\right)\right)
\end{aligned}
$$

Note that, comparing equations (33) and (34), it is clear that $L_{0}=L(0,0,0,0)$. At $(0,0,0$, 0) equation (D2) becomes

$$
L_{0} \frac{\partial L(0,0,0,0)}{\partial E_{x}\left(x_{1}, y_{1}\right)}=\left(x_{1}-x_{2}\right)
$$

By repeating this argument for each of the four error terms and dividing by $L_{0}$,

$$
\begin{aligned}
& \frac{\partial L}{\partial E_{x}\left(x_{1}, y_{1}\right)}=\frac{\left(x_{1}-x_{2}\right)}{L_{0}} \\
& \frac{\partial L}{\partial E_{x}\left(x_{2}, y_{2}\right)}=-\frac{\left(x_{1}-x_{2}\right)}{L_{0}} \\
& \frac{\partial L}{\partial E_{y}\left(x_{1}, y_{1}\right)}=\frac{\left(y_{1}-y_{2}\right)}{L_{0}} \\
& \frac{\partial L}{\partial E_{y}\left(x_{2}, y_{2}\right)}=-\frac{\left(y_{1}-y_{2}\right)}{L_{0}}
\end{aligned}
$$


Introducing (D4) into (D1) one gets

$$
\begin{aligned}
L=L_{0}+\frac{\left(x_{1}-x_{2}\right)}{L_{0}} E_{x}\left(x_{1}, y_{1}\right) & -\frac{\left(x_{1}-x_{2}\right)}{L_{0}} E_{x}\left(x_{2}, y_{2}\right) \\
& +\frac{\left(y_{1}-y_{2}\right)}{L_{0}} E_{y}\left(x_{1}, y_{1}\right)-\frac{\left(y_{1}-y_{2}\right)}{L_{0}} E_{y}\left(x_{2}, y_{2}\right)
\end{aligned}
$$

Now, one can apply the sum of variance formula, using the fact that the variance of a constant is zero in order to get equation (35). 


\section{APPENDIX E: MACSYMA Program to Generate the Kinematic Model Error}

Equations

I* Construct the list of error components *I

list 1:[ezy,eyy,dxy,axy,exy,dyy,dzy]\$

list2:[ezx,eyx,dxx,exx,dyx,dzx,ezz]\$

list3:[eyz,dxz,axz,exz,dyz,ayz,dzz]\$

list:append(list 1, list2,list3)\$

$1 *$ Construct the homogeneous transformation of y relative to reference */

/* Ideal motion along $\mathrm{y} *$ I

row $1:[1,0,0,0] \$$

row2: $[0,1,0, y] \$$

row3: $[0,0,1,0] \$$

row4: $[0,0,0,1] \$$

rty:matrix(row1,row2,row3,row4)\$

I* Rotational and translational errors along y */

row $1:\left[1,-e z y, e y y, d x y-a x y^{*} y\right] \$$

row2:[ezy, $1,-$ exy,dyy] $\$$

row3:[-eyy,exy, $1, \mathrm{dzy}] \$$

row4: $[0,0,0,1] \$$

errty:matrix(row1,row2,row3, row4)\$

I* Final y motion relative to reference coordinates */

rty:rty.errty\$

$1 *$ Construct the homogeneous transformation of $\mathrm{x}$ relative to $\mathrm{y} * /$

* Ideal motion along $\mathrm{x} *$ /

row $1:[1,0,0, \mathrm{x}] \$$

row2: $[0,1,0,0] \$$

row3:[0,0,1,0]\$

row $4:[0,0,0,1] \$$

ytx:matrix(row 1 ,row2,row3,row4)\$

I* Rotational and translational errors along $\mathrm{x} *$ I

row1:[1,-ezx,eyx,dxx]\$

row2:[ezx,1,-exx,dyx]\$

row3:[-eyx,exx, $1, \mathrm{dzx}] \$$

row4:[0,0,0,1]\$

errytx:matrix(row1,row2,row3,row4)\$

$1 *$ Final error matrix of $\mathrm{x}$ rlative to y motion $* /$

ytx:ytx.errytx $\$$

$1 *$ Construct the relative position of the workpiece relative to $\mathrm{x} * /$

row $1:[1,0,0,-x] \$$

row2:[0,1,0,-y]\$

row3:[0,0,1,z]\$

row4: $[0,0,0,1] \$$

$\mathrm{xtw}$ :matrix(row 1 ,row2, row3, row4)\$ 
I* No rotational and translational error here */

/* Final error matrix of workpiece relative to the reference */

rtw:rty.ytx.xtw\$

$1 *$ Construct the motion of $\mathrm{z}$ relative to the reference system */

/* Ideal motion of $\mathrm{z} *$ /

row $1:[1,0,0,0] \$$

row $2:[0,1,0,0] \$$

row $3:[0,0,1, \mathrm{z}] \$$

row4: $[0,0,0,1] \$$

rtz:matrix(row 1 ,row2,row3,row4)\$

$1 *$ Rotational and translational errors of $\mathrm{z} * /$

row $1:[1,-e z z, e y z, d x z-a x z * z] \$$

row2:[ezz,1,-exz,dyz-ayz*z]\$

row3:[-eyz,exz, $1, \mathrm{dzz}] \$$

row4: $[0,0,0,1] \$$

errtz:matrix(row 1 ,row2,row3,row4)\$

$1 *$ Final error matrix of $\mathrm{z}$ relative to reference $* /$

rtz:rtz.erritz\$

I* Tool relative to $\mathrm{z} * /$

ztt:ident(4)\$

I* Final error matrix of tool relative to $\mathrm{z}$ /

rtt:rtz.ztt\$

$/ *$ Get the inverse of $\mathrm{rtt} * /$

rttinv:rtt^^-1\$

$1 *$ Compute the final error matrix */

err:rttinv.rtw\$

/* Linearize the displacement error terms by a first order Taylor Series about $0 *$ / ex:taylor(err[1,4],list, 0,1$)$;

ey:taylor(err[2,4], list, 0,1$)$;

ez:taylor(err[3,4],list,0,1); 


\section{APPENDIX F: Circle Fit Algorithm}

Before we describe the algorithm for computing the least squares fitting of a circle we need to introduce the notion of a symmetric positive definite (SPD) matrix. A real $n \times n$ matrix $A$ is symmetric if it equals its transpose, i.e. $A=A^{T}$. It is positive definite if $x^{T} A x>0$ for all n-vectors $x$. There are some useful properties of a SPD matrix. First of all the largest entry in absolute value falls on the main diagonal, all of whose entries are positive. Furthermore, if the matrix is symmetric and the main diagonal is positive and the main diagonal entry of each row is larger than the sum of the absolute values of all the other elements of that row then the matrix is SPD. This means that if we add a large enough positive multiple of the identity matrix to the original symmetric matrix, then we can make it SPD. This property plays a part in the algorithm below. Finally a SPD matrix $A$ can be factored as

$$
A=L L^{T}=R^{T} R
$$

where $L$ is a lower triangular matrix and $R$ is an upper triangular matrix. Either of these factorizations is called a Cholesky factorization. In terms of $L$ a matrix equation of the form

$$
A x=L L^{T} x=b
$$

can be solved in two steps by

$$
\begin{aligned}
& L v=b \\
& L^{T} x=v
\end{aligned}
$$

where $v$ is an intermediate vector. The algorithm for computing $L$ is relatively simple and can also be used to detect when $A$ is not SPD. This check is used in the circle fitting program. The Cholesky algorithm begins by setting

$$
L_{11}=\sqrt{A_{11}}
$$

Then going down the first column

$$
\begin{array}{r}
\text { for } i=2 \text { to } n \\
L_{i 1}=\frac{A_{i 1}}{L_{11}}
\end{array}
$$

For column $j=2$ to $n$ 


$$
\begin{gathered}
L_{j j}=\sqrt{A_{j j}-\sum_{k=1}^{j-1} L_{j k}^{2}} \\
\text { for } i=j+1 \text { to } n \\
L_{i j}=\frac{A_{i j}-\sum_{k=1}^{j-1} L_{i k} L_{j k}}{L_{j j}}
\end{gathered}
$$

The test on the positive definiteness of $A$ is done by checking whether a quantity under the square root sign is positive. If not then the main circle fitting algorithm is signaled that the matrix $A$ is not positive definite. For further discussion of the Cholesky factorization see Nash [30].

The circle fitting algorithm is a combination of Newton's Method and that of Marquardt - Levenberg. For the basic algorithm see Nash [30] and for stopping criteria see Dennis and Schnabel [33]. Start with a set of points in the plane $\left(x_{1}, y_{1}\right), \cdots,\left(x_{N}, y_{N}\right)$. Then define the residual functions

$$
R_{i}(a, b, r)=\left(x_{i}-a\right)^{2}+\left(y_{i}-b\right)^{2}-r^{2}
$$

where $(\mathrm{a}, \mathrm{b})$ is the center and $\mathrm{r}$ is the radius to be determined. In order to simplify notation let $p_{1}=a, p_{2}=b, p_{3}=r$. Let $\vec{p}=\left(p_{1}, p_{2}, p_{3}\right)^{T}$. Form the sum-of-squares function

$$
S(\vec{p})=\sum_{i=1}^{N}\left(R_{i}(\vec{p})\right)^{2}
$$

The object is to minimize $S$ over $a, b$, and $r$. At its minimum any constant multiple of the gradient of $S$ is zero. For notation, let

$$
\vec{g}(\vec{p})=\frac{1}{2} \vec{\nabla} S(\vec{p})
$$

The components of $\vec{g}(\vec{p})$ are given by

$$
\begin{aligned}
& g_{1}(\vec{p})=\sum_{i=1}^{N} R_{i}(\vec{p}) \frac{\partial R_{i}}{\partial p_{1}}(\vec{p})=\sum_{i=1}^{N}\left[\left(x_{i}-p_{1}\right)^{2}+\left(y_{i}-p_{2}\right)^{2}-p_{3}^{2}\right]\left[-2\left(x_{i}-p_{1}\right)\right] \\
& g_{2}(\vec{p})=\sum_{i=1}^{N} R_{i}(\vec{p}) \frac{\partial R_{i}}{\partial p_{2}}(\vec{p})=\sum_{i=1}^{N}\left[\left(x_{i}-p_{1}\right)^{2}+\left(y_{i}-p_{2}\right)^{2}-p_{3}^{2}\right]\left[-2\left(y_{i}-p_{2}\right)\right] \\
& g_{3}(\vec{p})=\sum_{i=1}^{N} R_{i}(\vec{p}) \frac{\partial R_{i}}{\partial p_{3}}(\vec{p})=\sum_{i=1}^{N}\left[\left(x_{i}-p_{1}\right)^{2}+\left(y_{i}-p_{2}\right)^{2}-p_{3}^{2}\right]\left[-2 p_{3}\right]
\end{aligned}
$$

Let 


$$
J=\left(\begin{array}{ccc}
\frac{\partial R_{1}}{\partial p_{1}} & \frac{\partial R_{1}}{\partial p_{2}} & \frac{\partial R_{1}}{\partial p_{3}} \\
\vdots & \vdots & \vdots \\
\frac{\partial R_{N}}{\partial p_{1}} & \frac{\partial R_{N}}{\partial p_{2}} & \frac{\partial R_{N}}{\partial p_{3}}
\end{array}\right)
$$

If $R$ is the column vector with components $R_{i}$, then from (F10) the three element column vector $g$ is

$$
\vec{g}=J^{T} \vec{R}
$$

The next job is to estimate the step length that will take the point $\vec{p}$ to a new point $\vec{p}+d \vec{p}$ in such a way that $\vec{g}(\vec{p}+d \vec{p})=\overrightarrow{0}$. This can be done by using the Taylor series to write

$$
g_{i}(\vec{p}+d \vec{p})=g_{i}(\vec{p})+\sum_{k=1}^{3} d p_{k} \frac{\partial g_{i}}{\partial p_{k}}(\vec{p})+O(2)
$$

for $i=1, \cdots, 3$. In order to select $d \vec{p}$ so that $\vec{g}(\vec{p}+d \vec{p})=0$ one needs to solve

$$
\sum_{k=1}^{3} d p_{k} \frac{\partial g_{i}}{\partial p_{k}}(\vec{p})=-g_{i}(a, b, r)
$$

for $i=1, \cdots, 3$. Now, from (F10)

$$
\frac{\partial g_{j}}{\partial p_{k}}(\vec{p})=\sum_{i=1}^{N}\left[\frac{\partial R_{i}}{\partial p_{k}}(\vec{p}) \frac{\partial R_{i}}{\partial p_{j}}(\vec{p})+R_{i}(\vec{p}) \frac{\partial^{2} R_{i}}{\partial p_{k} \partial p_{j}}(\vec{p})\right]
$$

Note that

$$
\frac{\partial^{2} R_{i}}{\partial p_{k} \partial p_{j}}(\vec{p})=\left\{\begin{array}{lr}
0 & k \neq j \\
2 & k=j=1 \\
2 & k=j=2 \\
-2 & k=j=3
\end{array}\right.
$$

so that $(\mathrm{F} 15)$ can be written in matrix form as

$$
H=J^{T} J
$$


Now (F14) can be written, using (F12), as

$$
H d \vec{p}=-\vec{g}=-J^{T} \vec{R}
$$

Although $H$ is symmetric it is not necessarily positive definite and in fact may be singular. The scaling of (F18) may also need adjustment. This is discussed by Marquardt [1963]. Also, see Nash []. Instead of (F19) consider

$$
\left(J^{T} J+\lambda I\right) d \vec{p}=-J^{T} \vec{R}
$$

If we scale the parameters by a matrix with only a positive main diagonal then we can write

$$
\begin{aligned}
& \hat{p}=D p \\
& \hat{R}(\hat{p})=R\left(D^{-1} \hat{p}\right)=R(\vec{p})
\end{aligned}
$$

Then, in terms of the scaled parameters, (F19) could be written

$$
\left(\hat{J}^{T} \hat{J}+\lambda I\right) d \hat{\vec{p}}=-\hat{J}^{T} \hat{R}
$$

where, it is not hard to show that

Then, (F21) becomes

$$
\begin{aligned}
& \hat{J}(\hat{\vec{p}})=J(\vec{p}) D^{-1} \\
& d \hat{\vec{p}}=D d \vec{p}
\end{aligned}
$$

$$
\left(\left(D^{-1}\right)^{T} J^{T} J D^{-1}+\lambda I\right) D d \vec{p}=-\left(D^{-1}\right)^{T} J^{T} R
$$

or

$$
\left(J^{T} J+\lambda D\right) d \vec{p}=-J^{T} R
$$

In Nash [30], $D$ is selected as

$$
D_{i i}=\left(J^{T} J\right)_{i i}+\phi
$$

where $\phi$ is set chosen so that the scale is not too small.

Before describing the algorithm we to select stopping criteria for the final algorithm. For this we choose criteria suggested by Dennis and Schnabel [33]. These criteria depend on the fact that near the optimum both the gradient and the difference between succeeding parameter vectors should be near zero. The relative gradient will be used instead of 
simply the gradient since it is insensitive to scaling and for the parameters the relative change in the parameters will be used. These criteria are

$$
\begin{aligned}
& \max _{1 \leq i \leq 3}\left|\frac{g_{i} \max \left(\left|p_{i}\right|, 1\right)}{\max \left(\sum_{k=1}^{N} R_{i}^{2}, 1\right)}\right| \leq \varepsilon^{\frac{1}{3}} \\
& \max _{i \leq i \leq 3}\left|\frac{p_{i}^{(k)}-p_{i}^{(k-1)}}{\max \left(\left|p_{i}^{(k-1)}\right|, 1\right)}\right| \leq \varepsilon^{\frac{2}{3}}
\end{aligned}
$$

where the components of the gradient $\vec{g}$ are computed in (F12) and $\varepsilon$ is the machine epsilon which is that machine number that when added to 1 returns 1.

The algorithm can be stated as follows.

1. Initialize

$$
\begin{aligned}
& \vec{p}_{0}=\left(\begin{array}{l}
a_{0} \\
b_{0} \\
r_{0}
\end{array}\right) \\
& \lambda=0.0001 \\
& \phi=0.5 \\
& \text { inc }=10 \\
& \text { dec }=0.04 \\
& \text { max_iter }=20 \\
& \text { loop_count }=0 \\
& \vec{p}=\vec{p}_{0}
\end{aligned}
$$

2. While $l o o p_{\text {_ }}$ count $<\max \_$iter perform the following operations

2.1 If loop_count $>0$ set $\lambda=\lambda * d e c$

$2.2 f=\sum_{i=1}^{N} R_{i}^{2}$

$2.3 R=\left(\begin{array}{c}\left(x_{1}-p_{1}\right)^{2}+\left(y_{1}-p_{2}\right)^{2}-p_{3}^{2} \\ \vdots \\ \left(x_{N}-p_{1}\right)^{2}+\left(y_{N}-p_{2}\right)^{2}-p_{3}^{2}\end{array}\right)$

2.4 Form the Jacobian matrix $J$ using (F11) 
2.5 Form the gradient vector $\vec{g}$ using (F12). This test uses $f$.

2.6 Perform the gradient test in (F26)

2.7 If the test is true exit with the final parameters $\vec{p}$, otherwise continue

2.8 If loop_count $>0$ then perform the relative parameter test

2.9 If that test is true exit with the final parameters $\vec{p}$, otherwise continue

$2.10 \quad$ Form $H=J^{T} J$

2.11 Set flag $=-1$ and augment_count $=0$

2.12 While flag $<0$ perform the following operations

2.12.1 Set augment_count $=$ augment_count +1

2.12.2 If augment_count $>1$ then set $\lambda=\lambda *$ inc

2.12.3 Set $D=\operatorname{diag}(H)$

2.12.4 Using (F24) and (F25) form augH $=H+\lambda D$

2.12.5 Perform the Cholesky decomposition as given in (F4) to (F6) and return $L$ and flag, where flag $=-1$ if not positive definite and +1 if it is.

2.12.6 Continue the while loop. For sufficiently large $\lambda$ the augmented matrix will become positive definite. When it does exit the loop and continue.

2.13 Solve $(\operatorname{augH}) d \vec{p}=-J^{T} \vec{R}$ for $d \vec{p}$ using (F3)

2.14

Set $\left\{\begin{array}{c}\vec{p}_{\text {old }}=\vec{p} \\ \vec{p}=\vec{p}_{\text {old }}+d \vec{p} \\ \text { loop_count }=\text { loop_count }+1\end{array}\right.$

2.15 Return to step 2, the beginning of the while loop. 


\section{APPENDIX G: Analysis of Variance for Computed Orthogonalities from CMM Measurements}

\begin{tabular}{|c|c|c|c|c|c|c|c|c|}
\hline & & & Orthogonality & Uncertainty & Table & & & \\
\hline Part & & Measurement & Replications & (arc sec) & & Mean & $\mathrm{df}$ & "Stand. Dev. \\
\hline 1 & 2.165 & 4.387 & 4.935 & 9.156 & 2.116 & 4.552 & 4 & 2.872672 \\
\hline 2 & 11.583 & 8.341 & 7.122 & 10.142 & 3.885 & 8.215 & 4 & 2.958529 \\
\hline 3 & 2.803 & 8.321 & 1.93 & 7.987 & 6.22 & 5.452 & 4 & 2.943944 \\
\hline 4 & -5.523 & -5.859 & -8.61 & -8.631 & -8.007 & -7.326 & 4 & 1.518122 \\
\hline 5 & -5.834 & -3.276 & & & & -4.555 & 1 & 1.809033 \\
\hline 6 & .1 .076 & 0.976 & & & & -0.05 & 1 & 1.450953 \\
\hline 7 & -0.178 & -5.235 & & & & -2.707 & 1 & 3.576137 \\
\hline 8 & -12.286 & -2.569 & & & & -7.427 & 1 & 6.870819 \\
\hline 9 & -5.311 & -9.561 & & & & -7.436 & 1 & 3.004845 \\
\hline 10 & 8.835 & 11.289 & & & & 10.062 & 1 & 1.735044 \\
\hline 11 & 10.31 & 10.295 & & & & 10.303 & $\overline{\mathrm{I}}$ & 0.010287 \\
\hline 12 & 25.389 & 25.348 & & & & 25.368 & 1 & 0.028781 \\
\hline 13 & -8.481 & -12.965 & & & & -10.723 & 1 & 3.171258 \\
\hline 14 & -14.406 & -12.813 & & & & -13.609 & 1 & 1.126567 \\
\hline 15 & -3.403 & -14.142 & & & & -8.772 & 1 & 7.593938 \\
\hline 16 & 14.823 & 12.433 & & & & 13.628 & 1 & 1.690476 \\
\hline 17 & -7.164 & -5.542 & & & & -6.353 & 1 & 1.146354 \\
\hline 18 & -6.462 & -0.771 & & & & -3.617 & 1 & 4.024526 \\
\hline 19 & -13.728 & -14.365 & & & & -14.047 & 1 & 0.450572 \\
\hline 27 & -9.597 & -8.828 & & & & .9 .213 & 1 & 0.543542 \\
\hline 21 & -6.243 & -1.735 & & & & -3.989 & 1 & 3.188012 \\
\hline Grand Mean & $=$ & -1.059 & & & & & & \\
\hline Var.of the & Means & $=$ & 80.284741 & & Unc. Of & the Means & & 8.960175277 \\
\hline Var. of the & Stand. Dev. & $=$ & 8.768066 & & Unc. Of & $\begin{array}{l}\text { the Std. } \\
\text { Dev. }\end{array}$ & $=$ & 2.961092028 \\
\hline
\end{tabular}

Table G1: Orthogonality Uncertainty Table for Parts Manufactured on the Hurco Machining Center. 


\section{APPENDIX H: Analysis of Variance Tables for Circularities Computed from CMM Measurements}

\begin{tabular}{|c|c|c|c|c|c|c|c|c|}
\hline & & lnner & Circle & Circularity & Uncertainty & Table & & \\
\hline Part & & Measurement & Replications & (micromet.) & & Mean & $\mathrm{df}$ & Stand. Dev. \\
\hline 1 & 18.62 & 20.25 & 22.92 & 21.92 & 18.11 & 20.364 & 4 & 2.066962 \\
\hline 2 & 19.81 & 21.39 & 20.13 & 18.04 & 19.25 & 19.724 & 4 & 1.225594 \\
\hline 3 & 19.58 & 19.35 & 19.05 & 20.41 & 19.64 & 19.606 & 4 & 0.505698 \\
\hline 4 & 20.56 & 20.58 & 18.34 & 17.78 & 19.5 & 19.352 & 4 & 1.273232 \\
\hline 5 & 30.77 & 27.03 & & & & 28.9 & 1 & 2.644579 \\
\hline 6 & 22.83 & 21.47 & & & & 22.15 & 1 & 0.961665 \\
\hline 7 & 25.34 & 24.16 & & & & 24.75 & 1 & 0.834386 \\
\hline 8 & 21.76 & 23.03 & & & & 22.395 & 1 & 0.898026 \\
\hline 9 & 17.74 & 16.46 & & & & 17.1 & 1 & 0.905097 \\
\hline 10 & 18.42 & 19.3 & & & & 18.86 & 1 & 0.622254 \\
\hline 11 & 22.93 & 22.12 & & & & 22.525 & 1 & 0.572756 \\
\hline 12 & 22.69 & 17.59 & & & & 20.14 & 1 & 3.606245 \\
\hline 13 & 19.25 & 24.58 & & & & 21.915 & 1 & 3.768879 \\
\hline 14 & 16.2 & 22.7 & & & & 19.45 & 1 & 4.596194 \\
\hline 15 & 22.32 & 19.49 & & & & 20.905 & 1 & 2.001112 \\
\hline 16 & 20.58 & 18.23 & & & & 19.405 & 1 & 1.661701 \\
\hline 17 & 17.45 & 18.87 & & & & 18.16 & 1 & 1.004092 \\
\hline 18 & 22.44 & 21.71 & & & & 22.075 & 1 & 0.516188 \\
\hline 19 & 18.07 & 16.44 & & & & 17.255 & 1 & 1.152584 \\
\hline 27 & 16.49 & 16.65 & & & & 16.57 & 1 & 0.113137 \\
\hline 21 & 27.7 & 30.53 & & & & 29.115 & 1 & 2.001112 \\
\hline Grand Mean & $=$ & 20.986 & & & & & & \\
\hline Var. of the & Means & $=$ & 7.378079 & & Uncer. Of the & Means & 2.716 & \\
\hline Var. of the & Stand. Dev. & $=$ & 3.129735 & & Uncer. Of the & Stand. Dev. & 1.769 & \\
\hline
\end{tabular}

Table H1: Circularity Results for Inner Slot Surface 


\begin{tabular}{|c|c|c|c|c|c|c|c|c|}
\hline & & Outer & Circle & Circularity & Uncertainty & Table & & \\
\hline Part & Measurement & Replications & (micromet.) & & & Mean & $\overline{\mathrm{df}}$ & Stand. Dev. \\
\hline 1 & 18.37 & 17.87 & 18.02 & 17.38 & 19.09 & 18.146 & 4 & 0.63642 \\
\hline 2 & 27.71 & 28.39 & 26.09 & 29.28 & 29.88 & 28.27 & 4 & 1.474161 \\
\hline 3 & 20.86 & 19.42 & 19.2 & 21.48 & 21.08 & 20.408 & 4 & 1.029621 \\
\hline 4 & 29.23 & 22.31 & 22.57 & 22.51 & 23.92 & 24.108 & 4 & 2.933517 \\
\hline 5 & 23.23 & 24.59 & & & & 23.91 & 1 & 0.961665 \\
\hline 6 & 35.16 & 36.56 & & & & 35.86 & 1 & 0.989949 \\
\hline 7 & 19.4 & 16.69 & & & & 18.045 & 1 & 1.916259 \\
\hline 8 & 22.09 & 22.83 & & & & 22.46 & 1 & 0.523259 \\
\hline 9 & 21.67 & 23.13 & & & & 22.4 & I & 1.032376 \\
\hline 10 & 28.22 & 24.04 & & & & 26.13 & 1 & 2.955706 \\
\hline 11 & 24.14 & 22.81 & & & & 23.475 & 1 & 0.940452 \\
\hline 12 & 31.27 & 32.18 & & & & 31.725 & 1 & 0.643467 \\
\hline 13 & 30.97 & 32.28 & & & & 31.625 & 1 & 0.92631 \\
\hline 14 & 26.06 & 22.94 & & & & 24.5 & l & 2.206173 \\
\hline 15 & 23.35 & 26.32 & & & & 24.835 & T & 2.100107 \\
\hline 16 & 19.96 & 22 & & & & 20.98 & 1 & 1.442498 \\
\hline 17 & 25.28 & 25.86 & & & & 25.57 & 1 & 0.410122 \\
\hline 18 & 23.66 & 24.11 & & & & 23.885 & 1 & 0.318198 \\
\hline 19 & 24.39 & 26.08 & & & & 25.235 & 1 & 1.19501 \\
\hline 27 & 27.34 & 26.55 & & & & 26.945 & 1 & 0.558614 \\
\hline 21 & 46.42 & 49.32 & & & & 47.87 & 1 & 2.05061 \\
\hline Grand Mean & $=$ & 26.018 & & & & & & \\
\hline Var. of the & Means & $=$ & 35.83599 & & Uncer. Of the & Means & 5.986 & \\
\hline Var. of the & Stand. Dev. & $=$ & 2.556287 & & Uncer. Of the & Stand.Dev. & 1.599 & \\
\hline
\end{tabular}

Table H2: Circularity Results for the Outer Surface 


